\title{
DEMANDA DERIVADA POR CRÉDITO NA DIVISÃO REGIONAL AGRÍCOLA DE CAMPINAS
}

LUIZ ANTONIO PINAZZA

Orientador: JOAQUIM JOSÉ DE CAMARGO ENGLER

Dissertação apresentada à Escola Superior de Agricultura "Luiz de Queiroz" da Universidade de São Paulo, para obtenção do titulo de Mestre em Economia Agrária.

PIRACICABA

Estado de São Paulo - Brasil

agosto de 1978 
11.

Aos meus pais Maria e Hermínio

A meu Irmão Antonio Hermínio com seus familiares 


\section{AGRADECIMENTOS}

A Empresa Brasileira de Pesquisa Agropecuária - EMBRAPA, pela oportunidade oferecida para frequentar o Curso de Pós Graduação.

Ao Instituto de Economia Agrícola, pelo suporte financeiro a esta pesquisa, que integra o Profeto "Projeção e Planejamento do Desenvolvimento Agrícola do Estado de São Paulo:.

Ao Professor Joaquim José de Camargo Engler, pela valiosa orienta ção oferecida.

Ao Professor Fernando C. Peres, pelo estímulo e críticas importan tes com que tratou o desenvolvimento do trabalho.

Ao Professor José F. Noronha, pela leitura dos originais deste tra balho, enriquecendo-o com importantes sugestões e comentários.

A Fundação Ford pelos recursos financeiros para a publicação des te trabalho.

Aos Professores e Funcionários do Departamento de Economia e Sociolo gia Rural da ESALQ, que direta ous indiretamente colaboraram com esta pesquisa.

Aos Colegas Antonio C. Roessing, Antonio C. Gemente e Yuly Toledo, pela contribuição prestada a esta pesquisa.

A todos que direta ou indiretamente contribuiram na realização deste trabalho. 
Pág.

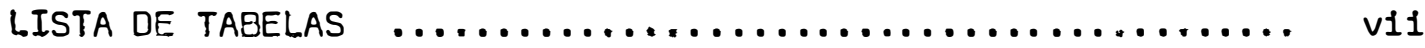

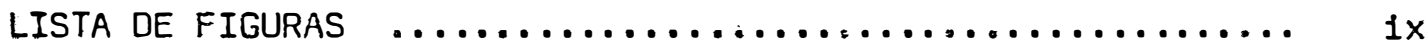

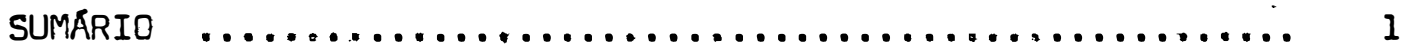

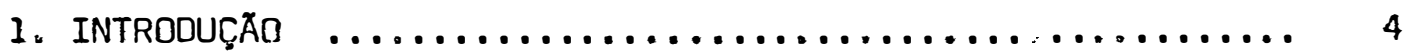

1.1 - O Problema $\ldots \ldots \ldots \ldots \ldots \ldots \ldots \ldots \ldots \ldots \ldots \ldots \ldots, 6$

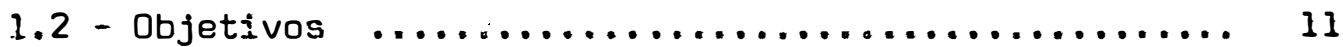

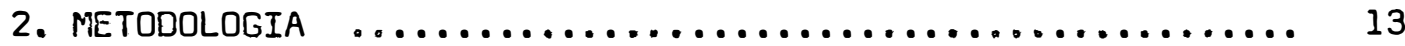

2.1 - Modelo Conceitual $\ldots \ldots \ldots \ldots \ldots \ldots \ldots \ldots \ldots \ldots . \ldots \ldots$

2.1.1 - 0 modelo de programação recursiva $\ldots \ldots \ldots . .14$

2.1.1.1 - o setor de produção $\ldots \ldots \ldots \ldots .20$

2.1.1.2 - 0 setor de investimento ....... 24

2.1 .1 .3 - 0 setor financeiro $\ldots \ldots \ldots \ldots .27$

2.1.1.4 - Equação complementar $\ldots \ldots \ldots \ldots .28$

2.1.1.5 - Limites comportamentals ....... 29

2.1.2 - Modelo de expectativa de inflação ....... 30

2.1.3 - A demanda derivada por crédito $\ldots \ldots \ldots \ldots .32$

2.2 - Modelo Empírico $\ldots \ldots \ldots \ldots \ldots \ldots \ldots \ldots \ldots \ldots \ldots, 36$

2.2.1 - Fonte de dados $\ldots \ldots \ldots \ldots \ldots \ldots \ldots \ldots \ldots$. 36

2.2 .2 - A região do estudo $\ldots \ldots \ldots \ldots \ldots \ldots \ldots \ldots$. 37

2.2 .3 - 0 modelo empirico $\ldots \ldots \ldots \ldots \ldots \ldots \ldots \ldots, 38$

2.2.3.1 - Função objetivo $\ldots \ldots \ldots \ldots \ldots \ldots . \quad 39$

2.2 .3 .2 - Atividades $\ldots \ldots \ldots \ldots \ldots \ldots \ldots .39$ 
Pág.

2.2.3.2.1 - Atividades de produção

2.2.3.2.2 - Atividades de transferência de terra .....

2.2.3.2.3 - Atividades de contrata ção de mão-de--obra residente não familiar e aluguel de mão-de-obra familiar

2.2.3.2.4 - Atividades de compra de insumos

2.2.3.2.5 - Atividades de consumo

2.2.3.2.6 - Atividades de investimento em máquinas, equipamentos, animais de trabalho e culturas pe renes

2.2.3.2.7 - Atividades de emprésti mos de crédito ..... 43

2.2.3.2.8 - Aplicação de dinheiro no mercado financeiro

2.2.3.3 - Conjunto restricional

$2.2 \cdot 3.3 .1-$ Terra 44

2.2.3.3.2 - Mão-de-obra ...... 45

2.2.3.3.3 - Animal de trabalho .. 45

2.2 .3 .3 .4 - Trator .........4 46

2.2.3.3.5 - Colhedeira de soja .. 46 
vi.

Päg.

2.2.3.3.6 - Obrigações fixas $\ldots$...

2.2.3.3.7 - Dinheiro disponível em caixa

2.2.3.3.8 - Crédito

2.2.3.3.9 - Limites comportament8is 48

3. RESULTADOS E DISCUSSOEES $\ldots \ldots \ldots \ldots \ldots \ldots \ldots \ldots \ldots \ldots \ldots$

3.1 - Resultados Para o Ano Agrícola $70 / 71$........... 50

3.2 - Resultados Para o Ano Agrícola $73 / 74 \ldots \ldots \ldots \ldots . . .57$

3.3 - Resultados Para o Ano Agrícola $76 / 77$.......... 65

3.4 - Discussão dos Resultados $\ldots \ldots \ldots \ldots \ldots \ldots \ldots \ldots \ldots$. 1

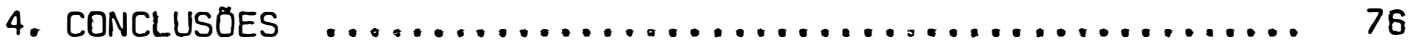

4.1 - Recomendações Para Pesquisas futuras ........... 78

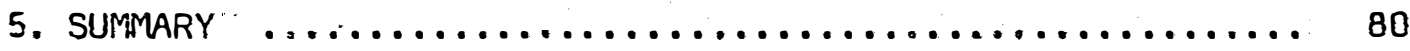

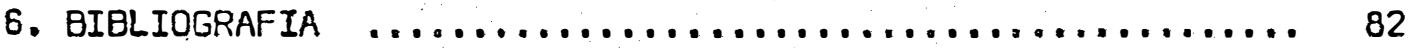

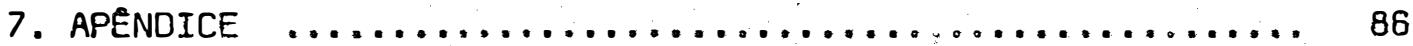


vii.

\section{LISTA DE TABELAS}

TABELA

Pág.

I Matriz dos Coeficientes A .................. 18

2 Classe de área, número e área dos imóveis rurais. Trés estratos de propriedades agrícolas. DIRA de Campinas, 1967

3 Demanda Derivada por Crédito. Trés estratos de propriedades agrícolas. DIRA de Campinas, 1970/71 ...

4 Quantidade total de Crédito Efetivamente Demandado. Très estratos de propriedades agrícolas. DIRA de

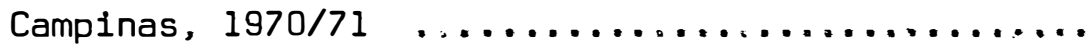

5 Renda Agrícola, Subsídio Recebido e a relação entre Subsídio por Renda Agrícola. Très estratos de propriedades agrícolas. DIRA de Campinas, 1970/71 ...

6 Efeito da taxa de juros no Valor da Renda Agrícola (em Cr\$). Três estratos de propriedades agrícolas. DIRA de Campinas, 1970/71

7 Demanda Derivada por Crédito. Três estratos de propriedades agrícolas. DIRA de Campinas, 1973/74 ... 58

8 Quantidade total de Crédito Efetivamente Demandado. Trés estratos de propriedades agrícolas. DIRA de Campinas, 1973/74

9 Renda Agrícola, Subsídio Recebido e a relạ̧āo entre Subsídio por Renda Agrícola. Très estratos de propriedades agrícolas. DIRA de Campinas: 1973/74 . . 
10 Efeito da taxa de juros ro Valor da Renda Agrícola (em Cr\$). Trés estratos de propriedades agrícolas.

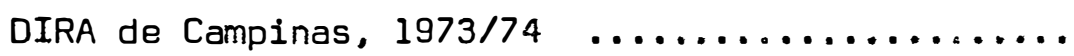

11 Demanda Derivada por Crédito. Trés estratos de propriedades agrícolas. DIRA de Campinas, 1976/77 ... 65

12 Quantidade total de Crédito Efetivamente Demandado. Trés estratos de propriedades agrícolas. DIRA de

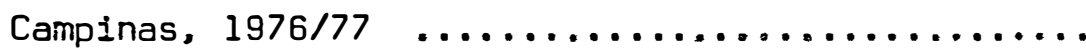

13 Renda Agrícola, Subsídio Recebido a a relação entre Subsídio por Renda Agrícola. Très estratos de propriedades agrícolas. DIRA de Campinas 1976/77 ...

14 Efeito da taxa de juros no Valor da Renda Agrícola (em $C r \$$ ). Três estratos de propriedades agrícolas. DIRA de Campinas, 1976/77 


\section{LISTA DE FIGURAS}

5 Demanda Derivada para o estrato dos pequenos produtores (Ep), médios produtores (Em) e grandes produ-

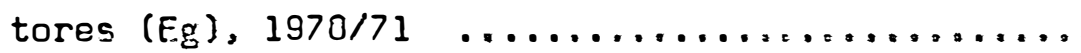

6 Subsídio Recebido pelo estrato dos médios produtores $(\mathrm{Sm}), 1970 / 71$

7 Subsídio Recebido pelo estrato dos grandes produtores $(\mathrm{Sg}), 1970 / 71$

8 Demanda Derivada para o estrato dos pequenos produtores (Ep), médios produtores (Em) e grandes produtores $(\mathrm{Eg}), 1973 / 74$

9 Subsídio Recebido pelo estrato dos pequenos produto

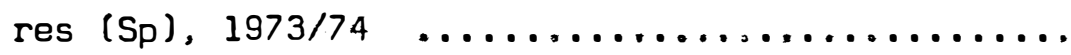

10 Subsídio Recebido pelo estrato dos médios produto-

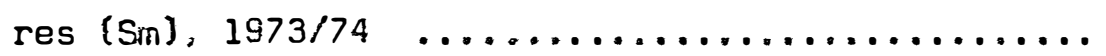

11 Subsídio Recebido pelo estrato dos grandes produto-

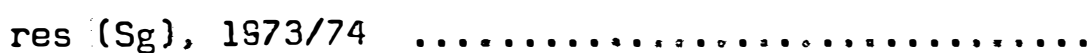

12 Demanda Derivada para o estrato dos pequenos produtores (Ep) e médios produtores $(E m), 1976 / 77 \ldots . .66$ 
13 Demanda Derivada para o estrato dos grandes produto res $(E g), 1976 / 77, \ldots \ldots \ldots \ldots \ldots \ldots \ldots \ldots \ldots \ldots \ldots . \ldots \ldots$

14 Subsídio Recebido pelo Estrato dos mëdios produtores $(\mathrm{Sm}), 1976 / 77 \ldots \ldots \ldots \ldots \ldots \ldots \ldots \ldots \ldots . \ldots \ldots 6 . \ldots \ldots$

15 Subsidio Recebido pelo estrato dos grandes produto-

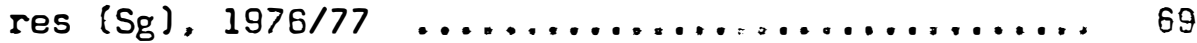


SUMARIO

As políticas económicas implementadas no Brasil para o setor agrícola vem sendo executada através da instituição de variados programas especiais de crédito. As taxas de juros administra das nesses programas são menores aos prevalecentes no mercado. Como a inflaçāo trata-se de um problema constante na economia brasileira, essas taxas de juros correspondem, muitas vezes, a taxas de juros reais negativas. Isto sugere que os programas de crédito estäo fundamentados sob a pressuposiçāo que os agricultores exibem alta elas ticidade com respeito a taxa de juros. No entanto, pouca comprovação empírica tem sido efetuada a fim de confirmar tal pressuposição. o objetivo do estudo foi derivar curvas de demanda por crédito, usando um modelo de programaçāo recursiva, como sugeri do por Day. Este modelo incorpore ainda um processo de formaşão de expectativa de preços na tomada de decisão do agricultor. objetivos 
de identificação e ánálise dos fatores que afetam a demanda por cré dito também são visados, assim como sugerir propostas com a finalidade de aprimorar as políticas de crédito, para tornä-lo instrumento mais efetivo de estímulo ao desenvolvimento agrícola.

0 período estudado começa no ano agrícola 1970/71 e termina em 76/77, sendo a região escolhida para a pesquisa a da Divisão Regional Agrícola (DIRA), de Campinas. Os dados foram extrafdos de diversas fontes e estratificados para as classes de pequenos produtores médios produtores e grandes produtores.

As principais conclusōes do estudo foram que: aumentando as taxas de juros do crédito agrícola, recursos financeiros são transferidos dos grándes produtores para os pequenos e médios,e depois, dos médios para os pequenos, as polfticas de crédito a baixas taxas de juros estão aumentando a dependência dos pequenos produtores pelo crédito; a elasticidade da demanda por crédito de um estrato está relacionado com a sua mobilidade na alocação dos recur sos: se o governo continuar a instituir programas de crédito ccm ta xas de juros menores aos que prevalecem em outros mercados, recursos devem ser canalisados para aparelhar a fiscalização do crédito; as variações nas taxas de furos não causam mudanças significativas na renda agrícola, sendo que, deve ser discutivo, ao nível da socie dade, se os benefícios das políticas de crédito estäo compensando os seus custos que acarretam de inflaçäo; a relação entre subsiduo recebido e renda agrícola está caindo, sendo que a relação está favo- 
recendo mais o estrato dos médios produtores, em comparação ao estrato dos médios e pequenos produtores. 


\section{INTRODUÇÃO}

As polfticas econômicas implementadas no Brasil para - setor agrícola vem sendo executadas através da instituição de variados programas de crédito. Acredita-se que estes programas são im portantes instrumentos para acelerar o desenvolvimento da agricultu ra.

Sendo a inflação um problema crônico na economia bra sileira, as baixas taxas de juros administradas nos programas de cré dito correspondem, muitas vezes, a taxas de juros reais negativas. En consequência deste mecanismo, duas distorções, pelo menos, apare cem no mercado de crédito agrícola: uma de excesso de demanda e outra na desigual alocação do crédito entre diferentes classes de agricultores. Estas distorções são explicadas pelo comportamento das agências creditíctas. Suas disponibilidades limitadas de crédito não satisfazem à demanda estimulada pelos baixos juros, levando-os a em 
prestar seus fundos de forma a garantir segurança máxima e minimizar seus custos operacionais.

0 fato dos programas de crédito instituirem taxas de juros menores às prevalecentes no mercado fundamenta-se na pressupo sição implícita de que a demanda por crédito agrícola é elásticacom respeito a taxas de juros. Contudo, pouca comprovação empírica tem sido efetuada a fim de confirmar tal pressuposição.

O objetivo do estudo é derivar curvas de demanda por crédito, usando o modelo de programação recursiva, como sugerido por DAY (1963). Este modelo incorpora ainda um processo de formação de expectativa de preços na tomada de decisão do agricultor entre as alternatıvas de produção.

A região de estudo corresponde à área da Divisão Regional Agrícola (OIRA) de Campinas, uma das mais desenvolvidas regiões do Estado de São Paulo, muito bem dotado de instituiçães com pesquisa, extensão e crédito no setor agrícola. A agricultura da re gião pode ser considerada como tipicamente empresarial e apresenta uma variada gama de atividades de produção, que estão distribuídas em propriedades de diferentes tamanhos.

0 estudo está dividido em quatro capítulos. 0 primei ro apresenta problemas pertinentes ao uso, distribuição e eficiēncla do crédito rural no Brasil, levantados em pesquisas recentes e arrola os objetivos e justificativas do estudo. 0 segundo apresenta o procedimento metodolágico adotado, que por sua vez está subdividido em duas secçöes:a primeira descreve o modelo conceitual, que 
contém o embasamento teórico do instrumento de pesquisa utilizado e a segunda apresenta o modelo empírico, composto da região em estudo, da fonte de dados, bem como dos critérios assumidos na seleção dos dados. O terceiro capítulo expõe e discute os resultados obtidos e o quarto, finalmente, apresenta as conclusões do estudo e recomenda novas pesquisas.

Por último, cabe ressaltar que o presente trabalho in tegra o programa de pesquisa do Projeto "Projeção e Planejamento do Desenvolvimento Agrícola do Estado de São Paulo" do Instituto de Economia Agrícola (IEA) da Secretaria dos Negócios da Agricultura do Estado de São Paulo.

\section{1 - O Problema}

O comportamento da agricultura brasileira no período

1948 a 1968, pelos indices de crescimento apresentados, pode ser con siderado satisfatório. Este fato é surpreendente, ao considerar que a polftica econômica geral, até 1965/66, discriminou bastante contra o setor através de estímulos a uma industrialização capital-in tensiva, da supervalorização da taxa de câmbio, de tratamento especial de crédito e tributação aos setores não-agrícolas, além dos con tingenciamentos aps excedentes agrícolas (SCHUH, 1968).

Mas se até 1965/66, as políticas econômicas adotadas penalızaram a agricultura, após esse período ocorreu reversão nesse processo. Uma nova estratégia política econômica foi delineada pelo 
governo, a fim de capitalizar o setor para que o mesmo aumentasse seus Indices de crescimento. Assim foi que, originado de profundas modificaçöes no chamado crédito comercial, já que este era incapaz de atender às necessidades do setor agrícola ... (GUIMARẢES, 1974), - crédito rural foi institucionalizado pela Lei 4289 , de 5 de novem bro de 1965. Nela se estabelecia que:

\begin{abstract}
"o crédito rural sistematizado nos termos desta lei, será distribuído e apli cado de acordo com a polftica de desen volvimento da produção rural. tendo em vista o bem estar da sociedade rural".
\end{abstract}

A intervenção do governo nas políticas de crédito íns titucionalizado, fundamenta-se na pressuposição de que a natureza do mercado de capital não é capaz de sustentar um rápido desenvolvimen to para o setor (WHIITE, s.d.). Especificamente essas pressuposições são: (1) a oferta do crëdito não institucional é inadequada aos pro dutores agrícolas: (2) os agricultores não deverão contrair empréstimos às taxas de juros que vigoram no mercado, mas sim às taxas subsidiadas e (3) existe um grupo de alternativas possíveis que satisfazem mais os desejos e necessidades da sociedade, os quais não serão escolhidos pelos agricultores, salvo se providos por incentivos, como na forma de crédito subsidiado, De fato, RAO (1970) estudando o crëdito subsidiado no sul do pais mostrou que nas proprieda des rurais em que é usado em quantidades substanciais, "o crédito no vo" (somatória dos novos emprëstimos recebidos durante o ano) repre 
senta cerca de $50 \%$ a $70 \%$, ou até mais das despesas operacionais anuais, existindo alta correlação entre os aumentos no emprego dos in sumos modernos com o uso do crédito.

No entanto, resultados de trabalhos efetuados por SCHUH (1971) permitem questionar a efetividade das polfticas de desenvolvimento aplicadas na agricultura brasileira. SCHUH asseveraem seus estudos que:

$$
\begin{aligned}
& \text { "os ganhos de produção do setor agrícola } \\
& \text { deve-se em grande parte à expansão da } \\
& \text { ärea plantada, e não corresponde a au- } \\
& \text { mentos de rendimentos e produtividade de } \\
& \text { outros fatores, sendo que, o desempenho } \\
& \text { da agricultura brasileira está muito dis } \\
& \text { tante do seu plano potencial, apesar da } \\
& \text { sua substancial cortribuição para o } \\
& \text { crescimento da economia". }
\end{aligned}
$$

Nas condições pressupostas no mercado competitivo, a total flexibilidade das taxas de juros permite que o equilfbrio entre a oferta e demanda por crédito seja determinada. Entretanto, quan do se estabelecem políticas de crédito rural com táxas de juros sub sidiadas e menores do que as vigentes no mercado, como no Brasil, res tringem-se as tendências naturais das forças do mercado. Esta inter ferència faz surgir problemas de discriminação no lado da oferta de crédito, derivado do comportamento das agências creditícias. O obje tivo de auferir lucro em suas operações, faz corn que os bancos empreguem métodos que minimizem seus gastos operacionais e diminuam 
riscos relativos aos seus empréstimos. Assim, devido ao excesso de demanda por crédito, o resultado provável é de que o crédito não se ja destinado aos pequenos agricultores em quantidades suficientes. Suas baixas garantias para lastrear o empréstimo representam maiores riscos, e o pequeno valor dos empréstimos representam custos ad ministrativos elevados para as agências creditícias. De fato, segun do ARAUJO e MEYER (1977) muitos agricultores ainda não participam no mercado de crédito institucional, apesar do volume de crédito manter-se gradativamente inflando, sendo especialmente baixa a quantidade tomada pelos pequenos produtores.

Segundo RASK (1972), o efeito das politicas de crédi to rural, apresentar caráter seletivo na sua distribuiçāo, aparece da falha na concepção original dessas politticas, em não considerar expilcitamente os fatores de extensão da área e capacidade de recur sos das propriedades agrícolas, que acarretam algumas vezes superca pitalização em certos subsetores da agricultura. NELSON (1971) afir ma que a facilidade encontrada por muitos agricultores em tomar cré dito tem estimulado o uso de insumos modernos, especialmente fertilizantes, além do ponto de ótima utilização econômica. ENGLER(197I) também verificou que modelos simulados de exploração agrícola, para algumas culturas que alcanȩaram preços eventua?mente altos, geraram soluções ötimas com maior diversificação de atividades, as quals exigiam uso mais intensivo de máquinas.

Alëm das dificuldades de acesso an crédito por parte dos pequenos agricultores, a prudência com relação ao aumento nos 
custos de produçäo, os quais podem superar as receitas esperadas, faz com que esses agricultores não se empenhem em tomar crédito a altos juros e a mudar sua tecnologia de produção. PERES (1976) estu dando a demanda por crédito a curto prazo, verificou que os produto res com menores recursos mostraram-se mais aversos a risco e com um perfil de demanda para crédito indicativo de maior elasticidade que os grandes agricultores. OLIVEIRA (1977) utilizando um modelo de pro gramação dinâmica, sem estratificar classes de agricultores, verifi cou que a demanda por crédito permaneceu a mesma perante alterações na taxa de juros, com exceção a mudançás muito violentas, sendo ine lásticas as demandas a curto, médio e longo prazo.

Ressalte-se ainda que, apesar dos programas de crédi to agrícola instituídos no Brasil, administrarem taxa de juros subsidiadas e menores que as vigentes no mercado, muito pouca evidência empírica está aparecendo para corroborar a pressuposição de que a demanda por crédito exibe alta elasticidade. Por isso, atualmente continua procedendo a afirmativa de ADAMS e CALYER (1972) de que as pesquisas têm fracassado no objetivo de produzir um consenso sobre a validade dessa pressuposiçäo.

As controvërsias e discussões sobre o uso, distribui çäo e eficiência do crédito rural no Brasil, apresentam também importáncia sob a ótica de uma análise macroeconômica. A polftica do créd1to rural näo é independente da política econômica geral, tratando-se de um componente näo dissociado dos mecanismos de controle da politica monetäris, pelo montante de recursos financeiros empre- 
gados na sua implementação. Sendo assim, a sua má alocação causa re flexos negativos na eficácla das politicas de controle de inflação, a qual no Brasil tem-se constituido principalmente, em um sistemáti co controle da oferta dos meios de pagamentos.

Em resumo, as considerações comentadas nesta secção visaram apresentar os principais problemas relacionados com os programas especials de crédito executados no Brasil. Menclonou-se que o mecanismo de administração das taxas de juros do crédito provoca desigualdades na sua distribuição, não favorecendo os pequenos agri cultores e causando supercapitalização em alguns subsetores da agri cultura. Referiu-se ainda à falta de comprovação empírica da pressu posição de que os agricultores possuem demanda elástica com relação ao uso do crédito, argumento básico da implementação de programas de crédito com baixas taxas de juros. E finalmente, relacionou-se as correspondências entre os programas de crédito agrícola com as poIfticas de controle da Inflação, haja visto que eles não podem ser tratados como se fossem independentes, sob pena de comprometer o su cesso de um deles ou de ambos.

\section{2 - Objetivos}

O objetivo geral deste estudo é ampliar os conhecimentos sobre a demanda por crédito pelos agricultores de diferentes classes de propriedades e determinar quals os maiores beneficiärios das polfticas da crédito rural. Especificamente, os objetivos são: 
1) Derivar curvas de demanda por crédito para pequenos, médios e grandes produtores agrícolas;

2) Estimar o subsíduo recebido pelos produtores de cada estrato de produçãos

3) Avaliar o efeito das variações nas taxas de juros sobre a renda agrícola para as três categorias de propriedades agrícolas;

4) Verificar quais atividades mostraram maiores variações nos seus níveis, quando o modelo simulou situações que alteraram o preço do crédito;

5) Apresentar sugestões que possam aprimorar as polfticas de crédito agrícola, tornando-as instrumentos mais eficazes para est1mular o desenvolvimento agrícola. 
13.

\section{METODOLOGIA}

Este capitulo compreende a descrição do método empre gado no estudo e está dividido em duas secçcess. A primeira apresenta o modelo conceitual e a segunda formula o modslo empírico.

\section{1 - Modelo Conceltual}

A apresentação do modelo conceitual visa mostrar o embasamento teórico que fundamenta o estudo. Para tanto, a sua descrição fol separada em três partes: a primeira discorre sobre o modelo de programação recursiva, a segunda incorpora o modelo de expectativa de inflaçäo e a tercelra descreve como o modelo é utiliza do para derivar a demanda por crédito. 


\subsection{1 - O modelo de programação recursiva}

A aplicação do modelo de programação recursiva ajustada às unidades de produção, como recurso técnico matemático para formular uma teoria de mudanças, num contexto de crescimento econōmico, surgiu dos estudos pioneiros de DAY (1963). DAY (1965) inicialmente define o modelo de programação recursiva como uma sequência de problemas programados de matemática, cujos parâmetros estão rela cionados ao objetivo de otimizar funçōes a cada etapa da sequência. Mais adiante, afirma ainda que a programação recursiva, de certa for ma, é uma programação dināmica, pois avalia o processo de decisão as sumido dentro de certas características utilizando sequências de otimização que descrevem modos de comportamento.

As propriedades do modelo de programação recursiva permitem a sua utilização numa grande variedade de problemas denàmi cos. na economia positiva. Eles consideram a influência das decisões assumidas nos períodos anteriores sobre o processo de decisões correntes, a rigidez no emprego de certos recursos que impede suas totais mobilidades e, muito relacionado som esta, os limites comporta mentais exercidos pelos produtores, os quais podem ser entendidos como atitudes que objetivam eiiminar riscos.

A formulação explf́cita de um critêrio ótimo constitui elemento principal no sistema estrutural de programação recursiva.Adaptando à função lexicogräfica de Debrel. Day e Singh sugerem uma função de preferência do agricultor, postuladá por um caminho lexi- 
cográfico de utilidade com quatro metas ordenadas em termos de abso luta prioridade:

(1) satisfazer às necessidades de subsistência;

(2) comparar a função de utilidade do consumo de dinheiro corrente com a renda futura:

(3) tomar a decisão de optar sobre dada alternativa, dentre um conjunto de alternativas, com base na maior segurança contra riscos e incertezas; e

(4) maximizar o retorno líquido do dinheiro.

Em paralelo à função lexicogräfica de utilidade, o modelo incorpora os seguintes critérios de sequência:

(1) a função que estabelece o uso do dinheiro representa o con sumo de subsistência;

(2) a alocação dos recursos em dinheiro para consumo e poupança representa a preferência entre o consumo de dinheiro e o fluxo de renda futura;

(3) as restriçōes de flexibilidade e adoção garantem as tendēn cias comportamentais do agricultor: e

(4) a maximização do retorno Ifquido do dinheiro sujeito aos três critérios anteriores.

O modelo de programaçãollinear recursivo possui basi camente três componentes: a) uma função objetivo a ser otimizada:b) ativisades representando meios alternativos de produção e finalmen te, c) todo um conjunto restricional limitando o número e o dominio 
das variäveis. 0 estabelecimento de una equação complementar, que deve ser satisfelta após a resoluçäo do modelo para um período, determina como a renda gerada num período é computada no perf́odo posterior.

Utha vez delineadas as sequênclas dos critéríos de otimização, conforme apresentado, a expressäo da funçāo objetiva a ser maximizada è: Il

$$
\pi(t)=\sum_{j=1}^{n} z_{j}(t) x_{j}(t), \text { com } j=1,2, \ldots, n
$$

sujeito a:

$$
A_{1 j}(t) x_{j} \leq b_{i}(t), c o m i=1,2, \ldots, m
$$

e:

$$
x_{j}(t) \geq 0
$$

onde: $\pi(t)=$ valor da funçäo objetivo no tempo $t$;

$z_{j}(t)=$ vetor de dimensäo $n$ dos coeficientes da funçäo objetiVO:

$x_{j}(t)=$ vetor de dimensäo $n$ do $n f v e l$ de atividade para o perío do $t_{3}$

$A_{1 j}(t)=$ matriz $m \times n$ dos coeficientes representando a estrutura técnica e institucional da produçäo;

$b_{1}(t)=$ vetor de dimensäo $m$ representando a disponibilidade dos fatores e restriçōes comportamentais.

1/ A apresentação do modelo segue a notação de HEIDHLES (1SêE). 
0 mecanismo que possui o modelo para introduzir limi tes no espaço de decisāo corrente, como consequências de decisões assumidas ariteriormente, para o período programado de estudo, è obtido pela solução ótima de cada fase.

Sendo a soluçăo ótima indicada pelas variāveis assinaladas com asterisco, os limites de disponibilidade são formalizados genericamente por:

$$
b(t)=A(t-1) x^{*}(t-1)+\Gamma b(t-1)+v(t),
$$

onde: $\Gamma \times$ matriz diagonal $m \times n$ que permite a transferéncia parciai ou total da disponibilidade do período anterior $(t-1)$ para $o$ período posterior, quer seja utilizado no período previsto ou não:

$v(t)=$ registra interferências externas durante o período abrangido pelo modelo. A introdução de um registrador de inter ferèncias externas no modelo, simplifica a estruturaçāoma temätica e enfatiza os fatores que influenciam o desenvel vimento da firma.

A matriz dos coeficientes $A$, que aparece na tabela 1 , está dividida en sub-matrizes $A_{i j}$ com $1=1,2, \ldots, 5$ e $j=1,2, \ldots, 5$ p互 ra especificar os grupos de atividades. Esse mesmo procedimento é adotado para $o$ vetor das restrições $b=b_{1}, b_{2}, \ldots b_{m}$. 
Tabela 1 - Matr $1 z$ dos Coeficientes A.

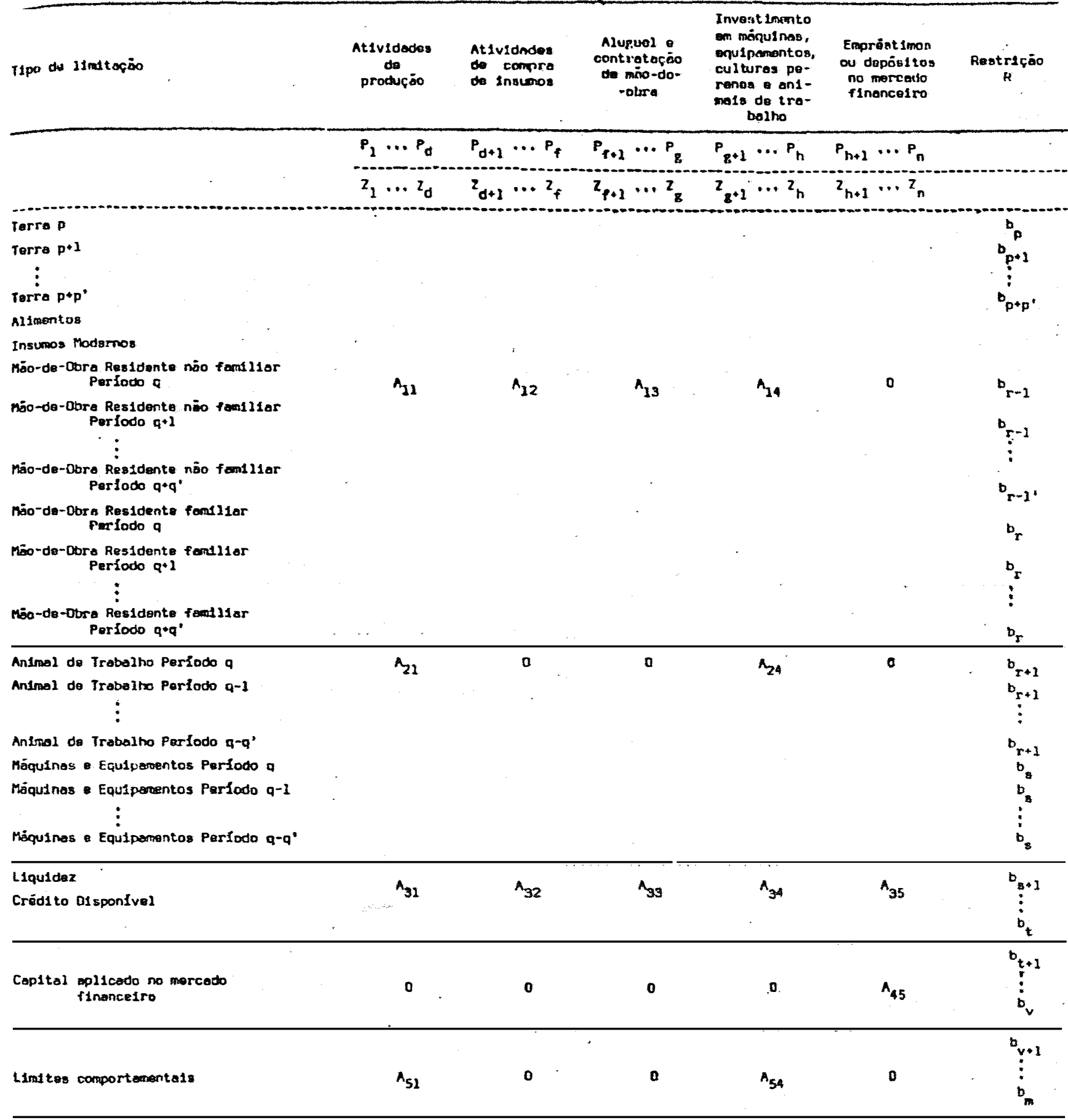


Os grupos de atividades incluem:

1 - os vetores $P_{1} \ldots P_{d}$ do setor de produção representando as atividades de produção do agregado de todas unidades produ tivas, incluindo compra e venda de produtos;

2 - os vetores $P_{d+1} \ldots P_{f}$ do setor de produção envolvendo as "atividades de dispêndios na compra de insumos;

3 - os vetores $P_{f+l} \cdots P_{g}$ do setor de produção descrevendo as atividades de venda de mão-de-obra residente familiar e con tratação de mão-de-obra residente não familiar e temporäría:

4 - os vetores $P_{g+1} \ldots P_{h}$ do setor de investimento envolvendo as atividades de gastos com investimento em culturas perenes, animais de trabalho e máquinas e equipamentos;

5 - os vetores $P_{h+1} \cdots P_{n}$ do setor financeiro com atividades que abrangem a aplicação do capital poupado no mercado financeiro e tomadas de emprestimos no mercado de crédito agrícola.

A estrutura das restrições inclui:

1 - expressões limitando a disponibilidade de terra, alimento, mäo-de-obra e insumos;

2 - limitações pertinentes a animais do trabalho máquinas e equipamentos;

3 - limitações de liquidez, investimento, disponibilidade de crëdito agrícola para regular o fluxo interno e externo do capital em dinheiro; 
4 - limitaçōes relativas às quantidades alocaḍas em dỉnheirono mercado financeiro;

5 - limitações comportamentais referentes às magnitudes des a tividades de produção e investimento.

As equaçōes complementares estabelecem as retiradas de dinheiro que são feitas pelos agricultores para consumo internoe cumprimento dos débitos fixos, para determinar a disponibilidade de dinheiro em caixa.

\subsubsection{1 - 0 setor de produção}

Este setor agrega os três primeiros grupos de atividades, ou seja: produção, compra de insumos e, por último, aluguel de mão-de-obra residente familiar mais contratação de mão-de-obra re sidente não familiar e temporária.

Os coeficientes $z_{I} \ldots z_{d}$ são as receitas líquidas das atividades de produçăo, não deduzidos gastos de mão-de-obra e dos insumos incluidos nas atividades de compra. Para as atividades de produção que possuem compra e venda de produto, os valores são iguais aos preços pagos e recebidos com sinais negativos e positivos respectivamente.

As atividades de produção envolvem o processo que vai da conversão dos produtos intermediários e insumos em produtos finais. O uso de distintas fontes de recursos (sementes melhoradas,animais ou máquinas, insumos modernos, etc.) serve cono indicadores para diferenciar tecrologias e mostrar que uma dada atividade ce pro 
dução pode ter mais de uma linha de produção.

As atividades de mão-de-obra reunem os trabalhadores rurais residentes familiares, residentes não familiares e temporärios. A inclusão de trabalhadores temporários deve-se ao fato especial do mercado de mão-de-obra agrícola apresentar frequentes movimentos cíclicos de ascendência e queda na quantidade demandada de mão-de-obra.

Os valores $z_{d+1} \cdots z_{f}$ são negativos e equivalentes aos respectivos preços de aquisição de cada insumo. Os $Z_{f+1} \ldots z_{g}$ são iguais aos salários normeis percebidos pelos trabalhadores resi dentes familiares residentes não familiares e temporário. O sinal é positivo quando tratar-se de aluguel de mäo-de-obra famtliar e ne gativo quando tratar-se de contratação de mão-de-obra residente não familiar e temporária.

As restriçōes para o primeiro grupo são definidas pe. los elementos $b_{p} . . b_{q}$. A área para produção pode ser categorizada, segundo classe de uso, para quantos tipos de terra desejados, sendo suas disponibilidades consideradas fixas durante o perfodo do estudo. Subdividindo-se os vetores $P_{1} \ldots P_{d}$ em $P_{1} \ldots P_{c}$ para as ativi dades em produção em terra $p, P_{C+1} \cdots P_{C}$, para as atividades em pro dução em terra $p^{+1}, P_{C^{\prime}+1} \ldots P_{c^{\prime \prime}}$ para as atividades em produção em terra p+2 e assim por diante, tem-se:

$$
\sum_{j=1}^{c} a_{i j}(t) x_{j}(t) \leq \gamma_{i} b_{i}(t-1) \quad, \text { com } i=p \gamma_{i}=1
$$




$$
\begin{aligned}
& \sum_{j=c+1}^{c^{\prime}} a_{i 1 j}(t) x_{j}(t) \leq \gamma_{i i} b_{i 1}(t-1)+\gamma_{i} b_{i}(t-1)-\sum_{j=1}^{c} a_{i j}(t) x_{j}(t),(5) \\
& \operatorname{com} \gamma_{i i}=1 ; \text { ii }=p+1 ; \\
& \text { c" } \\
& \sum_{c^{c}+1}^{c_{i i j j}} a_{j}(t) \leq \gamma_{i i i} b_{i i i}(t+1)+\gamma_{i i} b_{i i}(t-1)+\gamma_{i} b_{i}(t-1)- \\
& -\sum_{j=c}^{c} a_{i j}(t) x_{j}(t)- \\
& -\sum_{j=c+1}^{c^{\prime}} a_{i i j}(t) x_{j}(t)
\end{aligned}
$$

$\operatorname{com} \gamma_{i i 1}=1 ;$ iii $=p+2$

0 conjunto das inequaçöes $(4),(5)$ e $(6)$ estabelece que as terras da classe $p$ podem ser utilizadas na classe $p+1, e$,que as terras das classes $p$ e $p+1$ podem ser utilizadas na classe $p+2$. Isoladamente para cada expressão tem-se: a inequação (4) mostrando que as quantidades de terra $p$. em produção no tempo $t$, não podem su perar a área disponível de terra em t-1; a inequação (5) mostrando que as quantidades de terra $p+1$, em produção no tempo $t$, não podem superar a soma da area disponível de terra $p$ e $p+1$ em $t-1$, subtraí da pela ärea com atividades de produção na terra $p$ no tempo $t$; a inequação (6) mostrando que as quantidades de terra $p+2$, em produção no tempo $t$, não podem superar a soma da ărea disponível de terra $p$, $p+1$ e p+2 em $t-1$, subtraĺdas pela área com atividades de produção na terra $p$ e p+l no tempo t. 
Os limites de disponibilidades para os insumos foram considerados livres, sob a pressuposiçāo de que uma vez estabelecido os preços nos mercados, as suas ofertas são suficientes para satisfazer as necessidades correntes dos agricultores.

As restrições com mão-de-obra mostram uma variedade de formas. Normalmente, um certo volume de mão de-obra (soma dos tra balhadores residentes familiares e não familiares) está disponível numa quantidade fixa num tempo $t$, apesar de sofrer efeito de migrações entre tempos $t$. Subdividindo-se os vetores $P_{f+1} \cdots P_{g}$ em $P_{f+1} \ldots P_{f}$, para as atividades de contratação de mão de-obra tempo rária. $P_{f^{\prime}+1} \cdots P_{f^{\prime \prime}}$ para as atividades de venda de mẽo-de-obra residente representando o custo de oportunidade do trabalho nesta ca tegoria de trabalhadores e $P_{f^{\prime \prime}+1} \ldots P_{g}$ para as atividades de contratação de mão-de-obra residente familiar e não familiar. As restrições que devem ser satisfeitas são:

$$
\sum_{f^{\prime}+1}^{f^{\prime \prime}} a_{i j}(t) x_{j}(t) \leq \gamma_{i} b_{i}(t-1)+v(t),
$$

$\operatorname{com} i=r$;

$$
\begin{aligned}
\sum_{j=1}^{d} a_{i j}(t) x_{j}(t) \leq & -\sum_{j=f+1}^{f \prime} a_{i j}(t) x_{j}(t)+\gamma_{i} b_{i}(t-1)+ \\
& +\gamma_{i i} b_{i i}(t-1)+v(t)
\end{aligned}
$$

$\operatorname{com}$ ii $=r-1$. 
A inequação (7) mostra que a quantidade de mão-de-obra familiar vendida em $t$ não pode superar a sua disponibilidade em t-1. ponderada pelo fator $Y_{i}$, que incorpora o efeito de migração. A inequação (8) mostra que a quantidade empreģada de mão-de-obra na produção agrícola em $t$, não pode exceder o balanço das quantidades de mão-de-obra vendidas e compradas, somado com a mão-de-obra de re sidente familiar e não familiar, ponderados pelus seus respectivos fatores $\gamma_{i}$ e $\gamma_{i i}$. Todas as variações de origem exógena que afetam a força de trabalho estão incluídas em $v[t]$.

A inequação de restrição referentes a alguns tipos de alimentos que são pagos em espécie é dada por:

$$
z\left[\gamma_{i} b_{i}(t-1)-\sum_{j=f+1}^{g} a_{i j}(t) x_{j}(t)\right] \leq \sum_{j=1}^{d} a_{i j}(t) x_{j}(t),
$$

com $i=q$, onde $z$ é a taxa per caṕlta da quantidade de alimento rece bido por trabalhador rural. Ou seja, a quentidade per caṕta de um certo alimento recebido pelos trabalhadores. rurais multiplicado pela soma do número de trabalhadores residentes familiares e não familiares, deve ser menor que a quantidade produzida mais a comprada.

\section{$2.1 .1 .2-0$ setor de investimento \\ 0 grupo de vetores $P_{g+1} \ldots P_{h}$ representando as ati.} vidades de investimento está subdividido em $P_{g+1} \ldots P_{g}$, para as cul turas perenes. $P_{g^{\prime}-1} \cdots P_{g^{\prime}}$, para máquinas e equipamentos e $P_{g^{\prime \prime}+1}$ ... Ph para animais de trabalio. 
Os valores dos coeficientes da função objetivo $Z_{g+1}$ $\ldots Z_{h}$ são estabelecidos de duas formas:

1) as atividades de investimento em cultura.perene são estimados pela média anual da diferença entre a renda bruta e custo total esperado durante toda sua vida ütil, calculado com base nos preços do período $t$;

2) as atividades de investimento em máquinas, equipamentos e animais de trabalho são iguais aos seus custos anuais de depreciaçäo.

As restriçōes para máquinas, equipamentos e animais de trabaliho são dadas por:

$$
\begin{aligned}
& \sum_{j=1}^{d} a_{i f}(t) x_{j}(t) \leq \sum_{j=g^{\prime}+1}^{g^{n}} a_{i j}(t) x_{j}(t)+\gamma_{i} b_{i}(t-1), i=s \quad(10) \\
& d \\
& \left.\sum_{j=1}^{d} a_{i f}(t) x_{j}(t) \leq \sum_{j=g^{\prime \prime}+1}^{n} a_{i j}(t) x_{j}(t)+\gamma_{i} b_{i}(t-1), i=r-1(1)\right)
\end{aligned}
$$

As inequaçōes (10) e (11) mostram que a capacidade utIlizada de máquinas, equipamentos e animais de trabalho pelas atividades de produção não pode exceder à soma da capacidade gerada através de investimento no tempo $t$ com a capaciidade do tempo $t-1$,pon derada pelo fator $\gamma_{1}$, que incorpora depreciação.

0 investimento em cultura perene está calcado na teo ria dos ativos fixos de JOHNSON (1955), a qual fundamenta-se na observaçäo empírica de f1xidez de certos recursos na aģricultura, enquanto o capital dispendido nos seus empreendimentos não forem com- 
pensados. Nessas circunstâncias, justifica-se a razão da ärea insta Iada com culturas perenes permanecer constante sob uma faixa bastan te ampla de condições econômicas, em que, os rendimentos esperados dependem da ótima organização da empresa nos períodos futuros.

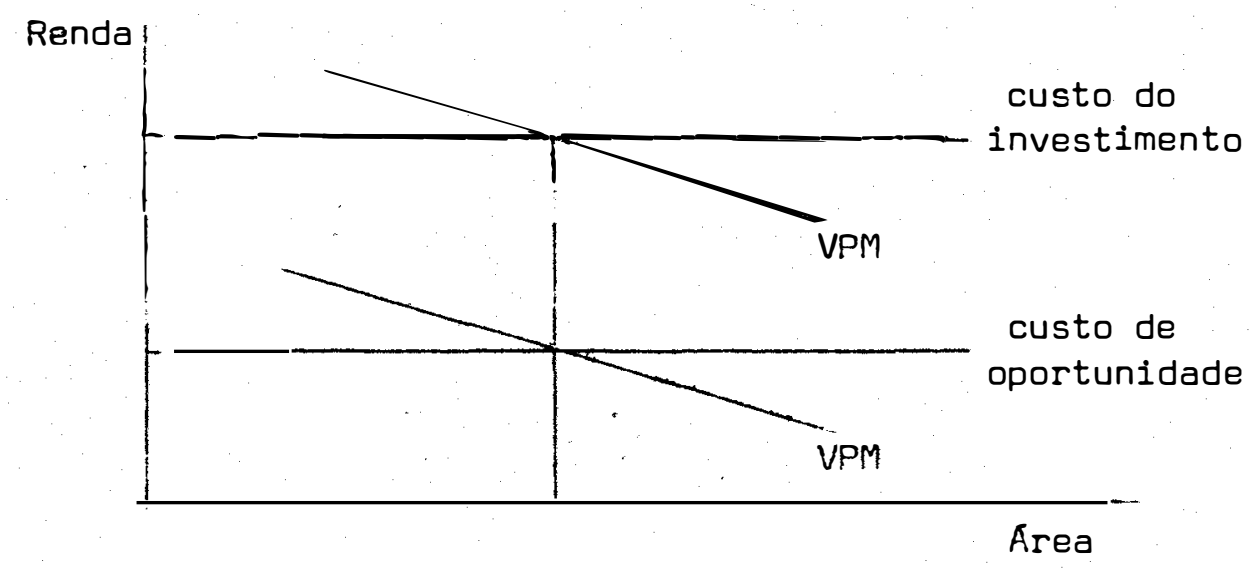

Figura 1 - Teoria dos Ativos Fixos.

A figura 1 mostra graficamente que a variação no pre ço do produto não provoca a menor reação no produtor, mesmo deslocando a curva do valor do produto marginal (VPM), enquanto estiver abaixo do valor do investimento inicial dispendido numa certa cultu ra perene e acima do custo de oportunidade da área ocupada por esta cultura. Este fato, segundo SCHUH (1973), que è a base da teoriados ativos fixos, contribui para explicar porque os agricultores não são sempre sensíveis a mudanças nos preços, como a teoria necclássice su gere.

A inequação de restrição (12) impõe que a ärea com cultura perene no tempo t não pode superar a área investida em cul- 
tura perene no tempo $t-1$ somado com a área em cultura perene em $t-1$, multiplicado por $\gamma_{i}$; que incorpcra depreciação. Fatores exógenos que afetam a área ocupara com cultura perene, como por exemplo: clima, praga, doença, etc., estão introduzidos em $v(t)$.

$$
b_{i}(t) \leq \sum_{j=g+1}^{g} a_{i j}(t-1) x_{j}(t-1)+\gamma_{1} b_{i}(t-1)+v(t)
$$

\subsubsection{3 - O setor financeiro}

Este setor agrega os vetores $P_{n+1} \ldots P_{n}$ e está subdividido em $P_{h+1} \ldots P_{h}$, para as atividades de tomadas de empréstimos por crédito agrícola e $P_{n^{\prime}+1} \ldots P_{n}$ para as atividades que envolvem aplicações de capital no mercado financeiro. As quatro limitações de capital compõem dois grupos restricionais: $b_{s+1} \ldots b_{t} e$ $b_{t+1} \ldots b_{v}$ que consistem de expressões formulando os limites restricionais aos quais os agricultores estão sujeitos. A primeira expressão inclui as condições de liquidez, a segunda a capacidade de investimento da propriedade, a terceira determina os limites das re lações institucionais de crédito e a quarta a quantidade de capital aplicado no mercado financeiro.

A restrição de liquidez, reguladora do fluxo interno e externo do capital é dada pela desigualdade:

$b_{1}(t)=\sum_{j=1}^{g} a_{1 j}(t) x_{j}(t)+\sum_{j=g+1}^{h} a_{i j}(t) x_{j}(t)+\sum_{j=h+1}^{n} a_{i j}(t) x_{j}(t),(13)$ $\operatorname{com} i=s+1$. 
Ou seja, o somatórío dos dispêndios anuais no tempo $t$ não podem superar a disponibilidade de dinheiro em caixa em $t$. Acrescente-se que. quando a relação acima não for suficiente. introduz-se uma atividade de transferéncia na série $P_{h+1} \ldots P_{n}$, que uma vez acionado permitirá que o dinheiro dos fundos de crédito ou do capital aplicado no mercado financeiro expanda os limites de liquidez. Para tanto, pressupõe-se que o uso do crédito rural é feito so mente em atividades dentro do setor agrícola, devido à existênciade perfeita fiscalização sobre esta prática. A inequação (14) mostra que o montante de capital aplicado no mercado financeiro não pode ultrapassar a disponibilidade de dinheiro em caixa.

$$
b_{i}(t)=\sum_{j=h+1}^{h^{\prime}} a_{i j}(t) x_{j}(t), i=s+1
$$

\section{1 .1 .4 - Equação complementar}

A equaçăo complementar é muito importante porque per mite formalizar relaçöes intertemporais com a renda. Através dela determina-se a renda agrícola disponível em caixa no início do ano agrícola, a qual representa a quantidade líquida de capital que o produtor dispõe para controlar o fluxo de entrada e saída de dinhei ro.

A renda agrícola obtida no tempo é dado por

$$
\sum_{j=1}^{n} z_{j}^{\prime}(t) x_{j}(t)
$$


onde $Z_{j}$ é o vetor dos preços efetivamente pagos ou recebidos pelos produtores. Estes coeficientes são nulos para as atividades de investimento em máquinas, equipamentos, animais de trabalho e iguais acs gastos por hectare com operações de máquinas e insumos não incluídos nas atividades de compra. Assim, o capital disponível em caixa para o início do ano agrícola t é dado pela soma da renda agrícola gerada em $t-1$ com a disponibilidade de capital em caixa no início do ano agrícola $t-1$, do qual se subtraem as retiradas de dinheiro para cumprir os déoitos fixos $K$ (pagamento do principaI e ju ros dos empréstimos contraídos) e consumo interno (dado pela propen säo de consumo da rerida $p$ ).

$$
b_{1}(t)=\left[\sum_{j=1}^{n} z_{j}^{\prime}(t-1) x_{j}^{*}(t-1)\right](1-p)+b_{i}(t-1)-k(t-1)+v(t)
$$

\section{1 .1 .5 - Limites comportamentais}

O grupo de atividades $b_{v+1} \because b_{m}$ está relacionado com as magnitudes das atividades de investimento e produção, uma vez que são formas de captação das decisões assumidas pelos produtores em diversos períodos de tempos, sob' situações de mudanças na disponibilidade de recursos.

A performance histórica das unidades produtivas, durante o período do estudo, para as atividades de produção e investi mento, revela limites comportamentais que podem ser estimados por coeficientes de fiexibilidade e coeficientes de adocão. Ambos säo 
calculados com base nos acréscimos e decréscimos percentuais de cada atıvidade. Quando tratar-se de atividade de produção o coeficien te estimado é chamado de "flexibilidade". e quando se tratar de ati vidade de investimento o coeficiente estimado é chamado de "adoção". A instituição de limites comportamentais estimados por "coeficientes de flexibilidade e adoção" obriga a resolução do modelo a fixar-se no intervalo:

$$
\underline{B} x_{t-1}^{*} \leq x_{t}^{*} \leq \bar{B} x_{t-1}^{*}
$$

onde: $\underline{B}=$ coeficiente de flexibilidade (ou adoção) inferior;

$\bar{B}=$ coeficlente de flexibilidade (ou adoção) superior:

$x_{t-1}^{*}=$ resultado da atividade em $t-1$.

\subsection{2 - Modelo de expectativa de inflação}

0 modelo simulador de expectativa de inflação é cons truído sob a pressuposição que os agricultares formulam suas expectativas de inflação futura, sensibilizados pelas experiências passadas, sendo as experiéncias recentes ponderadas como as mais importantes nesse processo. A sua importáncia é relevante porque estima valores esperados, que säo introduzidos na função objetivo, para avaliar o comportamento dos agricultores na elaboração dos seus planos de produção.

Formalmente, o modelo ë apresentado na forma linear como: $: 21$

2f 0 modelo é c mesmo usado por PERES (I976). 
31.

$$
\begin{gathered}
P_{t}^{*}=\alpha-\beta I_{t}^{*}-e_{t} \\
I_{t}^{*}=\gamma_{1} I_{t-1}+\gamma_{2} I_{t-2}+\gamma_{3} I_{t-3} .
\end{gathered}
$$

onde: $P_{t}^{*}=$ expectativa dos índices de preços recebidos pelos produtores no tempo $t ; \underline{3}$

$I_{t}^{* *}=$ expectativa do índice geral de preços no tempo $t$;

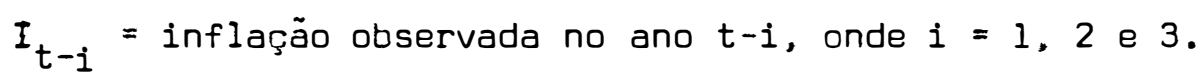

Substituindo (17) em (16) e fazendo $\beta \gamma_{1}=\alpha_{1}, \beta \gamma_{2}=$ $\alpha_{2}, B \alpha_{3}=\alpha_{3}$, tem-se finalmente:

$$
P_{t}^{*}=\alpha+\alpha_{1} I_{t-1}+\alpha_{2} I_{t-2}+\alpha_{3} I_{t-3}+e_{t}
$$

Admitindo que a diminuição no ritmo inflacionário no Brasil após 1964, influenciou a expectativa de inflação formada pe. los agricultores introduziu-se no modelo urr-variável "dummy" para capturar esse efeito 4 , ficando a equação acima ampliada para:

$$
\begin{aligned}
P_{t}^{*}=\alpha & +\alpha_{1} I_{t-1}+\alpha_{2} I_{t-2}+\alpha_{3} I_{t-3}+\alpha_{4} D+\alpha_{5} D I_{t-5}+\alpha_{6} D I_{t-6}+ \\
& +\alpha_{7} D I_{t-7}+e_{t}
\end{aligned}
$$

onde, $D=0$, se $t \leq 1963$, e $D=1$, se $t \geq 1964$.

3/ As variáveis com asteriscos indicam suas taxas de mudanças no tem po: $P_{t}^{*}=d n \ell P_{t} ; I_{t}^{*}=d n \ell I_{t}$.

4/ Na tentativa de capturar o efeito do recrudescimento inflacionário a partir de 1973, o mesmo recurso foi empregado, mas o mesmo não se mostrou significativo na equąão ajustada devido, provavelmente, ao pequeno númers de graus da liberdace para testar a significáricia do coeficiente estimado. 
A intercepção $\alpha$ indica a presença de aumentos sistemáticos (ou diminuições) no nível geral de preços. Uma intercepção positiva mostra que os preços recebidos pelos agricultores aumentam mais que a inflação, enquanto uma intercepção negativa mostra o con trário. Espera-se valor de $\alpha$ igual a zero e $\alpha_{1}, \alpha_{2}, \alpha_{3}$ com valores positivos, sendo que a pressuposição de que as experièncias recentes são mais importantes na formação das expectativas e sug̣ere que $\alpha_{1}>\alpha_{2}>\alpha_{3}$.

0 modelo considera a inflação explicitamente no mercado de produtos. Para o mercado de fatores assume-se que os produtores conhecem perfeitamente os preços que deverão pagar, uma vez vez que eles podem proteger-se contra desvios dos valores esperados através contratação prēvia de alguns dos insumos requeridos no pro* cesso produtivo (PERES, 1976). Acrescentando a cada ano uma nova ob servação, o valor do índice recebido é projetado para cada ano agrí cola do período em" estudo, ajustando a equação (18) e inflacionando a renda bruta esperada em cada atividade pela quantidade correspondente às expectativas de inflação dos produtores.

\subsection{3 - A demanda derivada por crédito}

Considerando que os produtores estão sob as condiçōes de mercado imperfeito de capital, em que a possibilidade de to mar emprestado e conceder empréstimos de capital em dinheiro numa mesma taxa de juros dificilmente ocorre, pode-se através da esquema tização da figura 2, para o caso de dois perílodos. derivar a curva de demanda por crédito dos agricultores. 
33.

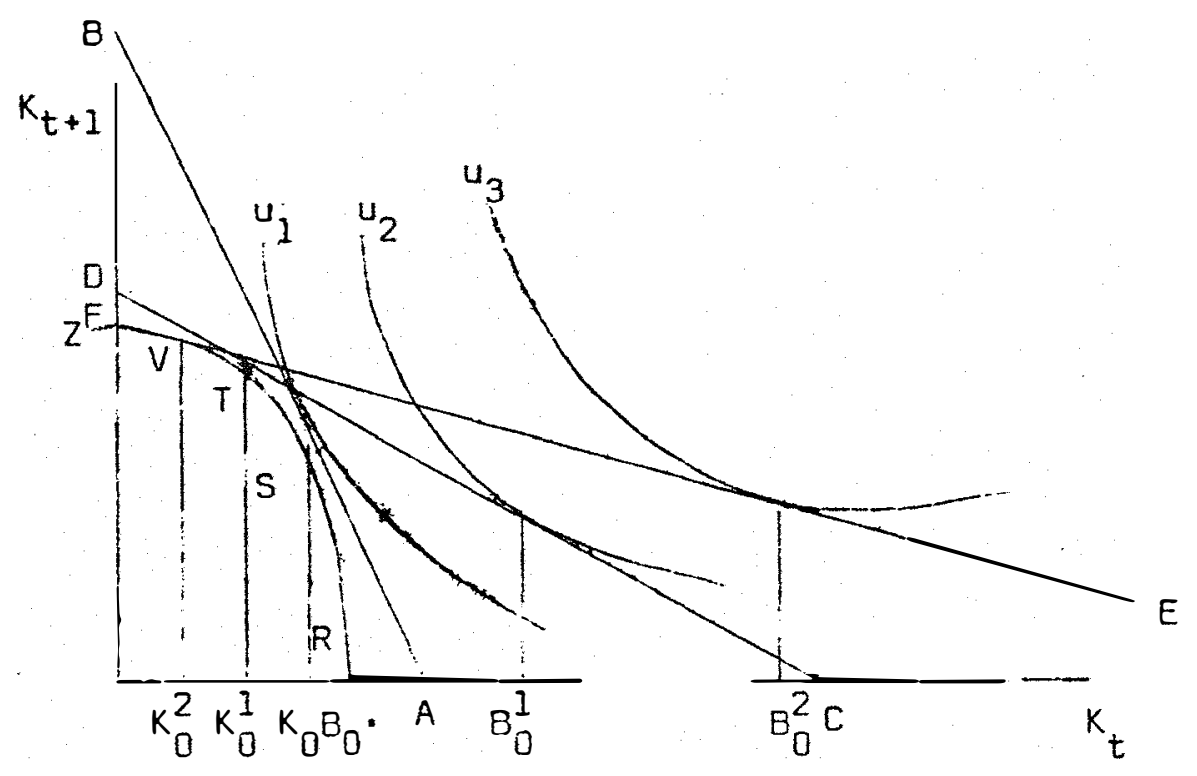

Figura 2 - Maximização do Valor Presente da Renda.

A curva de possibilidade de produção (RSTVZ) é o lugar geométrico dos pontos. que indicam a possibilidade dos indivíduos sacrificarem o consumo da renda corrente $\left(k_{t}\right)$ em favor de dispêndios que gerem rendimentos no perfodo subsequente $\left(k_{t+1}\right)$. As cur vas de indiferença $u_{1}, u_{2}, u_{3}$ mapeadas pelo método ordinal são derivadas da função de preferência por renda dos produtores. As rendas disponíveis em cada um dos dois períodos estão sujeitas a certas oportunidades e restriçōes, representadas respectivamente pelas linhas de oportunidade de mercado $(A B, C D, E F$ ) e pela curva de possibilidade de produção.

Os resultados fornecicos pelo modelo de programação recursiva, cue maximiza o valor presente da renda a cada tempo t do período em estudo, corresponúem aos pontos de tangência entre as li 
nhas de oportunidade de mercado com a curva de oportunidade de produção. Faz-se então a pressuposição, necessária mas não suficiente, que os agricultores alcançam maior curva de utilidade ao maximizar o valor presente da renda (BRANSON, 1972).

Tomando inicialmente que no ponto $S$, onde a linha de oportunidade de mercado $A B$ é simultaneamente tangente à curva de pos sibilidade de produção e a curva de indiferença $u_{1}$, o valor da taxa de juros $r_{0}$ é tão elevado que fundos disponíveis para empréstimos não são tomados. Caso a taxa de juros $r_{0}$ diminua para $r_{1}$, a nova li nha de oportunidade de mercado será dado por $C D$, tangente no ponto T da curva de possibilidade de produção. Em T, o produtor alcançauma curva de indiferença maior que a situação inicial, am $U_{1}$, ao to mar empréstimos no mercado de capital $\mathrm{K}_{0}^{1} \mathrm{~B}_{0}^{1}$ e aproveitando seu capital em $0 K_{0}^{1}$. Caso novamente a taxa de juros diminua mais ainda para $r_{2}$, o novo ponto. $V$ é obtido na tangéncia entre a curva de possibili dade de produção e a linha de oportunidade de mercado, maximizando sua utilidade em $S_{2}$, tomando empréstimo $K_{0}^{2} B_{0}^{2}$ no mercado de capital e utilizando seu pröprio capital em $0 \mathrm{~K}_{0}^{2}$.

O esquema da demanda por crédito é apresentado na fi gura 3, mostrando no eixo vertical os diferentes níveis de taxas de juros relacionados com as quantidades de crédito no eixo horizontal, que os agricultores estão dispostos a tomar. A demanda por crédito é obtida mantendo ceteris paribus a soluçēo ótima do modelo, somen te relaxando a disponibilidade de crédito no conjunto restrícionai e, simultaneamente, fixando valores alternativos de taxas de juros. 


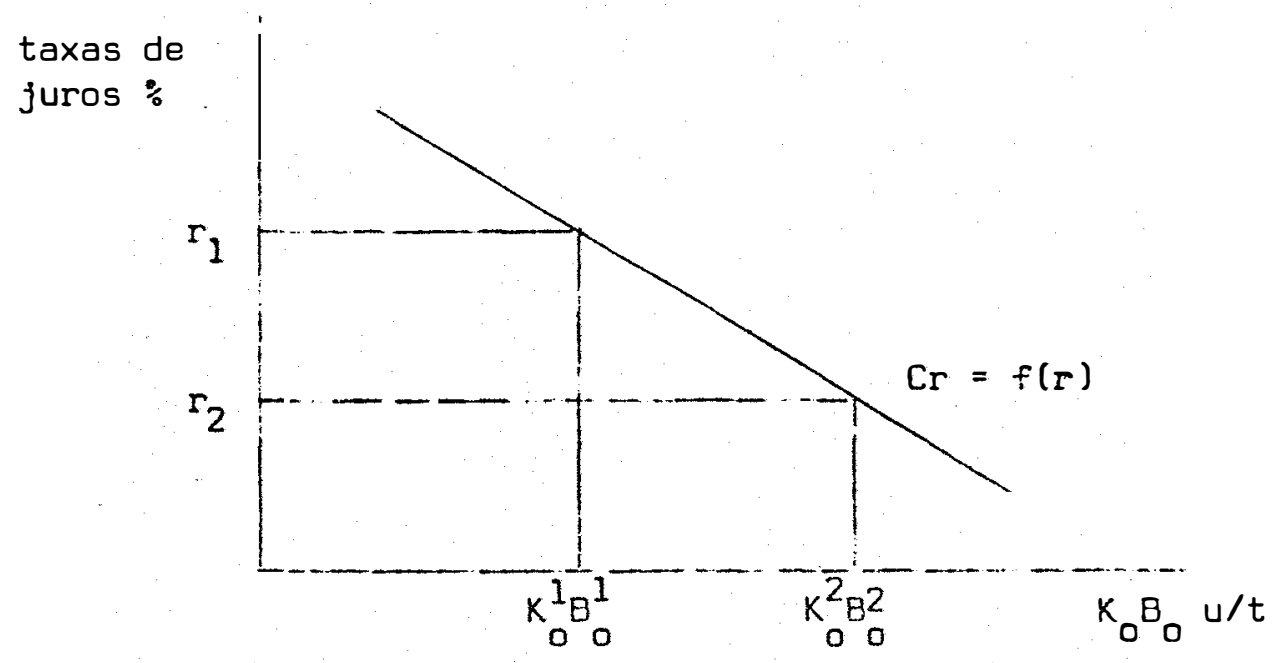

Figura 3 - Demanda Derivada por Crédito.

Uma vez derivada a curva de demanda por crédito pelos agricultores, pode-se mediante a incorporação de um conceito de excedente, estimar o subsídio que eles recebem. Para tanto, toma-se para um tempo $t$ escolhido, os valores observados de taxas de juros ( $r_{\text {obs }}$ ) e a quantidade demandada por crédito $\left(\mathrm{Cr}_{\text {obs }}\right.$ ), e posteriormen te, afusta-se na curva de demanda derivada pelo modelo a taxa de jü ros $\left(r_{m}\right)$ que os agricultores estariam dispostos a pagar por aquela quantidade de crédito, determinando a àrea do subsídio.

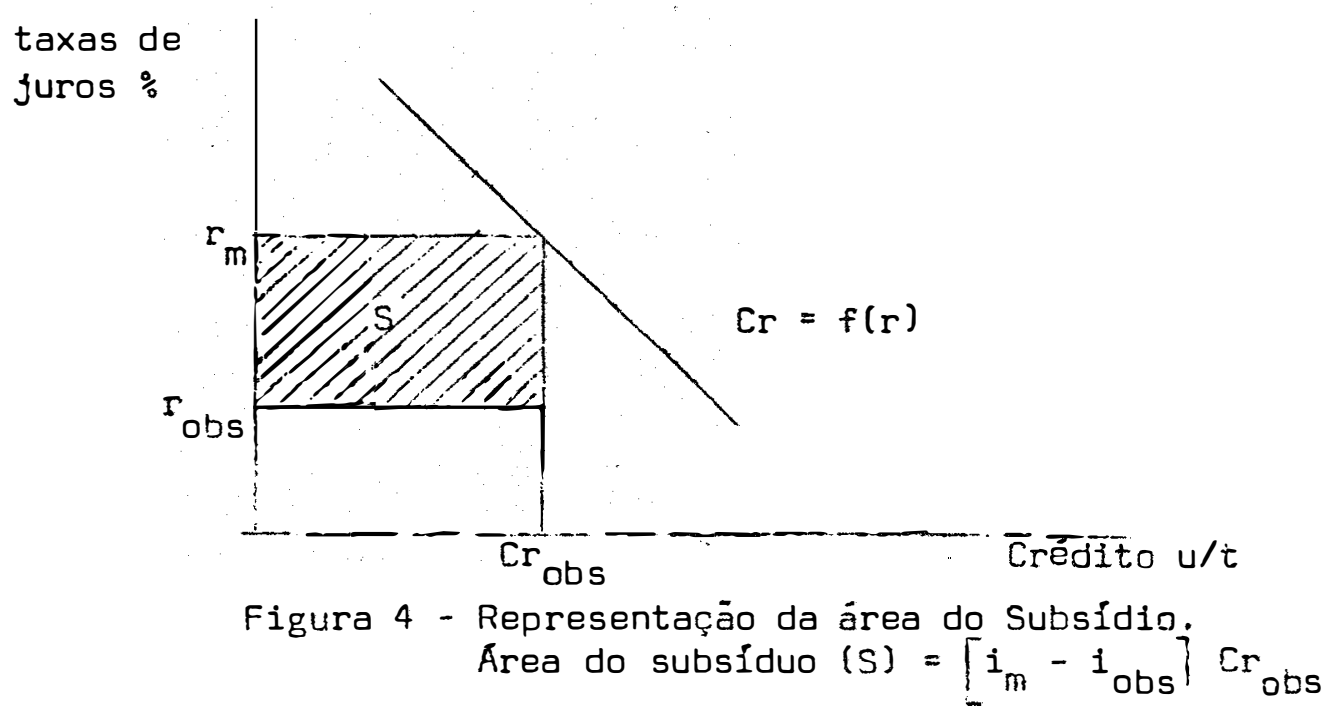




\section{2 - Modelo Empírico}

Esta secção está dividida em três partes. A primeira refere-se à fonte dos dados utilizados no modelo empírico. A se gunda discorre brevemente sobre a região de estudo. Finalmente, a terceira descreve os procedimentos adotados na elaboração do modelo empirico.

\subsection{1 - Fonte de dados}

Os dados utilizados no estudo foram extraídos de diversas fontes. Os coeficientes técnicos de produção foram retirados, basicamente, dos custos de produção estimados pelo Instituto de Eco. nomia Agrícola (IEA), da Secretaría da Agricultura do Estado de São Paulo, para áreas agrícolas dentro da região em estudo. Nos casos de completa inexistência de certos tipos de dados, como capacidade de suporte das pastagens E composição de rebanho para pecuáría de corte e leite, suinocultura tipo banha e carne, ponderou-se as informaçōes prestadas por técnicos de larga experiência na região com ma nuais de orientação técnica. Os indíces de preços recebidos mais os preços pagos e recebidos correntemente pelos produtores foram co letados do boletim mensal Informaçōes Econōmicas do IEA, SP. Os indices gerais de preços e as taxas de juros mais correção monetária pagas pelas cadernetas de poupança foram obtidos da revista Conjuntura Econômica publicada pela Fundação Getūlio Vargas. As taxas de juros dos empréstimos do crédito rural foram tomados junto a técni- 
cos que trabalham em carteiras agrícolas e da publicação anual Prog nóstico do IEA, SP.

Três tipos representativos de propriedades agrícolas säo consideradas no estudo, correspondentes a classes de pequenas, médias e grandes propriedades agrícolas. O critério para estratificação foi a dimensão em área da propriedade, como mostra a tabela 2. A construção dos valoresnumérices que compöem o conjunto restricional de cada estrato foram elaborados, principalmente com base nos levantamentos efetuados no banco de dados do Instituto de Economia Agráría.

Tabela 2 - Classe de área, número e área dos imóveis rurais. Três estratos de propriedades agrícolas. DIRA de Campinas, 1967.

\begin{tabular}{lrrr}
$\begin{array}{l}\text { Propriedade } \\
\text { Agrícola }\end{array}$ & $\begin{array}{c}\text { Classe de } \\
\text { Area }\end{array}$ & $\begin{array}{c}\text { Nümero de } \\
\text { Imóveis }\end{array}$ & $\begin{array}{c}\text { Area } \\
\text { (ha) }\end{array}$ \\
\hline Pequena & $0,1-10$ & 14.803 & 58.840 \\
Média & $10,0-100$ & 19.059 & 625.581 \\
Grande & 100 & 3.889 & 1.321 .639 \\
\hline Total & -1006.060 \\
\hline
\end{tabular}

\subsection{2 - A regiāo do estudo}

A área escolhida para o estudo foi a região administrada pela Divisão Regional Agrícola (DIRA) de Campinas, que agrega as subregiães de Casa Branca, Limeira, Campinas, Piracicaba, São João 
da Boa Vista e Rio Claro. A região é responsável por cerca de $14 \%$ do Valor da Produção Agrícola do Estado. A pecuäría, fruticultura e agricultura respondem, respectivamente por $9 \%, 21 \%$ e $70 \%$ do seu Valor de Produção.

Trata-se de uma das regiões mais capitalizadas do Es tado de Sãa Paulo, muito bem dotado de instituições que prestam ser viços de ensino, pesquisa, extensāo e crédito ao setor agrícola, as quais contribuem significativamente para o constante desenvolvimento da sua agricultura.

Existe na região uma variada gama de atividades de produção. A fruticultura, exceto Citrus, está concentrada numa ärea favorävel à produção de produtos de clima temperado. A produção ani mal é praticada em toda região, em atividades especlficas de pecuária de leite e corte, sulno tipo banha e carne além da avicultura. A agricultura está diversificada em atividades que vão desde a produção de produtos alimentares como arroz, feijão, milho, mandioca, batata, etc., até a produção de produtos característicos de exporta ção como café, cana, soja, etc. A exploração de essências florestais restringe-se quase que basicamente a Eucalliptus, enquanto que as atividades olerícolas mais importantes são as de tomate e cebola.

\subsection{3 - o modelo empírico}

A descrição dos procedimentos adotados para a formaiização do modelo emplrico está subdividido em três partes. A primeira focaliza a funçẽo objetıvo. A segunda os critérios assumidos 
na constituição das atividades. Por último, a terceira mostra a com posição do conjunto restricional. Maiores detalhes sobre a formalização do modelo empírico pode ser encontrado no estudo de GEMENTE (1978).

\subsubsection{1 - Função objetivo}

Os valores numéricos dos coeficientes da função obje tivo a ser otimizada em cada ano agrícola de 1970 a 1977 são as receitas esperadas (Margem Bruta) para as atividades de produção, cal culadas com base no f́ndice de preços esperados, determinado pelo mo delo de expectativa. Portanto, dado que o valor da solução ótima da função objetivo não possui significado para as condições ex-post, in troduziu-se uma nova linha na matriz com as receitas (Margem Bruta) para as atividades de produção, calculadas com base nos preços observados. O valor desta linha, uma vez obtida a solução ótima, corresponde à renda agrícola realmente obtida em cada ano agrícola.

\section{2 .3 .2 - Atividades}

Os critérios utilizados na seleção das atividades pa ra cada estrato de área são justificados, a seguir, separadamente pa ra as atividades de produção, transferência de terra contratação de mão-de-obra residente e temporária mais aluguel de mão de-obra fami liar, consumo, investimento em máquinas, equipamentos, animais de trabalho e culturas perenes. empréstimos de crédito agrícola e apli cação de dinheiro no mercado financeiro. 


\subsubsection{1 - Atividades de produção}

As atividades de produção foram selecionadas isolada mente para cada um dos trés estratos uma vez que a área ocupada e a importáncia económica de uma atividade agrícola, varia de acordo com as características de disponibilidade e alocação dos recursos por classe de área.

O estrato de área que agrega as propriedades médias é aquele que possui maior diversificação de atividades produtivas na DIRA de Campinas. Assim é que, as atividades incorporadas no modelo para este estrato foram: milho, arroz, feijão, batata das secas, ba tata das águas, feijão das secas, feijão das águas, mandioca, tomate, cana, soja. café, laranja, pasto natural, pasto artificial, pecuária de corte, pecuária de leite $B$, pecuária de leite $C$, suíno ti po banha e suíno tipo carne. A produção de soja foi acrescentada zo conjunto de atividades agrícolas do estrato, somente a partir de 1973/74, quando a sua expansão foi tal que mereceu imbortância.

A classe de área representativa das pequenas proprie dades apresenta em comum as mesmas atividades de produção das médias propriedades, com exceção ao cultivo de tomate e soja mais cria çāo de suÍno tipo carne. No estrato maior, foram consideradas as mes mas atividades do estrato médio, exceto a criação de suíno tipo car ne.

Por ser o Citrus mais disseminado na regiāo tomou-se a cultura da laranja como "proxy" para representar a érea, os cus- 
tos e rendimentos das atividades de produção em Citrus para todos os estratos. Este procedimento é justificado pela dificuldade em ob ter dados sobre as variadas atividades de produção na citricultura da região em estudo.

\subsubsection{2 - Atividades de transferência de terra}

o modelo considera trés tipos de terra, segundo critério de uso do solo: Terra l lárea disponível para cultura anual, perene e pasto), Terra 2 (área disponível para cultura perene e pas to), Terra 3 (área disponível para pasto).

\subsubsection{3 - Atividades de con‡ratação de mão-de-obra residente não fa miliar e aluguei de mão-de- -obra familiar}

A contratação de mão-de-obra residente não familiar e temporäria aumenta a disponibilidade do fator trabalho para as operações agrícolas, acarretando acréscimos nos custos de produção: que variam com os aumentos nas taxas de salärios correntes, durante os très períodos considerados de ano agrícola: Período 1 iagosto a novembro), Período 2 (dezembro a março), Peŕíodo 3 (abril a maio).

A possibilidade da mão-de-obra familiar alugar o seu fator trabalho representa um custo de oportunidade, que permite ao trabalhador familiar aumentar sua disponibilidade de dinheiro em cai xa: auferindo rendimentos em salärios noutras prooriedades rurais, 
naqueles períodos que permanecem em ociosidade e/ou subemprego.

\subsubsection{4 - Atividades de compra de in- sumos}

A aquisiçào desses insumos específicos aumentam as suas disponibilidades para uso durante o processo produtivo e, ao mesmo tempo, causa um fluxo de saída de dinheiro. Os insumos modernos considerados foram: corretivos, fertilizantes, defensivos, vacinas rações e medicamentos.

\subsubsection{5 - Atividades de corisumo}

O recebimento de produtos em espécie pela mäo-de-otra residente famiiiar e não familiar, como suplemento do saiéric pago pelos pródutores, foi considerado para os seguintes alimentos de sub sistência: arroz, feijão, milho e leite C. Considerou-se ainda que o milho consumido na suinocultura, pecuária de leite e por animais de trabalho pode ser comprado ou produzido na propriedade agrícola.

\subsubsection{6 - Atividades de investimento em mäquinas, equipamentos, ani- mais de trabalho e culturas perenes .}

0 montante de dinheiro dispendido na aquisição de cada trator com equipamentos foi est1mado sob a pressuposição de uma relaçăo fixa entre número de tratores" e equipamentos para cada ano agrícola, por estrato de produção. Os equipamentos considerados foram: arado, grade, semeadeira-adubadeira, cultivador, semeadeira sim 
ples, adubadeira simples, pulverizador, roçedeira e carreta. Para culturas perenes, foram considerados investimentos em café e laranja, com suas vidas úteis estimadas em 30 e 20 anos, respectivamente.

\subsubsection{7 - Atividades de empréstimos de crëdi to}

A criaçào de novas linhas especiais de crédito bem como as alterações efetuadas nas existentes, foram consideradas nos diversos casos etravés de variações nos valores das taxas de juros. Assim, considerou-se para o crédito tomado para compra de fertilizantes taxas de juros iguais a zero, durante os anos agrícolas de 70/71 a 74/75. Para 75/76 e 76/77 foram tomadas taxas de juros de 15\% e o preço do fertilizante com o subsídio de $40 \%$. A taxa de juros paga para crédito de custeio foi de $15 \%$ para o período todo do estudo. De $72 / 73$ em diante, introduziu-se uma linha de crédito para compra dos chamados insumos modernos com taxa de juros de $7 \%$ até $74 / 75$ e zero por cento para $75 / 76$ e 76/77.

Para o crédito dirigido para investimento. verificou-se inicialmente que, em média, càda propriedade dos estratos peque nos e médios tem quantidade de crédito menor a 50 M.V.R. (Maior Valor de Referéncia), enquanto que as propriedades do estrato maior tomam quantidades superiores a 50 M.V.R. Feita essa constataçảo, con siderou-se que as taxas de juros cobradas para investimento entre $70 / 71$ e $71 / 72$ foram de $12 \%$ para os estratos médios e pequenos e, IB\% para o estrato grande. Finalmente, assumiu-se que os produtores 
tomam seus empréstimos para investimento com um período de caréncia de dois anos e, posteriormente, saldam suas dívidas num prazo de se te anos.

\subsubsection{8 - Aplicação de dinheiro no mer} cado financeiro

o dinheiro disponível em caixa no início do ano agrí cola pelo produtor, pode ser alocado näo somente no setor agrícola, mas também no mercado financeiro, que representa uma oportunidade a mais para aumentar seus ganhos. Dado a existència de uma variedade de procedimentos a serem conduzidos pelos produtores para aplicarem seus capitais no mercado financeiro, tomou-se como "proxy" para representar o custo de oportunidade do capital, os rendimentos dos juros com a correção monetäría dos dinheiros depositados nas cadernetas de poupança.

\subsubsection{3 - Conjunto restricional}

Os valores e equações de restrições, em cada estrato de produção, foram estabelecidos individualmente para: terra, mão-de-obra, animal de trabalho, trator e equipamento, colhedeira de soja, obrigações fixas disponibilidade de dinheiro em caixa, dispo nibilidade de crédito e limites comportamentais.

\section{2 .3 .3 .1 - Terra}

Para todo o período do estudo foi determinado um valor numérico fixo: medido em hectares, segundo critério de uso do 
solo, dentro de cada estrato para cada um dos très tipos de terra.

\section{$2 \cdot 2 \cdot 3 \cdot 3.2$ - Mão-de-obra}

A quantidade de mão-de-obra residente familiar e não familiar disponível foi considerada em equivalentes dias homens, ten do sido assumido que cada unidade de mão-de-obra pode trabalhar 210 dias por ano, distribuídos uniformemente para cada um dos très períodos do ano agrícola. Mão-de-obra adicional pode ser contratada (trabalhadores temporários) pela taxa de salário predominante nomer cado rural, conforme a prática mais vigente nos períodos: agosto a novembro em que predominam as atividades de plantio, dezembro a mar ço em que os tratos culturais são as tarefas meis executadas,e abril a Junho quando a maioria das colhe1tas são realizadas.

\subsubsection{3 - Animal de trabalho}

Foi verificado que o número de animais de trabaiho caiu sistematicamente para os três sstratos de produção no decorrer do perfodo. Tomou-se então, para calcular a disponibilidade de animais de trabalho para cada ano agrícola, a equação abaixo:

$$
v_{n}=v_{0}(1+r)^{n} \text {, }
$$

onde: $V_{n}=$ nümero de animałs de trabal ho em 1976/77;

$V_{0}=$ nümero de animais de trabalho no ano base 1970/71:

$\Gamma=$ taxa geométrica;

$n$ = número de anos agrícolas a partir do ano base. 
Uma vez assumido, que cada animal de trabalho está lí vre para executar serviços em metade do tempo para cada período do ano agrícola, mensurou-se a quantidade disponível de animais de tra balho em termos de dias animais. Desta maneira, a restrição de animal de trabalho para cada ano agrícolá seria dada pela disponibilidade de animal de trabalho do ano agrícola anterior multiplicado pe la taxa geométrica de decrescimento.

\section{$2 \cdot 2 \cdot 3 \cdot 3 \cdot 4$ - Trator}

Como a quantidade de trator cresceu sistematicamente para os très estratos de produção durante o período do estudo, adotou-se procedimento similar ao estabelecido para animais de traba1ho. O estoque de tratores disponível para cada ano agrícola, medido em dias máquinas, é calculado multiplicando-se o número de trato res disponíveis no ano ag̣ícola anterior pela sua taxa geométrica de crescimento. Assumiu-se que cada trator está livre para realizar suas operações durante 50 dias para cada período de ano agrícola, num total de 150 dias por ano.

\section{$2 \cdot 2 \cdot 3 \cdot 3 \cdot 5$ - Colhedeira de soja}

Observou-se que a quantidade de colhedeira de soja tambëm aumentou sistematicamente durante o período do estudo. Miais uma vez, adotou-se o critério da taxa geométrica de crescimento para calcular a disponibilidade de colhedeiras de soja para cada ano agrícola. Assumiu-se que cada colhedeira de soja está disponível du rante 50 dias entre agosto a novembro; período em que se concentram 
as operações de colheita da cultura.

\subsubsection{6 - Obrigações fixas}

São dadas pela soma dos dispēndiós da renda para con sumo interna e pagamento dos débitos dos empréstimos contraídos. A quantidade da renda agrícola utilizada pelos produtores a fim de sa tisfazerem suas necessidades de consumo durante o ano agrícola, é calculada pela equação:

$$
Y_{0}(t)=Y(t) \cdot b \cdot
$$

onde: $Y_{0}(t)=$ renda consumida em $t$;

$Y(t)=$ renda agrícola obtida em $t$.

$b=$ propensão do consumo da renda.

Com base em MOREIRA (1973), os valores da propensão de consumo da renda foram considerados de $90 \%$. $80 \%$ e $70 \%$ para os es tratos pequeno, médio e grande respectivamente. Os débitos fixos sào reduçōes na renda, correspondentes aos pagamentos dos juros e principal dos empréstimos para investimento contraídos em períodos ante riores.

2.2.3.3.7 - Dinheiro disponivel em caixa

E tomado como a quantidade líquida de dinneiro dispo nível no início do ano agrícola, após o cumprimento dos débitos fixos e dos gastos de consumo, com a qual os agricultores realizam o balanço dos fluxos de entrada e saída de dinheiro durante o ano aagrícola em curso. 


\section{$2 \cdot 2 \cdot 3 \cdot 3.8$ - Crëdi to}

Os valores restritivos do crédito foram as quantidades estimadas de créditos tomados pelos estratos pequenos, médios e grandes durante cada ano agrícola, com base em CIDADE e MEYER(1977). Admitiu-se que a distribuição do crédito na DIRA de Campinas foi se melhante à do estado.

\subsubsection{9 - Limites comportamentais}

Os coeficientes de flexibilidade considerados paraes timar os limites comportamentais. foram calculados pela média dosacréscimos e decréscimos em área para as atividades de produção sele cionadas para cada estrato, durante o período que abrange o estudo. 
49.

\section{RESULTADOS E DISCUSSÖES}

Este capitulo apresenta e discute os resultados fornecidos pelo modelo em quatro secçōes. As très primeiras apresentam os resultados para cada um dos três anos agrícolas escolhidos para representar o período. A quarta analisa o período completo, com base nos resultados mostrados nas três secções anteriores.

Os anos agrícolas 70/71, 73/74 e 76/77, representati vos das fases inicial, intermediäria e final do perícdo que envolve o estudo, foram tomados como amostra para derivar demandas por crédito. $A$ equação do tipo $Q=A \cdot P^{b}$, onde $Q=$ quantidade demandada por crédito e $P=$ taxa de juros, fol a função escolhida para ajustar os pontos da demanda por crédito. Nesta equação, o valor estima do para o paràmetro b é o valor da elasticidade da curva de demanda $C b=\frac{d Q}{Q}: \frac{d P}{P}$ 
Devido à existência de taxas de juros diferentes para as diversas linhas de crédito, os valores correspondentes às quan tidades totais de crédito demandados foram calculados pelas médias ponderadas entre as quantidades tomadas de crédito em cada linha de crédito por suas respectivas taxas de juros.

\section{1 - Resultados Para o Ano Agrícola 70/71}

A tabela 3 mostra os resultados fornecidos pelo mode lo para as quantidades totais demandadas por crédito em cada estrato de produçāo, bem como os valores das taxas de juros ponderadas. 
Tabela 3 - Demanda Derivada por Crédito. Trēs Estratos de Proprieda des Agrícolas. DIRA de Campinas, 1970/71.

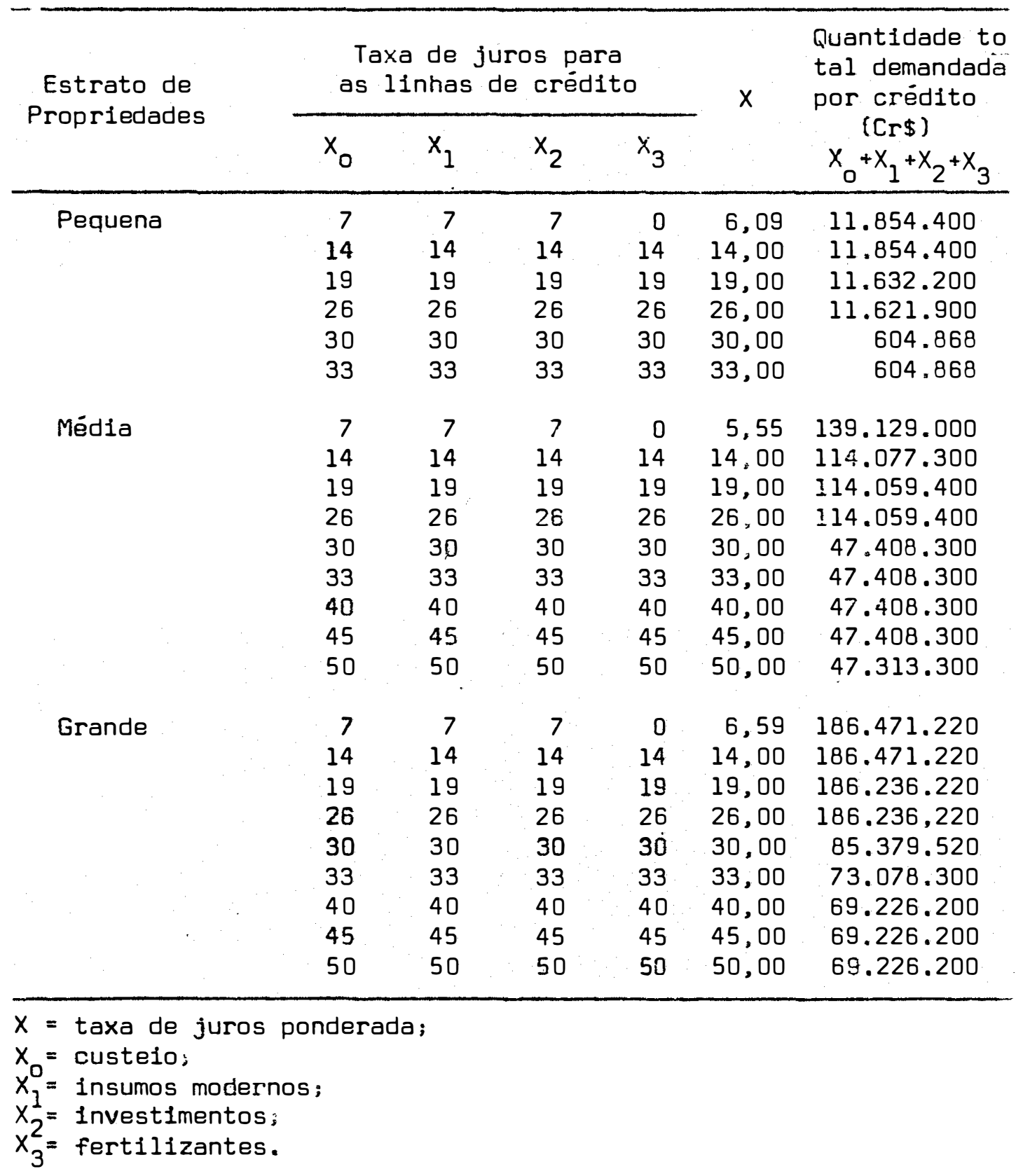


A taxa de juros fixada para o custo da oportunidade do capital (retorno anual das cadernetas de poupança) foi de $26,0 \%$. Observando a tabela 3 , nota-se que a partir do instante em que a ta xa de juros atinge o nível de $26,0 \%$, a quantidade demandada por cré dito sofre violenta queda nos três estratos de produção. Isto ocorre porque os rendimentos do dinheiro aplicado no mercado financeiro são inferiores aos juros pagos pelos empréstimos de crédito. Os agricultores então deixam de tomar emprestado crédito e transferem o dinheiro, que seria aplicado no mercado financeiro, para financiar as despesas com a produção.

Com base nas quantidades totais de crédito demandadas e nos valores das taxas de juros ponderadas, as seguintes funções de demanda foram estimadas:

$$
Q=10^{9,09} p^{-0,7576} \text {. }
$$

para o estrato dos grandes produtores.

$$
Q=10^{9.5960} \mathrm{p}^{-1.1807} \text {, }
$$

para o estrato dos mëdios produtores, e

$$
Q=10^{7,0042} P^{-0,2868} \text {, }
$$

para o estrato dos pequenos produtores: As representaçöes gráfícas dessas equações e dos pontos fornecidos pelo modelo estão na figura 5. 


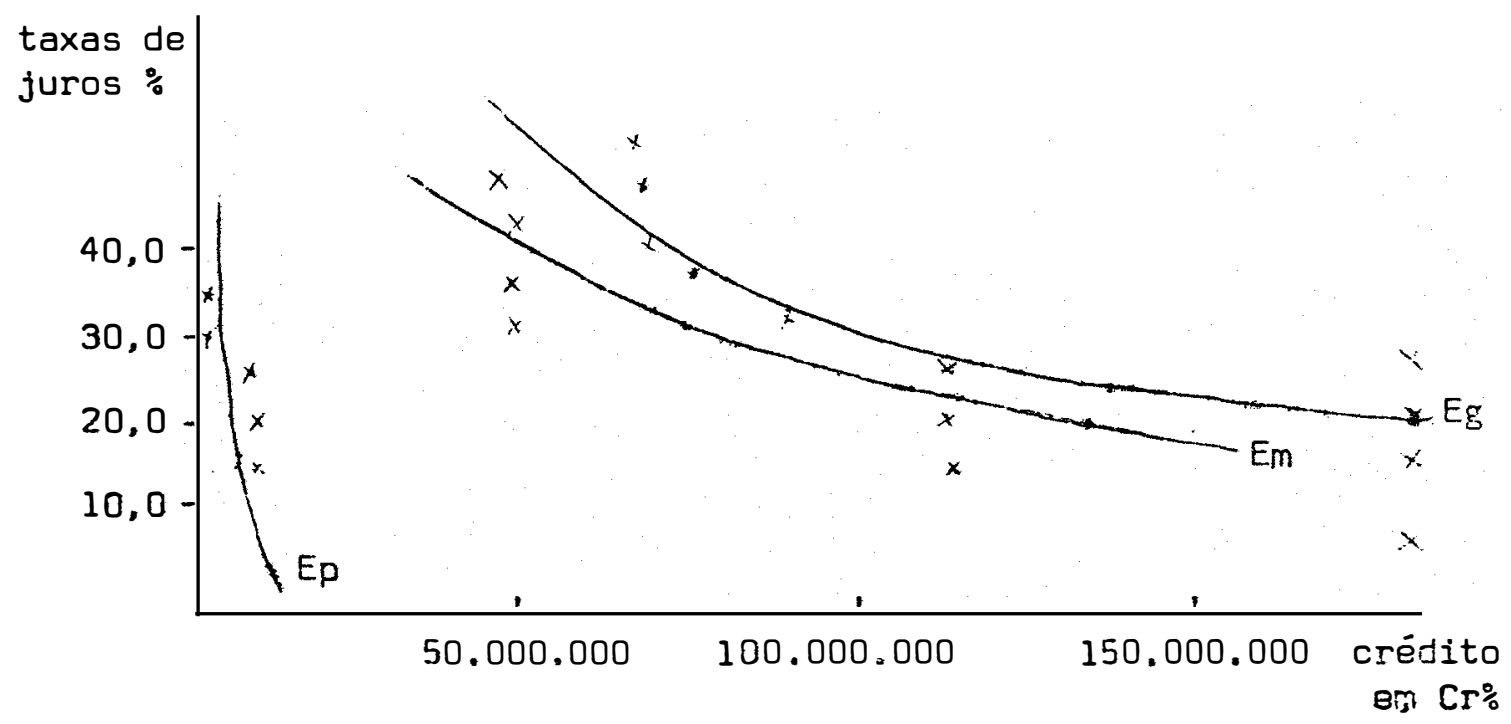

Figura 5 - Demanda Derivada para o estrato dos peque nos produtores $(E p)$, médios produtores (Em) e grandes produtores [Eg], 1970/71.

A tabela 4 mostra para cada estrato a média ponderada $\left(r_{0}\right)$ das taxas de juros parà a quantidade de crédito efetivamente demandado $(\mathrm{Cr})$.

Tabela 4 - Quantidade Total de Crëdito Efetivamente Demandado. Trés estratos de Propriedades Agrícolas. DIRA de Campinas, $1970 / 71$.

\begin{tabular}{|c|c|c|c|c|c|c|}
\hline \multirow{2}{*}{$\begin{array}{l}\text { Estrato de } \\
\text { Propriedade }\end{array}$} & \multicolumn{4}{|c|}{$\begin{array}{l}\text { Taxa de juros pagas pa } \\
\text { ra as Iinhas de crédito }\end{array}$} & \multirow{2}{*}{$x$} & \multirow{2}{*}{$\begin{array}{l}\text { Quantidade to } \\
\text { tal demandada } \\
\text { por crédito } \\
\text { [Cr } \$ \text { ] } \\
x_{0}+x_{1}+x_{2}+x_{3}\end{array}$} \\
\hline & $x_{0}$ & $x_{1}$ & $x_{2}$ & $x_{3}$ & & \\
\hline Pequenas & 14 & 14 & 14 & 0 & 12,49 & 9.434 \\
\hline Média & 14 & 14 & 14 & 0 & 12,11 & 43.580 .000 \\
\hline Grande & 14 & 14 & 18 & 0 & 13,50 & 142.752 .220 \\
\hline
\end{tabular}


Substıtuindo a quantidade de crédito efetivamente de mandada (Cr) por cada estrato em sua respectiva furiçāo de demanda es timada, obtem-se o valor da taxa de juros $\left(I_{1}\right)$ que representa o pre ço do crédito que o produtor estaria disposto a pagar por açuela quantidade de crédito. Esses valores foram de 1,30\% para o estrato dos pequenos produtores, $45,00 \%$ para os médios produtores e $17,00 \%$ para o dos grandes produtores.

As figuras 6 e 7 representam as áreas do subsidio re cebido pelos estratos dos médios e grandes produtores respectivamen te. O cálculo do subsídio é feito através da multiplicação de Cr com a diferença entre $r_{0}$ e $r_{1}$. Como o valor de $r_{1}$ foi maior que $r_{0}$ para o estrato dos pequenos produtores, tem-se que estes produtores não auferiram subsiduo.

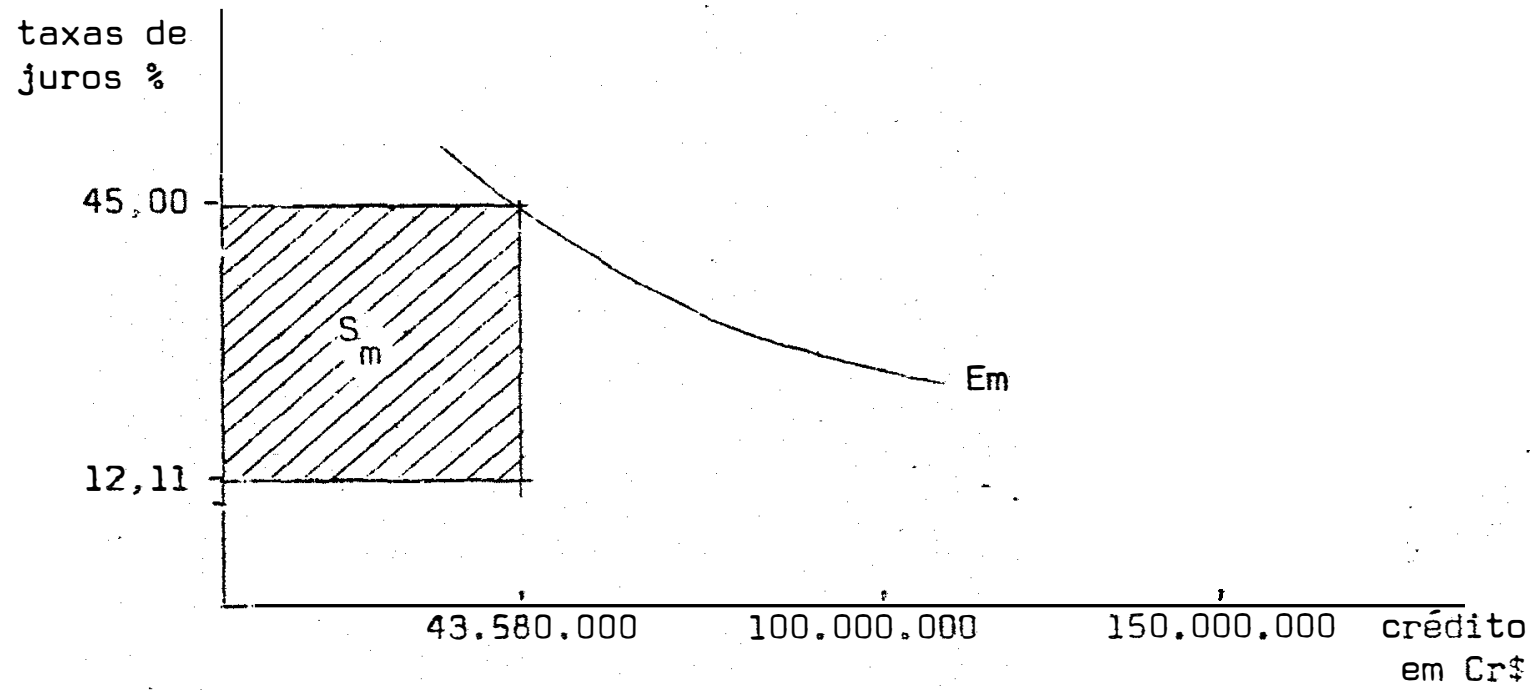

Figura 6 - Subsíduo Recebido pelo estrato dos médios produtores $\left(\mathrm{S}_{\mathrm{m}}\right), 1970 / 71$.

$$
\begin{aligned}
S_{m} & =(0,4500-0,1211) 43.580 .000 \\
& =14.333 .462 .
\end{aligned}
$$


55.

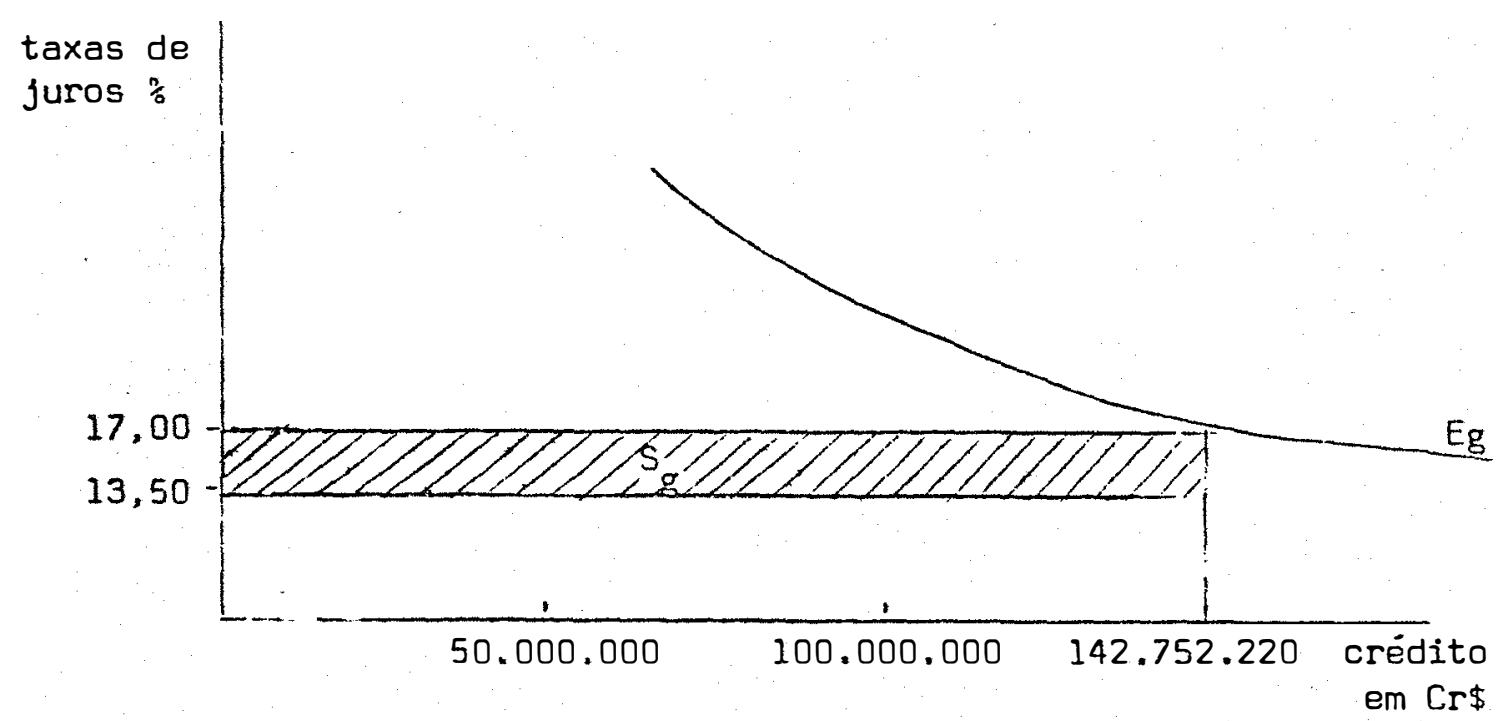

Figura 7 - Subsídio Recebido pelo estrato dos grandes produtores $\left(\mathrm{S}_{\mathrm{g}}\right.$ ). $1970 / 71$.

$S_{g}=(0,1700-0,1350) 142.752 .220$

$=4.996 .327$.

A tabela 5 mostra os resultados para a Renda Agrícola e o Subsídio Récebido em cada estrato de produção, juntamente com as suas respectivas participações percentuais. 0 valor da relaÇão entre Subsíd1o Recebido (S) e a Renda Agrícola (R) completa o quadro. 
Tabela 5 - Renda Agrícola, Subsidio Recebido e a relação entre Subsídio por Renda Agrícola. Très Estratos de Propriedades Agrícolas. DIRA de Campinas, 1970/71.

\begin{tabular}{lcccccc}
\hline \multirow{2}{*}{$\begin{array}{c}\text { Estrato de } \\
\text { Propriedade }\end{array}$} & \multicolumn{2}{c}{ Renda Agrícola } & & Subsidio Recebido & S/R \\
\cline { 2 - 3 } & $(R)$ & $\%$ & & $(S)$ & $\%$ & \\
Pequena & 32.876 .200 & 8,71 & & 0 & 0,00 & 0,0000 \\
Média & 175.470 .000 & 46,52 & 14.333 .462 & 74,15 & 0,0817 \\
Grande & 168.834 .000 & 44,76 & & 4.996 .327 & 25,85 & 0,0296 \\
\hline
\end{tabular}

A tabela 6 mostra os resultados das alterações daRen da Agrícola de cada estrato, quando variaram os niveis das taxas de juros.

Tabela 6 - Efeito da Taxa de Juros no Valor na Renda Agrícola (em Cr\$). Três estratos de Propriedades Agrícolas. OIRA de Campinas, $1970 / 71$.

\begin{tabular}{cccc}
\hline \multirow{2}{*}{ Taxa de Juros } & \multicolumn{3}{c}{ Estrato de Propriedade } \\
\cline { 2 - 4 } & Pequena & Média & Grande \\
\hline 7 & 33.923 .900 & 192.485 .000 & 173.863 .000 \\
14 & 32.986 .900 & 187.628 .000 & 166.712 .000 \\
$19^{*}$ & 32.542 .500 & 182.726 .000 & 151.663 .000 \\
30 & 31.578 .500 & 172.103 .000 & 134.575 .000 \\
40 & & 167.156 .000 & 132.504 .000 \\
50 & & 162.641 .000 & 125.588 .000 \\
\hline
\end{tabular}

(*) Valor de taxa de inflaçẽo em 1970. 
Os resultados do modelo mostraram que as variações nas taxas de juros provocam alteraçōes nos níveis das atividades dos estratos méóios e grandes, enquanto que, no estrato pequeno os $\mathrm{ni}$ veis das atividades permaneceram inalterados. Para o estrato grande, quando a taxa de juros foi elevada, os nívels das atividades de pro dução em café, pecuária de leite $C$ e pecuária de corte, juntamente com a atividade de contratação de mão-de-obra decresceram, enquanto que a atividade de produção em cana cresceu com a diminuição da taxa de juros. No estrato médio, o aumento da taxa de juros diminuiu a contratação de mão-de-obra residente familiar e temporária,enquan to que e diminuição na taxa de juros elevou o nível da atividade de produção em pecuäría de leite $\mathcal{E}$.

\section{2 - Resultados Para o Ano Agrícola $73 / 74$}

A tabela 7 mostra os resultados fornecidos pelo mode lo para as quantidades demandadas por crédito em cada estrato, bem como os valores das taxas de juros ponderadas. 
58.

Tabela 7 - Demanda Derivada por Crédito. Três Estratos de Proprieda des Agrícolas. DIRA de Campinas 1973/74்.

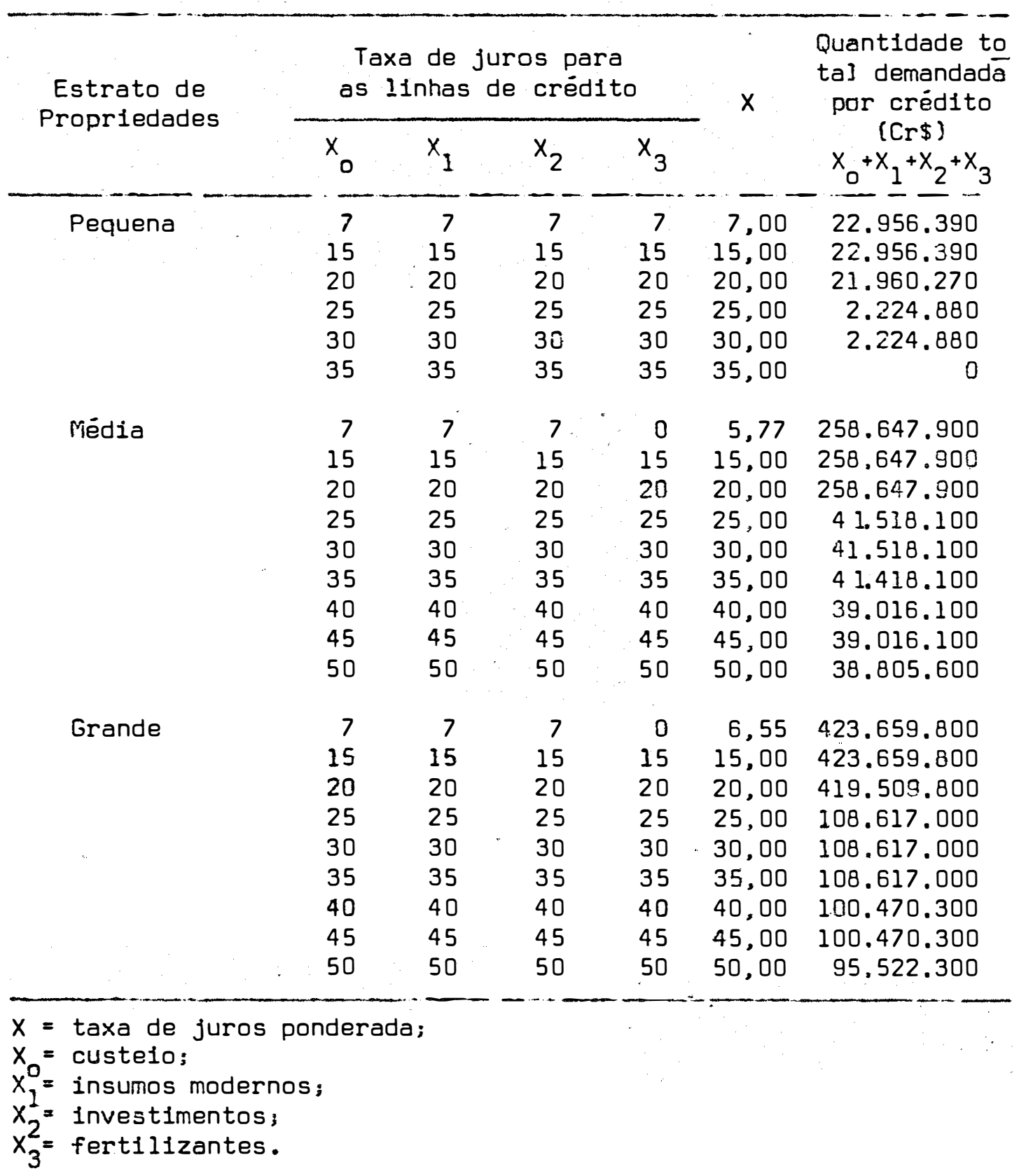


A taxa de juros fixada para o custo de oportunidade do capital (retorno anual das cadernetas de poupança) fol de $20,0 \%$ Com base nas quantidades totais de crédito demandados e nos valores das taxas de juros ponderadas, as seguintes funçōes de demanda foram estimadas:

$$
Q=10^{9,534} p^{-0,9395},
$$

para o estrato dos grandes produtores,

$$
Q=10^{17.382} P^{-6,80} \text {, }
$$

para o estrato dos médios produtores, e

$$
Q=10^{14,469} \mathrm{P}^{-6,7255} \text {, }
$$

para o estrato dos pequenos produtores. A figura 8 representa grafi camente essas equaçöes e 1lustra os pontos fornecidos pelo modelo.

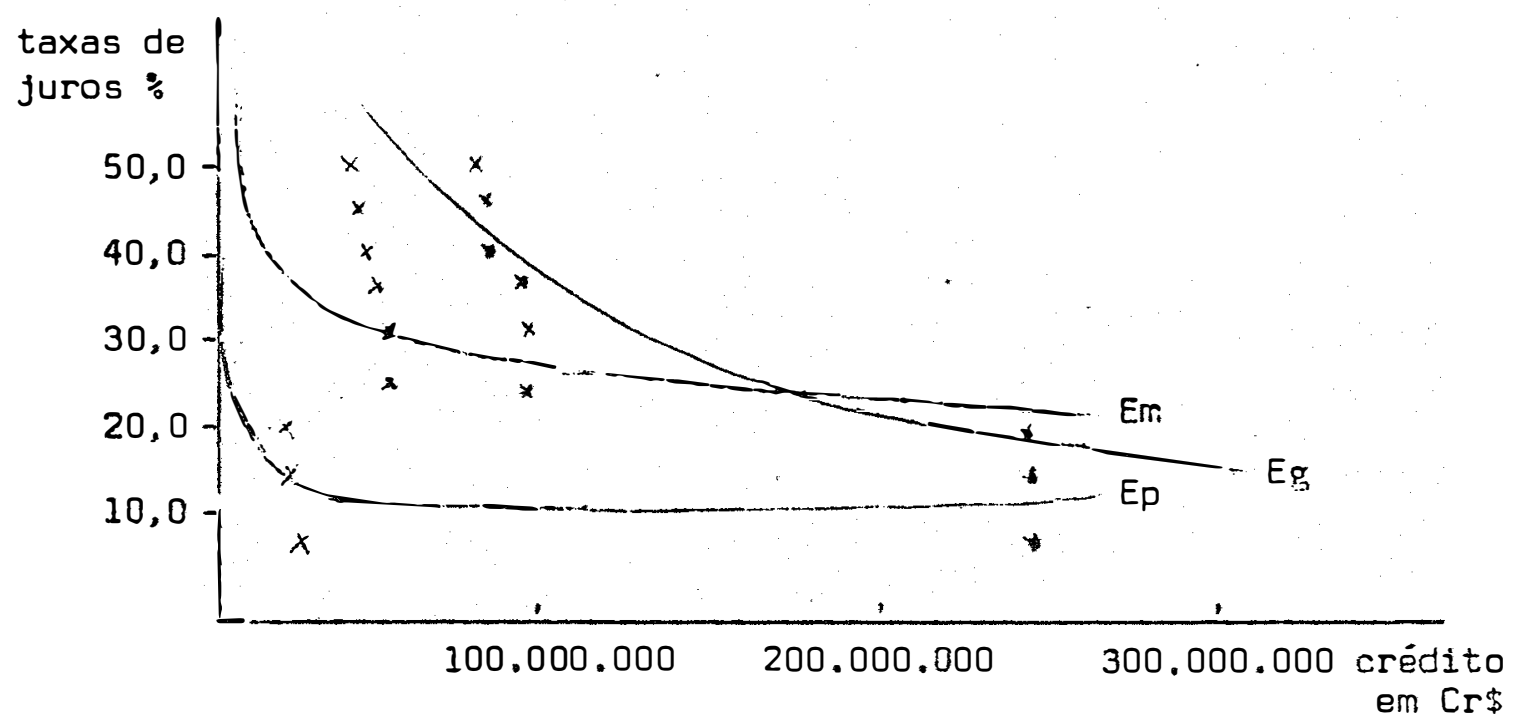

Figura 8 - Demanda Derivada para o estrato dos peque nos produtores (Ep), médios produtores(Em) e grandes produtores (Eg), 1973/74 
A tabela 8 mostra para cada estrato a média ponderada $\left(r_{0}\right)$ das taxas de juros para a quantidade de crédito efetivamente demandado $(\mathrm{Cr})$.

Tabela 8 - Quantidade Total de Crédito Efetivamente Demandado. Très Estratos de Propriedades Agrícolas. DIRA de Campinas, $1973 / 74$.

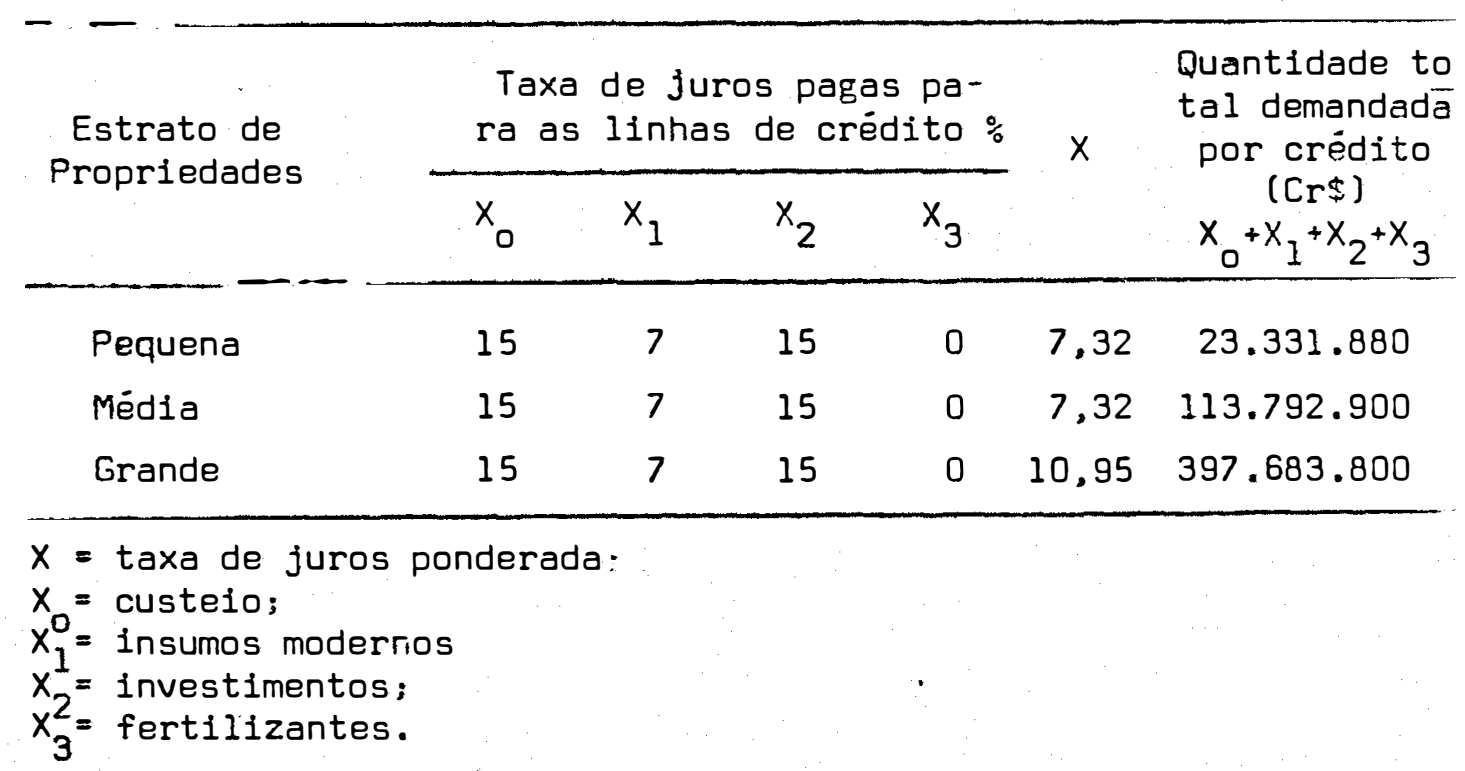

Substituindo a quantidade de crédito efetivamente de mandado $\left(C_{r}\right)$ por cada estrato em sua respectiva função de demanda estimada, obtém-se o valor da taxa de juros $\left(r_{1}\right)$. Esses valores foram de $11,0 \%$ para o estrato pequeno, $23,5 \%$ para o estrato médio e $10,95 \%$ para o estrato grande.

As figuras 9, 10 e 11 representam as áreas do subsidio recebido pelos estratos dos pequenos, médios e grandes produtores, respectivamente. 
61.

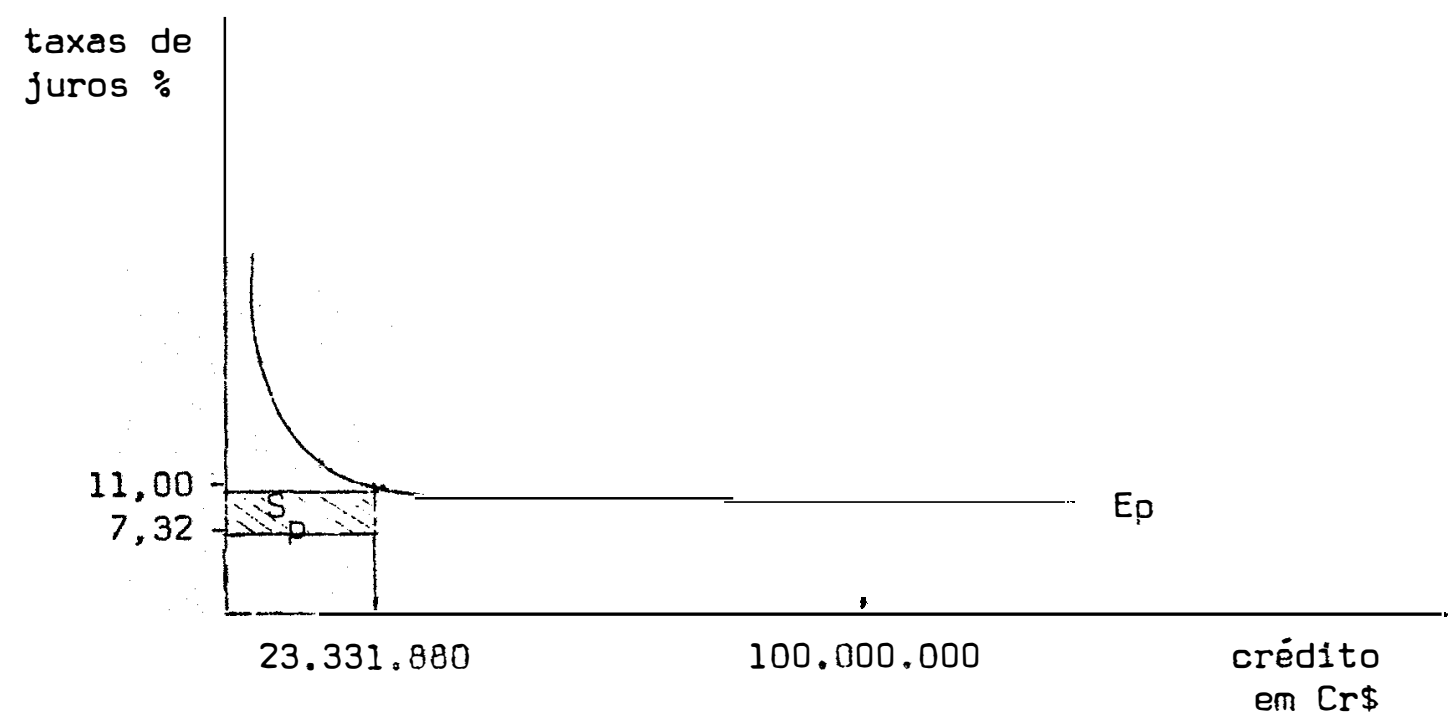

Figura 9 - Subsídio Recebido pelo estrato dos pequenos produtores, $1973 / 74$.

$(0,11-0,0732) \cdot 23.331 .880=853.379$.

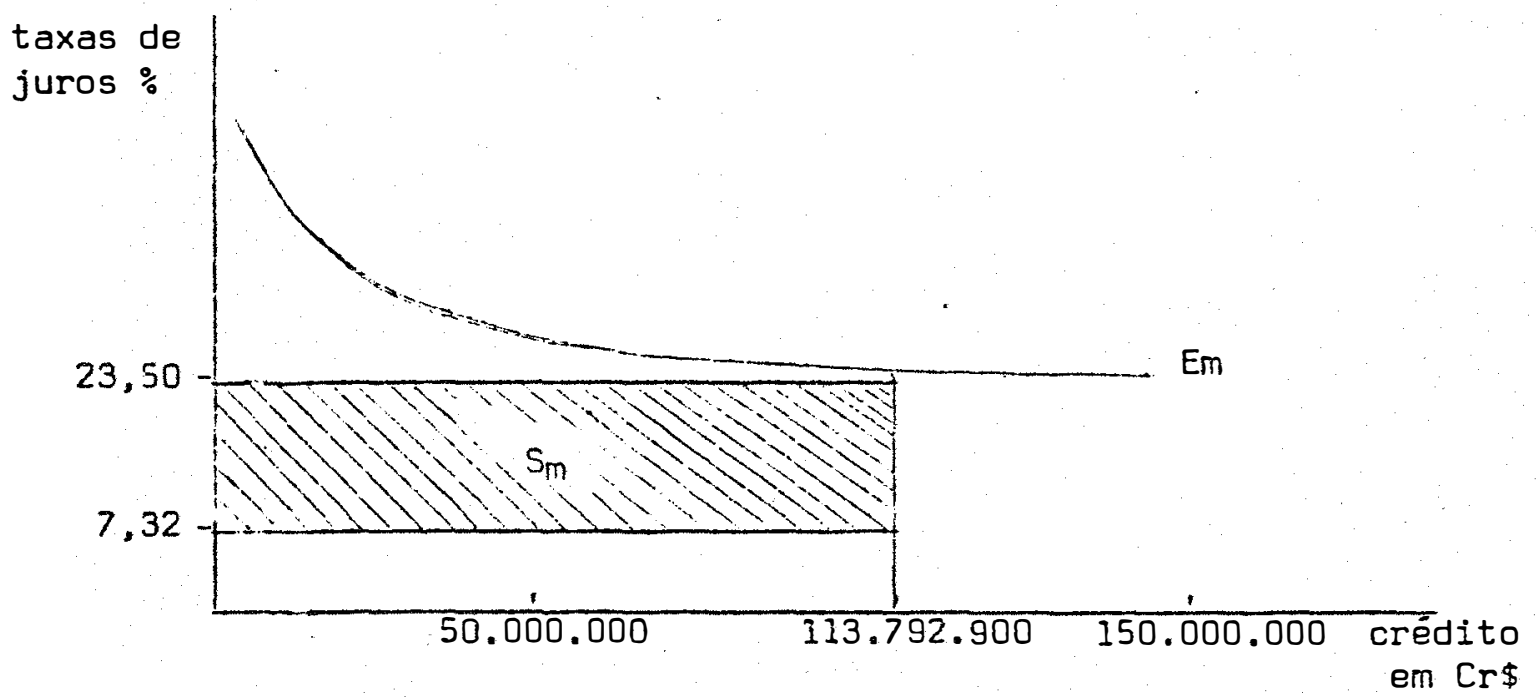

Figura 10 - Subsídio Recebido pelo estrato dos médios produtores, 1973/74. $(0,235-0.0732) \cdot 113.792 .900=18.411 .691$. 


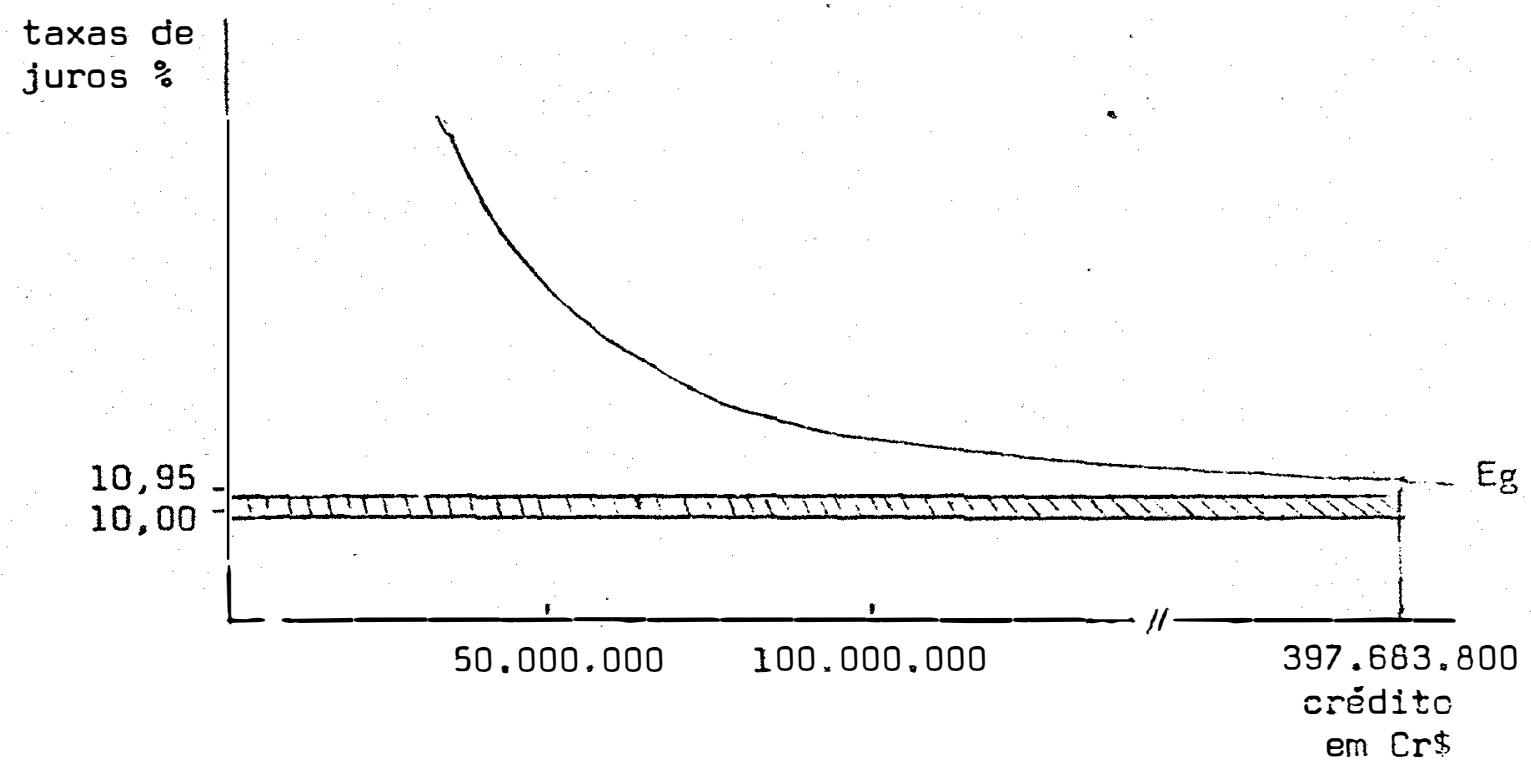

Figura 11 - Subsídio Recebido pelo estrato dos grandes produtores, $1973 / 74$. $(0,1095-0,10) \cdot 397.683 .800=3.777 .996$.

A tabela 9 mostra os resultados para a Renda Líquida 8 o Subsídio Recebido em cada estrato de produção, juntamente com as suas respectivas participações percentuais. O valor da relação entre Subsidio Recebido (S) e Renda Agrícola (R) completa o quadro. Tabela 9 - Renda Agrícola, Subsídio Recebido e a relação entre Subsídio por Renda Agrícola. Très estratos de Propriedades Agrícolas. DIRA de Campinas, 1973/74.

\begin{tabular}{|c|c|c|c|c|c|}
\hline \multirow{2}{*}{$\begin{array}{l}\text { Estrato de } \\
\text { Propriedade }\end{array}$} & \multicolumn{2}{|c|}{ Renda Agrícola } & \multicolumn{2}{|c|}{ Subsídio Recebido } & \multirow{2}{*}{$S / R$} \\
\hline & $(R)$ & $\%$ & (S) & $\%$ & \\
\hline Pequena & 81.894 .000 & 7,32 & 858.379 & 0,037 & 0,0105 \\
\hline Mëdia & 516.327 .000 & 46,20 & 18.411 .691 & 79,88 & 0,0357 \\
\hline Grande & 519.200 .900 & 45,46 & 3.777 .996 & 16,39 & 0,0016 \\
\hline
\end{tabular}


A tabela 10 mostra os resultados das alterações no valor da Renda Agrícola de cada estrato, quando variaram os níveis das taxas de juros.

Tabela 10 - Efeito da Taxa de Juros no Valor da Renda Ag,rícola (em Cr\$). Trés Estratos de Propriedades Agrícolas. OIRA de Campinas, $1973 / 74$.

\begin{tabular}{cccc}
\hline \multirow{2}{*}{ Taxa de Juros } & \multicolumn{3}{c}{ Estrato de Propriedade } \\
\hline & Pequena & Média & Grande \\
\hline 7 & 80.143 .700 & 536.646 .000 & 540.236 .000 \\
15 & 80.143 .700 & 514.338 .000 & 504.431 .000 \\
30 & 78.900 .400 & 501.466 .000 & 483.396 .000 \\
40 & 78.668 .700 & 496.936 .000 & 466.065 .000 \\
50 & & 493.324 .000 & 458.588 .000 \\
\hline
\end{tabular}

(*) Valor da taxa de inflação em 1973.

Os resultados do modelo indicam que os niveis das atividades dos très estratos de produçäo sofreram mudanças quando as taxas de juros foram aumentadas e diminuídas. O estrato dos grandes produtores diminuiu a contratação de mão-de-obra teinporáría e os ní veis das atividades de produção em algodão, batata das äguas, laran ja e pecuária de corte, quando as taxas de juros foram elevadas e díminuiu a área plantada com algodão, quando as taxas de juros foram diminuidas. No estrato dos médios produtores, sob taxas de juros altas, houve diminulção ria quantidade de mão-de-obra contratada 
e nos niveis das atividades de produção em pecuáría de corte, pasto natural, pecuária de leite c e laranja, enquanto que, sob taxas de juros baixas, houve aumento na atividade de produção em cana. Para o estrato dos pequenos produtores, quando as taxas de juros foram elevadas, os niveis das atividades de produção em batata das águas, pasto natural e pecuária de leite $C$ diminuiram e, quando as taxas de juros foram abaixadas, a atividade de produção em algodão aumentou.

\section{3 - Resultados Para o Ano Agrícola $76 / 77$}

A tabela 11 mostra os resultados fornecidos pelo modelo para as quantidades demandadas por crédíto em cada estrato,bem como os valores das taxas de juros ponderadas. 
Tabela 11 - Demanda Derivada por Crédito. Trés Estratos de Propriedades Agrícolas. DIRA de Campinas, 1976/77.

\begin{tabular}{|c|c|c|c|c|c|c|}
\hline \multirow{2}{*}{$\begin{array}{l}\text { Estrato de } \\
\text { Propriedades }\end{array}$} & \multicolumn{4}{|c|}{$\begin{array}{l}\text { Taxa de juros para } \\
\text { as linhas de crédito }\end{array}$} & \multirow{2}{*}{$x$} & \multirow{2}{*}{$\begin{array}{l}\text { Quantidade to } \\
\text { tal demandada } \\
\text { por crédito } \\
(\mathrm{Cr}) \\
x_{0}+x_{1}+x_{2}+x_{3}\end{array}$} \\
\hline & $x_{0}$ & $x_{1}$ & $x_{2}$ & $x_{3}$ & & \\
\hline \multirow[t]{5}{*}{ Pequena } & $\begin{array}{r}7 \\
15\end{array}$ & $\begin{array}{r}7 \\
15\end{array}$ & $\begin{array}{r}7 \\
15\end{array}$ & $\begin{array}{r}7 \\
15\end{array}$ & $\begin{array}{r}7 \\
15\end{array}$ & $\begin{array}{l}53.781 .500 \\
46.539 .344\end{array}$ \\
\hline & 23 & 23 & 23 & 23 & 23 & 46.539 .344 \\
\hline & 30 & 30 & 30 & 30 & 30 & 46.539 .344 \\
\hline & 41 & 41 & 41 & 41 & 41 & 46.539 .344 \\
\hline & 45 & 45 & 45 & 45 & 45 & 8.996 .144 \\
\hline \multirow[t]{6}{*}{ Grande } & 7 & 7 & 7 & 7 & 7 & 1.381 .190 .300 \\
\hline & 15 & 15 & 15 & 15 & 15 & 1.381 .190 .300 \\
\hline & 23 & 23 & 23 & 23 & 23 & 449.462 .300 \\
\hline & 30 & 30 & 30 & 30 & 30 & 449.462 .300 \\
\hline & 41 & 41 & 41 & 41 & 41 & $449.462,300$ \\
\hline & 45 & 45 & 45 & 45 & 45 & 127.095 .200 \\
\hline \multirow[t]{6}{*}{ Média } & 7 & 7 & 7 & 7 & 7 & 614.138 .300 \\
\hline & 15 & 15 & 15 & 15 & 15 & 614.138 .300 \\
\hline & 23 & 23 & 23 & 23 & 23 & 614.138 .300 \\
\hline & 30 & 30 & 30 & 30 & 30 & 605.170 .300 \\
\hline & 41 & 41 & 41 & 41 & 41 & 579.647 .900 \\
\hline & 45 & 45 & 45 & 45 & 45 & 55.956 .900 \\
\hline \multicolumn{7}{|c|}{ = taxa de juros ponderada } \\
\hline \multicolumn{7}{|c|}{$x_{0}=$ custeio: } \\
\hline \multicolumn{7}{|l|}{$\begin{array}{l}1=\text { insumos mode } \\
=\text { investimento }\end{array}$} \\
\hline
\end{tabular}

A taxa de juros fixada para o custo de oportunidade do capital (retorno anual das cadernetas de poupança) fol de $42 \%$. Com base nas quantidades totais de crédito demandados e nos valores das taxas de juros ponderadas, as seguintes fun- 
çöes de demanda foram estimadas:

$$
Q=10^{19,163} \mathrm{P}^{-7,834} \text {, }
$$

para o estrato dos grandes produtores,

$$
Q=10^{16,784} p^{-6,851} \text {, }
$$

para o estrato dos médios produtores e

$$
Q=10^{8,2724} P^{-0,5285} \text {, }
$$

para o estrato dos pequenos produtores. As figuras 12 e 13 mostram gra ficamente essas equações e ilustram os pontos fornecidos pelo modelo.

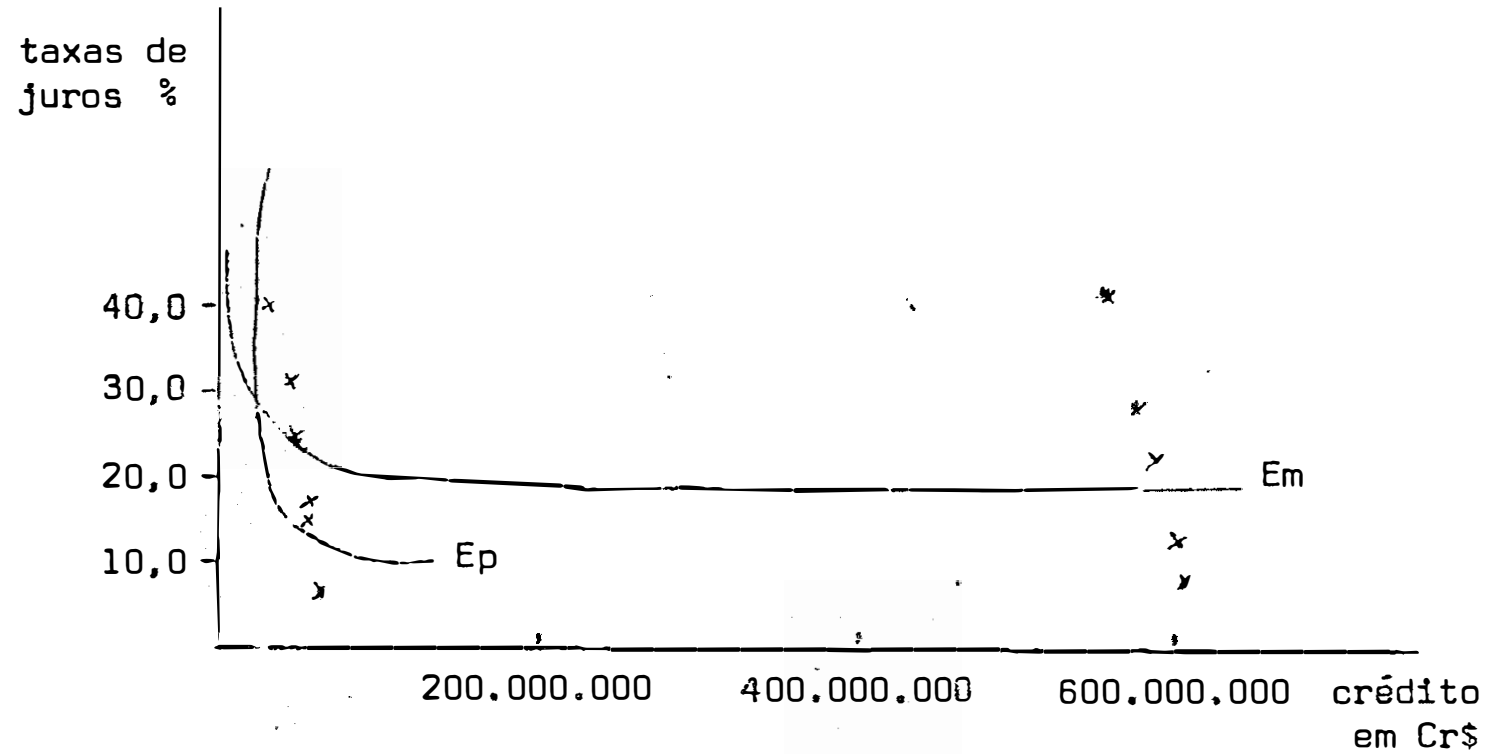

Figura 12 - Demanda Derivada por Crẻdito para o estra to dos pequenos produtores $\{E p\}$ e dos $m \bar{\varepsilon}-$ dos produtores $(\mathrm{Em}), 1976 / 77$. 


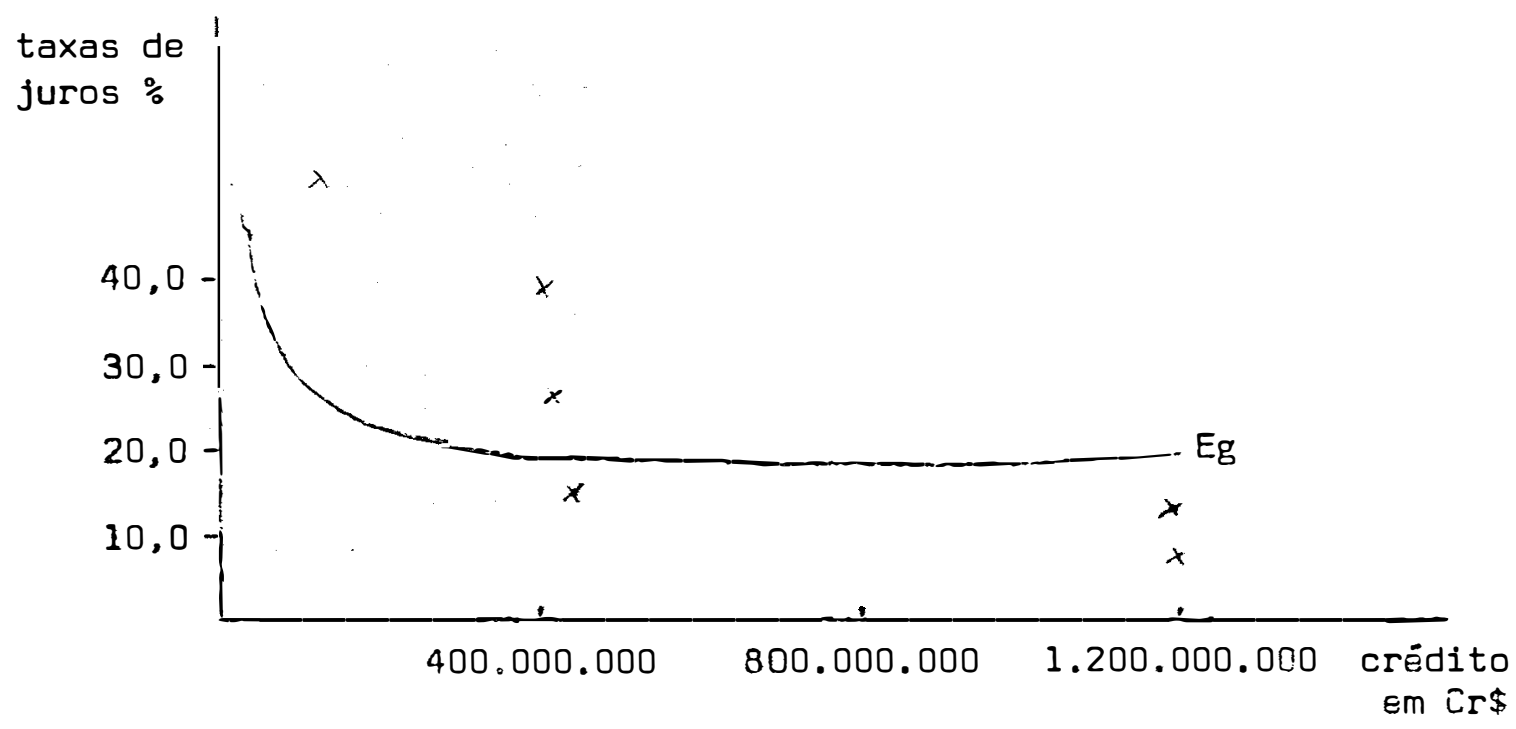

Figura 13 - Demanda Derivada por Crédito para o estrato dos grandes produtores (Eg), 1976/77.

A tabela 12 mostra para cada estrato a médía pondera da $\left(r_{0}\right\}$ das taxas de juros para a quantidade de crédito efativamente demandado $(\mathrm{C} r)$.

Tabela 12 - Quantidade Total de Crédito Efetivamente Demandado.Três Estratos de Propriedades Agrícolas. DIRA de Campinas, $1976 / 77$.

\begin{tabular}{|c|c|c|c|c|c|c|}
\hline \multirow{2}{*}{$\begin{array}{l}\text { Estrato de } \\
\text { Propriedades }\end{array}$} & \multicolumn{4}{|c|}{$\begin{array}{l}\text { Taxa de juros pagas pa- } \\
\text { ra as linhas de crédito }\end{array}$} & \multirow{2}{*}{$x$} & \multirow{2}{*}{$\begin{array}{l}\text { Quantidade to } \\
\text { tal demandada } \\
\text { por crédito } \\
\text { (Cr } \$ \text { ) } \\
x_{0}+x_{1}+x_{2}+x_{3}\end{array}$} \\
\hline & $x_{0}$ & $x_{1}$ & $x_{2}$ & $x_{3}$ & & \\
\hline Pequena & 15 & 0 & 15 & 15 & 12,09 & 51.814 .144 \\
\hline Média & 15 & 0 & 15 & 15 & 15,00 & 352.576 .600 \\
\hline Grande & 15 & 0 & 15 & 15 & 15,00 & 950.286 .300 \\
\hline
\end{tabular}


Substituindo a quantidade de crédito efetivamente de mandado ( $C \Gamma$ ) por cada estrato em sua respectiva função de demanda estimada, obtém-se o valor da taxa de juros $\left\{\Gamma_{1}\right\}$. Esses valores foram de $11,60 \%$ para o estrato pequeno, 16,0\% para o estrato médio e $20,0 \%$ para o estrato grande.

As figuras 14 e 15 representam as àreas do subsidic recebido pelos estratos dos médios e grandes produtores respectivamente. Como o valor de $r_{1}$ foi maior que $r_{0}$ para o estrato dos peque nos produtores, tem-se que este estrato não auferiu subsídio.

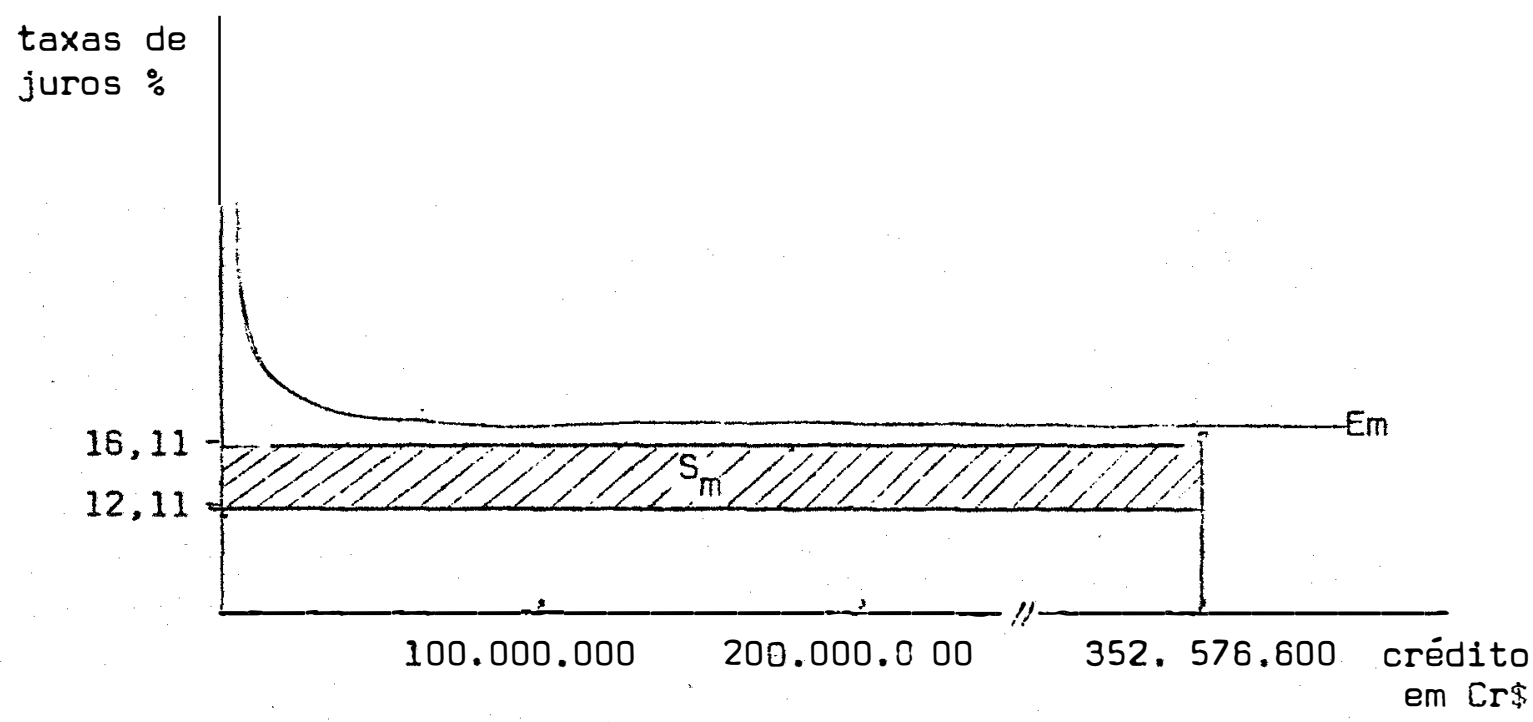

Figura 14 - Subsídio Recebido pelo estrato dos médios produtores. 1976/77. $(0,1611-0,1211) .352 .576 .600=13.715 .229$. 


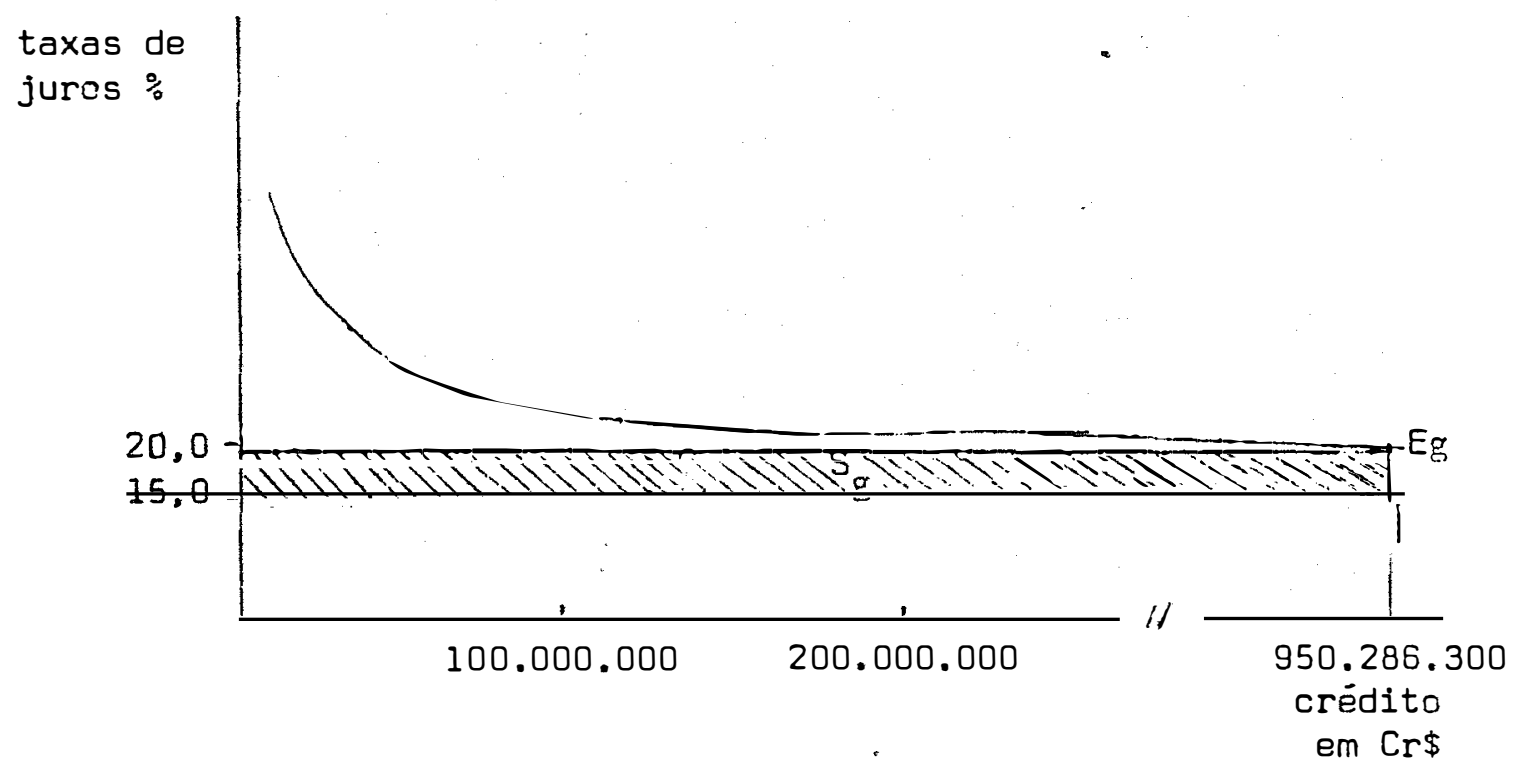

Figura 15 - Subsídio Recebido pelo estrato dos grendes produtores, $1975 / 77$. $(0,20-0,15) \cdot 950 \cdot 286 \cdot 300=47 \cdot 514 \cdot 315$.

A tabela 12 mostra os resultados para a Renda Agríco la e o Subsídio Recebido em cada estrato de produção, juntamente com as respectivas participações percentuais. O valor da relação en tre Subsídio Recebido (S) e Renda Agrícola (R) completa o quadro.

Tabela - Renda Agrícola, Subsídio Recebido e a relação entre Sub sídio por Renda Agrícola. Três Estratos de Propriedades Agrícolas. DIRA de Campinas, $1976 / 77$.

\begin{tabular}{|c|c|c|c|c|c|}
\hline \multirow{2}{*}{$\begin{array}{l}\text { Estrato de } \\
\text { Propriedade }\end{array}$} & \multicolumn{2}{|c|}{ Renda Agrícola } & \multicolumn{2}{|c|}{ Subsídio Recebido } & \multirow{2}{*}{$S / R$} \\
\hline & $(R)$ & $\%$ & $(S)$ & $\%$ & \\
\hline Pequena & 388.307 .000 & 6,48 & 0 & 0,00 & 0,0000 \\
\hline Média & 2.411 .820 .000 & 40,28 & 13.715 .229 & 22,40 & 0,0043 \\
\hline Grande & 3.186 .880 .000 & 53,22 & 47.514 .315 & 77,60 & 0,0015 \\
\hline
\end{tabular}


A tabela 13 mostra os resultados das alteraçōes no Valor da Renda Agrícola de cada estrato, quando variaram os níveis das taxas de juros.

Tabela 13 - Efeito da Taxa de Juros no Valor da Renda Agrícola lem Cr\$3. Três Estratos de Propriedades Agrícolas. OIRA de Campinas, $1976 / 77$.

\begin{tabular}{cccc}
\hline Taxa de juros & \multicolumn{3}{c}{ Estrato de Propriedade } \\
\cline { 2 - 4 } & Pequena & Média & Grande \\
\hline 7 & 366.889 .000 & 2.487 .040 .000 & 3.055 .560 .000 \\
15 & 384.408 .000 & 2.432 .020 .000 & 2.945 .060 .000 \\
23 & 378.884 .000 & 2.380 .480 .000 & 2.890 .500 .000 \\
$41^{*}$ & 375.623 .000 & 2.271 .210 .000 & 2.709 .660 .000 \\
45 & & 2.190 .420 .000 & 2.703 .840 .000 \\
\hline
\end{tabular}

(*) Valor da taxa de inflação em 1976.

Os resultados do modelo mostraram que os três estratos de produção sofreram mudanças nos seus níveis de atividades, quan do variaram os valores das taxas de juros. 0 estrato dos pequenos produtores, diminuiu os investimentos em tratares e equipamentos, a contratação de mão-de-obra temporárıa e atividade de produçāo em la ranja, enquanto que a taxa de juros baixos permaneceu inalterado. 0 estrato dos médios produtores aumentou os níveis das atividades de produção em pasto natural e feijão das águas a taxa de juros baixos, E diminulu as atividades em pasto artificial e algodẽo a taxas de 
juros elevadas. No estrato dos grandes produtores os níveis das at vidades ficaram inalteradas, sob taxas de juros baixas, e diminuiram as atividades de batata da seca, pasto natural, pecuária de leite $B$ e C, sob taxas de juros altas.

\section{4. - Discussão dos Resultados}

Esta secção ocupa-se em analisar os resultados apresentados. Primeiramente, faz-se referêncla às implicaçães dos valo* res das elasticidades de demandas por crédito nas políticas de crédito e consłderam-se suas correspondências com o grau de mobilidade dos recursos. Posteriomente, são analisados os pontos da demanda fornectdos pelo modelo, o impacto na renda agrícola das alterações nas taxas de juros e a distribuição do subsídio.

De acordo com os parāmetros estimados nas equações ajustadas, observa-se que os valores das elasticidades das demandas por crédito mostraram a tendêncla em se elevar mais para o estrato dos grandes produtores, e depois, para o dos médios, enquanto que pa ra o estrato dos pequenos produtores houve elevação de início e, em seguida, queda. Os valores das elasticidades das demandas por crédi to revelam as variações nas quantidades demandadas provocadas por alterações na taxa de juros. Isto significa que aumentando continua mente as taxas de juros, os suprimentos de recursos financeiros dos programas de crédito, primeiramente, seriam transferidos dos grandes produtores para os pequenos e médios produtores. Caso as taxas 
de juros continuassem sendo mantidas em elevaçāo, a seguir, os recursos dos médios produtores seriam transferidos para os pequenos produtores. Esta implicação, do aumento nas taxas de juros dos programas de crédito agrícola, è muito importante porque contribul positivamente para um dos objetivos específicos do crédito agrícola, qual seja, de possibilitar o fortalecimento económico dos produtores, notadamente pequenos e médios (BANCO CENTRAL). A queda no valor da elasticidade da demanda por crédito no estrato dos pequenos produtores significa, em outras palavras, um aumento na sua inelasticidade, que caracteriza uma maior dependência do crédito.

Os modelos simulados de polfticas agrícolas de crédi to mostraram que a elasticidade de um estrato está diretamente relacionada com a sua capacidade de alterar os niveis de atividades. Sob taxas de juros elevadas, os niveis das atividades que exigem malores quantidades de crédito são rebaixados e vice-versa. Isto de riva do fato da elasticidade da demanda por crédito de um estrato es tar relacionado com o seu grau de mobilidade de recursos que, por sua vez, é reflexo das alterações nos níveis das atividades. Em nenhum dos estratos foi verificado algum tipo de atividade que salien tasse grandes e frequentes mudanças a fim de merecer destaque. As condiçōes impostas, pelos coeficientes de flexibilidade no conjunto restricional, näo permitem ao modeio variar os níveis das ativi dades de produçäo fora de um certo intervalo.

Para todos os estratos, principalmente o médio e gran de, os resultados mostraram que, quando a taxa de juros atinge ni- 
veis equivalentes ou superiores a taxa de juros do custo de oportunidade do capital, as quantidades demandadas sofrem abrupta queda. Isto revela que as maiores elasticidades-ponto das demandas obtidas estão nesses níveis de taxa de juros. Tal característica da demanda por crédito somado ao fato da reglāo estudada desenvolver uma agricultura empresarial, parecem indicar que os produtores estão tomando dinheiro emprestado do crédito agrícola, para financiar os dispēndios durante o processo produtıvo, e aplicando seu próprio capital no mercado financeiro. A fim de contornar esse problema aparente, sugere-se que os valores das taxas de juros nas linhas de crédi to devem ser instituídos a níveis não muito distantes daqueles que vigoram no mercado financeiro, principalmente para as regiōes desen volvidas. Na alternativa de se continuar a instituir programas de crédito agrícola com taxas de juros administradas a níveis menores do que os prevalecentes no mercado, recursos cada vez maiores deveräo ser alocados no sentido de aparelhar a fiscalização quanto ao uso e aplicação do crédito. O modelo pressupós a ocorrência de perfeita fiscalização, não permitindo aos agricultores aplicarem, no mercado financeiro, quantidades superiores às suas disponibilidades de dinheiro em caixa no início do período. Na ausência desta restri ção, os agricultores aplicariam o dinheiro do crédito somente até o ponto em que o retorno esperado do dinheiro, aplicado na atividade agrícola, fosse igual ou superior (por razöes de risco), ao retorno esperado do dinheiro, aplicado no mercado finenceiro. E razoävel acreditar que, com o acúmulo de informações e experiēncias no decor 
rer do período, um fluxo cada vez maior de agricultores começaria a fazer uso desta oportunidade de realizar aplicaçõés no mercado financeiro. Foi por esta razāo que mencionou-se ser necessário alocaçào crescente de recursos para fiscalizar a aplicação do crédito,no caso de continuidade na atual polftica.

Os resultados ainda mostraram que as variações nas taxas de furos tem pequenos efeitos no valor da renda agrícola. As grandes variações nas taxas de juros acarretam baixas alterações na renda agrícola. Isto implica em que os ganhos dos agricultores, derivados das rendas de subsidios correspondentes aos créditos empres tados às taxas de juros baixas, não causam aumentos significativos nas suas rendas agrícolas. Considerando que os empréstimos concedi dos nos programas de crédito agrícola correspondem à expansão nos meios de pagamentos: um novo ponto deve ser melhor avaliado, tendo em vista que um dos objetivos principais das políticas económicas implementadas no Brasil é controlar a inflação. Trata-se de averiguar, ao nível da sociedade, se os benefícios das políticas de crëdito estão compensando os custos derivados da inflação que elas acarretam.

Quanto à distribuição do subsídio entre os três estratos, os resultados indicaram que a quantidade de subsidio recebi... do, por estrato de produtores, está diretamente relacionado com a renda agrícola do estrato. A proporçäo entre subsídio recebido e ren da agrícola está ficando cada vez menor, sendo que, o seu valor ë maior para o estrato dos médios produtores: seguido pelo dos gran- 
des e, finalmente, pelo dos pequenos. Houve anos em que o estrato dos pequenos produtores não auferiram subsídio. Isto sugere que a distribuição do subsídio sería mais equitativa, caso aumentassem as participações dos estratos dos grandes e pequenos produtores, principalmente destes ültimos, diminuindo a participação dos médios. 
76.

\section{CONCLUSOES}

As principais conclusões do estudo foram:

1) Os valores estimados para as elasticidades de demandas por crédito mostraram a tendēncia em se elevar mais para o estrato dos grandes produtores, e depois, dos médios, durante o período que abrange o estudo. Para o estrato dos pequenos houve, de início, elevaçāo nos valores das elasticidades e, em seguida, queda.

2) Com os valores estimados para as elasticidades das demandas por crédito, tem-se importantes implicações econōmicas. Assim, aumentando as taxas de juros do crédito agrícola, recursos financeiros seriam inicialmente transferidos dos grandes produtores para os pequenos e médios, e depois, dos médios para os pequenos. Para o estrato dos pequenos produtores, observa-se que as políticas de crédi. to a bałxas taxas de juros estão aumentando as suas dependéncias pe 
lo crédito.

3) Não foi verificado nenhum tipo de atividade que salientasse grandes e frequentes mudanças nos seus níveis de atividades. No entanto, observou-se que a elasticidade da demanda por crédito está relacionada com a sue mobilidade na alocação dos recursos.

4) As variações nas taxas de juros tem pequenos impactos sobre a renda agrícola. Isto implica que os ganhos dos agricultores, deri vados de subsidios correspondentes aos créditos emprestados a baixas taxas de juros, näo causam aumentos significativos na renda agrícola. Cabe então, indagar sobre os custos e benefícios das políticas de crédito, ao nível da sociedade.

5) A distribuição do subsídio está diretamente relacionado com a renda agrícola do estrato. Entretanto, a proporção entre subsídio recebido e renda agrícola está favorecendo mais o estrato dos médios produtores, em relação aos estratos dos grandes e pequenos produto res. Para uma distribuição mais equitativa do subsídio, deve-se aumentar as participações dos estratos dos grandes e pequenos produto res, diminuindo a participação dos médios produtores.

6). Caso se continue instituindo programas de crédito com taxas de juros menores do que os prevalecentes em outros mercados para re giöes desenvolvidas, recursos devem ser canalisados para aparelhar a fiscalização do uso do crédito. Para essas regiões, as taxas de juros nas linhas de crédito, devem ser normalmente instituídos a níveis não muito distante daqueles que vigoram no mercado financeiro. 


\section{1 - Recomendações Para Pesquisas Futuras}

Ainda que o modelo utilizado no presente estudo apre sente a vantagem de precisar com certa acuracidade as principais ca racterísticas que envolvem as transformações na região da pesquisa, alguns de seus aspectos podem ser melhorados e estendidos. O objeti vo desta secção é justamente arrolar breves recomendeções que possi bilitem melhor aperfelçoamento do modelo.

A utilização de uma matriz agregada a nível regional com os três estratos de propriedades agrícolas poderia melhorar a performance do modelo. Assim é, que permitiria competição entre estratos na alocação de certos recursos, como: mão-de-obra, crédito terra, etc. Isto evidentemente, enriqueceria o estudo, porque possibilitaria a capturação de certos elementos no sentido de mostrar quals estratos alugam máquinas, ou quais compram e vendem mäo-de.-obra. Uma divisão em períodos no ano agrícola, procurando eviden.. clar as características que envolvem cada fase, permitirla determi nar os momentos em que ocorrem as máximas e mínimas demandas por tra tor: mão-de-obra, etc. A introdução de atividades de compra e venda de terra consideraria o efeito do crescimento das propriedades agrí colas na área ocupada em cada estrato de propriedades no decorrer do período.

No caso particular de pesquisas sobre a demanda por crédito agrícola entre diferentes classes de propriedades agrícolas. a inclusão de elementos de riscos e incerteza acarretaria substan-. 
79.

cial contribuição ao estudo, porque permitiria evidenciar novas jus tificativas e interpretaçōes, uma vez que são fatores que poderiam afetar a demanda por crédito. 
80.

\section{SUMMARY}

This study is an attempt to derive the demand for agricultural credit for three representative farm firms, corresponding to small, medium and large farms. The model adopted is recursive programming that incorporates a model to simulate farmer's formation of expectations about future prices.

Policy makers in Brazil, recognizing the potential for using credit policy as an instrument for schieving more rapid agricultural development, have instituted a variety of specialized credit programs for agriculture. And the interest rate is set below prevailing market rate. This appears to be based on the assumption that the demand for agricultural credit exhibits high elasticity with respect to interest rates. However. litle or no empirical evidence has been generated to substantiate this goint. Thus, the present study attempted to utilize a model to derive the demand for 
The area selected for study corresponds to the regional unit of Campinas in the State of São Paulo, Brasil. The period of study began in the agricultural year of 1970/71 and ended in $1976 / 77$.

The results indicated that: the demand for agricultural credit is mor inelastic with respect to interest rate changes in the first place for large farms, in the second for medium-size farms and in the third for small farms; the elasticity of demand of agricultural credit for each representative firm is related to its mobility resources; the variations in the interest rates had litle impact on the farm income: the proportion subsidy/farm income is decreasing for all three farm strato; if agricuitural credit programs continue to be made with interest rates set below prevailing market rates, resource need to be transferred for the control of credit applications. 


\section{BIBLIOGRAFIA}

ADAMS, D.W., 1971. Agricultural Credit in Latin America: A Critical Review of External Funding Policy. Amer. J. Agr. Econ. 53:163-72.

AHN, C.Y., 1972. A Recursive Programming Model of Regional Agricultural Development in Southern Brazil (1960-1970); In: Application of Farm Size Decomposition, Columbus, The Ohio State University, 1972 (Dissertação de PhD apresentada ao Department of Agricultural Economics and Rural Sociology).

ARAdJo, P.F.C. e R.L. MEYER, 1977. "Agricultural Credit" Policy in Brazil: Objectives and Results. Amer. J. Agr. Econ. 59:957-61.

BRANSON, W.H., 1972. Macroeconomic Theory and Policy. Princeton University, p. 198-208.

COLYER, O., 1972. External Credit Policy for Latin America: Comment. Amer. J. Agr. Econ. 54\{2\}. 
ENGLER. J.J.C., 1971. Alternative enterprise cambinations under va rious price policies on wheat a cattle in southern Brazil. Columbus, The Ohio State University. (Dissertação de PhD apresentada ao Department of Agricultural Economics and Rural Sociology).

ENGLER, J.J.C. \& SINGH, I.J., 1971. Production response to technological and price changes: a study of wheat and cattle farming in shouthern Brazil. Ohio State University.

GOVERNO DO ESTADO DE SÃO PAULO, 1972. Desenvolvimento da Agricultura Paulista. São Paulo: Secretaria da Agricultura, Instituto de Economia figricola.

GOVERNO DO ESTADO DE SÃO PAULO. 1974. Prognóstico 74/75, São Paulo: Secretaria da Agricultura, Instituto de Economia Agrícola.

GOVERNO DO ESTADO DE SÅO PAULO, 1975. Prognöstico 75/76, São Paulo: Secretaria da Âgricultura. Instituto de Economia Agrícola.

GOVERNO DO ESTADO DE SÃO PAULO, 1976. Prognóstico 76/77. São Paulo: Secretaria da Agricultura, Instituto de Economia Agrícola.

GUIMARÃES, M.K., 1974. Crédito Rural: Enfoques da Política Agrária. Brasileira. São Paulo, Livraria Nobel S.A., 181 pp.

HEIDHUES, T., 1966. A recursive programming model of Farm Growth in Northern Germany. Journal of Farm Economics 48(3):668-684.

LANDMAN, J.R., 1974. A model of Credit Aplied to the Allocation of Mexican Farms. Economic Development and Cultural Change, 22(2). 
MEYER, R.L.: D.W. ADAMS; N.RASK e P.F.C. ARAÜJO, 1973. Rural Capital Markets and Small Farmers in Brazil, 1960 72. Small Farmer Credit in South America, Pp. 1-57. A.I.D. Spring Review of Small Farmer Credit, vol. III. Washington. D.C. Agency for International Development.

NELSON, W.C., 1971. Economic Analysis of Fertilizer Utilization in Brasil. Columbus, The Ohio State University, (Dissertação de PhD apresentada ao Department of Agricultural Economics and Rural Sociology)。

OLIVEIRA, A.J. 1977. Derived Demand for Agricultural Credit. A Mul-tipericd Investment Model. Faculty of Purdue University (Dissertação de $\mathrm{PhD}$ ).

PAIVA R.M.: S. SCHATTAN E C.F.T. FREITAS, 1976. O Setor Agrícola. 2. ed. Rio de Janeiro, Forense Universitária, São Paulo, Edição da Universidade de São Paulo, p. 1-15.

PERES, F.C., 1976. Derived Demand for Credit Under Conditions of Risk. Columbus. The ohio State University. (Dissertação de PhD apresentada ao Department of Agricultural Economics and Rural Sociology).

PIZA Jr., C.T., 1976. Alguns Indicadores de Desempenho e de Conjun tura de Crédito Rural. (Mimeografia). São Paulos Brasil: Instituto de Economia Agrícola.

RAO, B.P., 1970. The Economics of Agricultural Credit Use in Southern Brazil. Columbus The Ohio State University. (Dissertação de PhD apresentada ao Cepartment of Agricultural Economics and Rural Sociology?. 
RASK. N., 1969. Analysis of Cap1tal Formation and utilization in Less Developed Countries. Dcassional Paper $n^{8} 4$. Department of Agricultural Eoonomics and Rural Soclology. The Dhic State University.

SCHUH, G.E., 1963. Effects of some General Economic Policier on Agricultural Development. American Journal Agricultural Econometr1cs, $50(5): 1283-1293$.

SCHUH. G.E., 1971. Pesquisa para Desenvolvimento Agrícola na Bras11. Ed1tora Atlas.

STITZLEIN, J.N.; 1967. The Characteristics and Significance of the Non-Institutionel Credit Market in Rural Ecuador. AFC Research Publication $n^{\circ}$ 117. Department of Agricultural Fconomics and Rural Soclology. Onio State University.

WHITE. T.K., s/d. Crédito Com Modelo de Programaçäo Linear na Zona da Mata. em Minas Gerais.

WHITE, T.K., 1975. Cred1t and Agr Icultural Economic Development. Some Observations on $f$ Brazilian Case. Station Bulletin $n^{9} 101$. Purdue University. 
86.

7. APENOICE 
MATRIZ DOS COEFICIENTES PARA O ANO AGRICOLA INICIAL $(1970 / 71)$

CDLUMNS

\begin{tabular}{|c|c|c|c|c|}
\hline $\begin{array}{l}\text { SUINC } \\
\text { SUINC }\end{array}$ & $\begin{array}{l}\text { RECEITA } \\
\text { RETORNO }\end{array}$ & $\begin{array}{l}3069.66000 \\
3069.66000\end{array}$ & $\begin{array}{l}\text { MO1FAM } \\
\text { MO2FAM }\end{array}$ & $\begin{array}{l}5.00000 \\
5.00000\end{array}$ \\
\hline SUINC & MOZFAM & 5.00000 & MHSMON & 1093.98000 \\
\hline $\begin{array}{l}\text { SUINC } \\
\text { SUINC }\end{array}$ & $\begin{array}{l}\text { TFMLH } \\
\text { LMSPSINC }\end{array}$ & $\begin{array}{r}4.50000 \\
17.10000\end{array}$ & LMIFSINC & 17.10000 \\
\hline TOMATE & PECEITA & 10858.89000 & TERRAI & 1.00000 \\
\hline TOMATE & RETORND & 10000.00000 & MOIFAM & 556.00000 \\
\hline TONATE. & MOZFAM & 222.35000 & MOBFAY & 40.88000 \\
\hline TOMATE & MITRON & 0.37800 & FOSFOR & 0.81800 \\
\hline TOMATE & POTASS & 0.62560 & CORRET & 3.72000 \\
\hline TOMATE & MNSMOD & 6536.07000 & TRT 1 & 6.14000 \\
\hline TOMATE & TRT? & 4.90000 & TRTOMATI & 1.00000 \\
\hline TOMATE & TRTOMATS & 1.00000 & & \\
\hline$M A L G 1$ & RECEITA & 1173.61000 & TERPAI & 1.00000 \\
\hline MALG 1 & RETORNO & 1224.17000 & MOLFAM & 1.65000 \\
\hline MALOL & MOZFAM & 12.51000 & MO $3 F A M$ & 36.67000 \\
\hline$M A L G L$ & NITRON & 0.04780 & FOSFOD & 0.06900 \\
\hline MALGI & POTASS & 0.06900 & CORRET & 1.26000 \\
\hline MALGI & TRT 1 & 1.40000 & TPT? & 0.49000 \\
\hline MALGI & MNS:AOO & 166.45000 & MANIT 2 & $5 \cdot 14000$ \\
\hline MALG: & TPALBI & 1.00000 & TPALGS & 1.00000 \\
\hline MALG? & RECEITA. & 1270.89000 & TERRA: & 1.00000 \\
\hline$M A L G ?$ & RETORNO & $1328 \cdot 12000$ & MOIFAN & 1.65000 \\
\hline MALQZ & MOZFAM & 8.92000 & MO $3 F A Y$ & 36.67000 \\
\hline MALG? & NITRON & 0.04780 & FOSFOR & 0.06900 \\
\hline MALG? & POTASS & 0.06900 & CORRET & 1.26000 \\
\hline MALG? & TRT 1 & 1.40000 & TPT? & 0.69000 \\
\hline$M B L G 2$ & MNSMOD & 166.45000 & TRALGT & 1.00000 \\
\hline$M A L G ?$ & TAALGS & 1.00000 & & \\
\hline
\end{tabular}




\begin{tabular}{|c|c|c|c|c|}
\hline $\begin{array}{l}\text { BATAGI } \\
\text { BATAGI }\end{array}$ & $\begin{array}{l}\text { RECEITA } \\
\text { RETORNO }\end{array}$ & $\begin{array}{l}2585.88000 \\
2581.12000\end{array}$ & $\begin{array}{l}\text { TERRAI } \\
\text { MOIFA }\end{array}$ & $\begin{array}{r}1.00000 \\
46.44000\end{array}$ \\
\hline BATAGI & $\begin{array}{l}\text { MOZFAM } \\
\text { FOSFOR }\end{array}$ & $\begin{array}{r}24.54000 \\
0.20300\end{array}$ & NITRON & $\begin{array}{l}0.05800 \\
0.11600\end{array}$ \\
\hline PATAGI & $\begin{array}{l}\text { FOSFOR } \\
\text { MNSMOD }\end{array}$ & 1199.96000 & MANT 1 & 13.71000 \\
\hline $\begin{array}{l}\text { PATAGI } \\
\text { PATAGI }\end{array}$ & $\begin{array}{l}\text { MANT2 } \\
\text { TPRATAGS }\end{array}$ & $\begin{array}{l}5.46000 \\
1.00000\end{array}$ & TRBATAGI & 1.00000 \\
\hline $\begin{array}{l}\text { BATAG2 } \\
\text { BATAG2 }\end{array}$ & $\begin{array}{l}\text { RE CEITA } \\
\text { RETOQNO }\end{array}$ & $\begin{array}{l}2608.65000 \\
2603.73000\end{array}$ & $\begin{array}{l}\text { TERRA! } \\
\text { MOIFA }\end{array}$ & $\begin{array}{r}1.00000 \\
43.58000\end{array}$ \\
\hline $\begin{array}{l}\text { RATAG2 } \\
\text { BATAG2 }\end{array}$ & $\begin{array}{l}\text { MOZFAM } \\
\text { FOSFOR }\end{array}$ & $\begin{array}{r}24.54000 \\
0.23520\end{array}$ & $\begin{array}{l}\text { NITRON } \\
\text { POTASS }\end{array}$ & $\begin{array}{l}0.06720 \\
0.13440\end{array}$ \\
\hline RATAGZ & COPRET & 0.55000 & MNSMON & 1245.98000 \\
\hline BATAG2 & TATI & 1.24000 & MANTI & 7.66000 \\
\hline RATAG? & MANT? & 5.46000 & TRBATAGI & 1.00000 \\
\hline BATAG2 & TPBATAGS & 1.00000 & & \\
\hline RATSC & RECEITA & 2379.96000 & TERRA I & 1.00000 \\
\hline BATSC & RETURNO & 1970.74000 & MO2F AN & 71.82000 \\
\hline A A TSC & MOZFAM & 18.55000 & NITRON & 0.22440 \\
\hline BATSC & FOSFOR & 0.78540 & POTASS & 0.44880 \\
\hline BATSC & MNSIAOD & 1507.71000 & TRT2 & 1.01000 \\
\hline RATSC & MANT2. & 6.50000 & MANT 3 & 5.40000 \\
\hline RATSC. & TPAATSCI & 1.00000 & TPBATSCS & 1.00000 \\
\hline PANO & PECEITA & 665.41000 & TERRAI & 1.00000 \\
\hline MAN & RETORNO & 978.99000 & MOZFAM & 34.77000 \\
\hline$M A N D$ & FOSFOR & 0.02700 & POTASS & 0.04800 \\
\hline$M A N D$ & MNS:AOD & 97.58000 & TRT 3 & 1.30000 \\
\hline $\begin{array}{l}\text { MANO } \\
\text { MAND }\end{array}$ & $\begin{array}{l}\text { MAMT3 } \\
\text { TRMANOS }\end{array}$ & $\begin{array}{l}3.46000 \\
1.00000\end{array}$ & TPMANOI & 1.00000 \\
\hline$F J A G 1$ & RECEITA & -50.03000 & TERRAI & 1.00000 \\
\hline FJAGI & RETURNO & -50.03000 & MOIFAM & 11.62000 \\
\hline FJAGI & MOZFAM & 5.67000 & NITRON & 0.00656 \\
\hline$F \backslash A G 1$ & FOSFOR & 0.02296 & POTASS & 0.01312 \\
\hline F JAGI & MNS:100 & 84.99000 & MANT 1 & 5.96000 \\
\hline$F J A G I$ & MANTZ & 0.58000 & $T F F J$ & -9.00000 \\
\hline$F J A G 1$ & $c x$ & 50.03000 & TPF JAGI & 1.00000 \\
\hline FJALI & TPF JAGS & 1.00000 & & \\
\hline$F J A G$ ? & RECEITA & -130.81000 & TERRA1 & 1.00000 \\
\hline$F J A C 2$ & RETORNO & -130.81000 & MOLFAU & 8.81000 \\
\hline FJAG? & MOZFAM & 5.79000 & NITRON & 0.00740 \\
\hline$F J A G ?$ & FOSFOP. & 0.02590 & POTASS & 0.01480 \\
\hline F JAG? & MNSMOO & 84.52000 & TRT1 & 1.15000 \\
\hline$F \$ \triangle G ?$ & TRT? & 0.29000 & MANTI & 2.78000 \\
\hline$F J A G 2$ & TFFJ & .9 .00000 & $c x$ & 130.81000 \\
\hline FJAG? & TRF JAGI & 1.00000 & TRF JAGS & 1.00000 \\
\hline F JSC 1 & RECEITA & -64.77000 & TERRAI & 1.00000 \\
\hline FJSC 1 & PETUPNO & -64.77000 & MO2FAM & 13.04000 \\
\hline FJSC1. & MOZFAM & .7 .00000 & NITROV & 0.00696 \\
\hline $55 C 1$ & FBSFOR & 0.02436 & POTASS & 0.01392 \\
\hline 5.1501 & $1.15 \times 00$ & $2 ? .85000$ & MAMT? & 6.05000 \\
\hline$F J \leq C I$ & MANT3 & 0.71000 & $T F F$ & -14.00000 \\
\hline
\end{tabular}




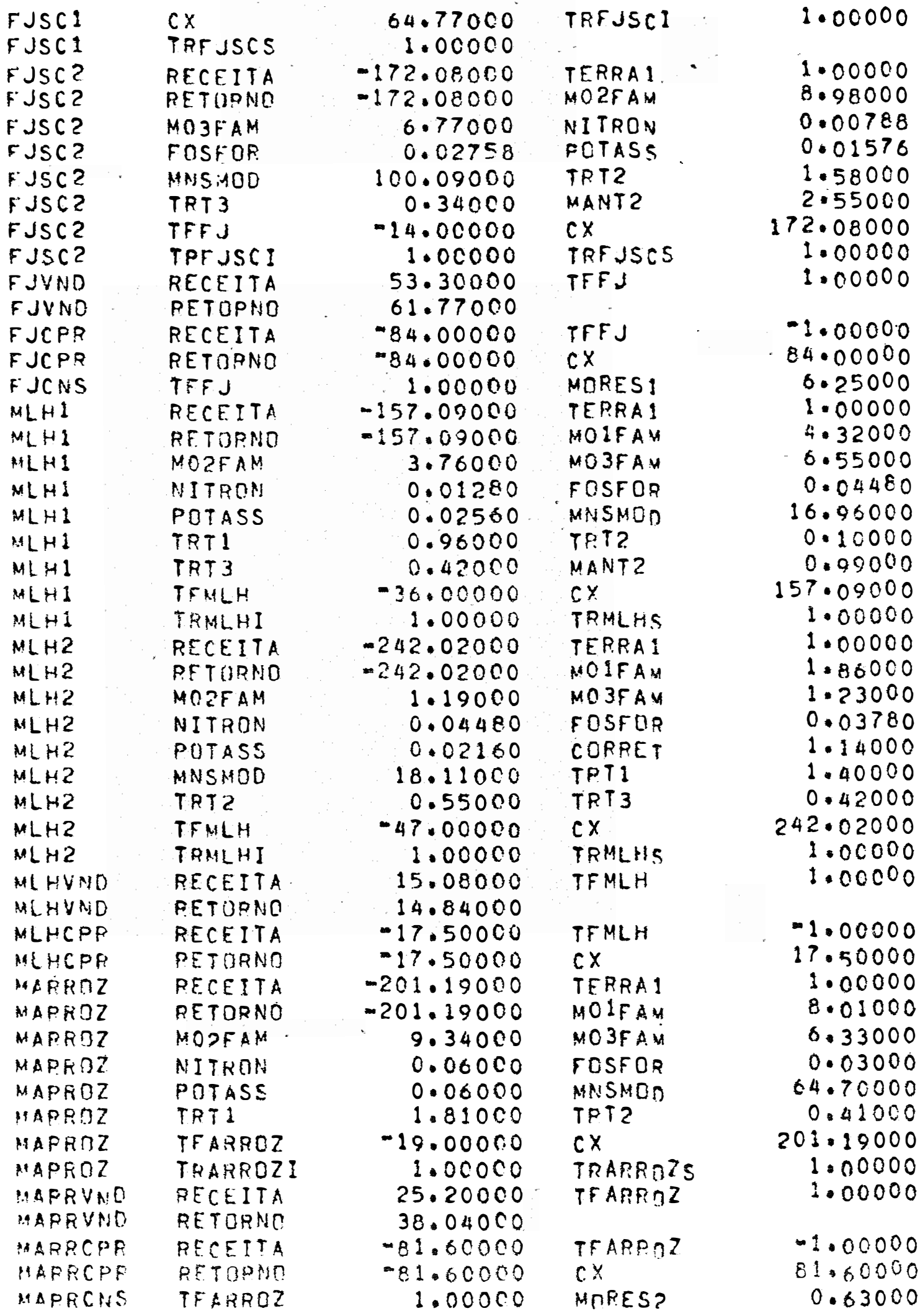




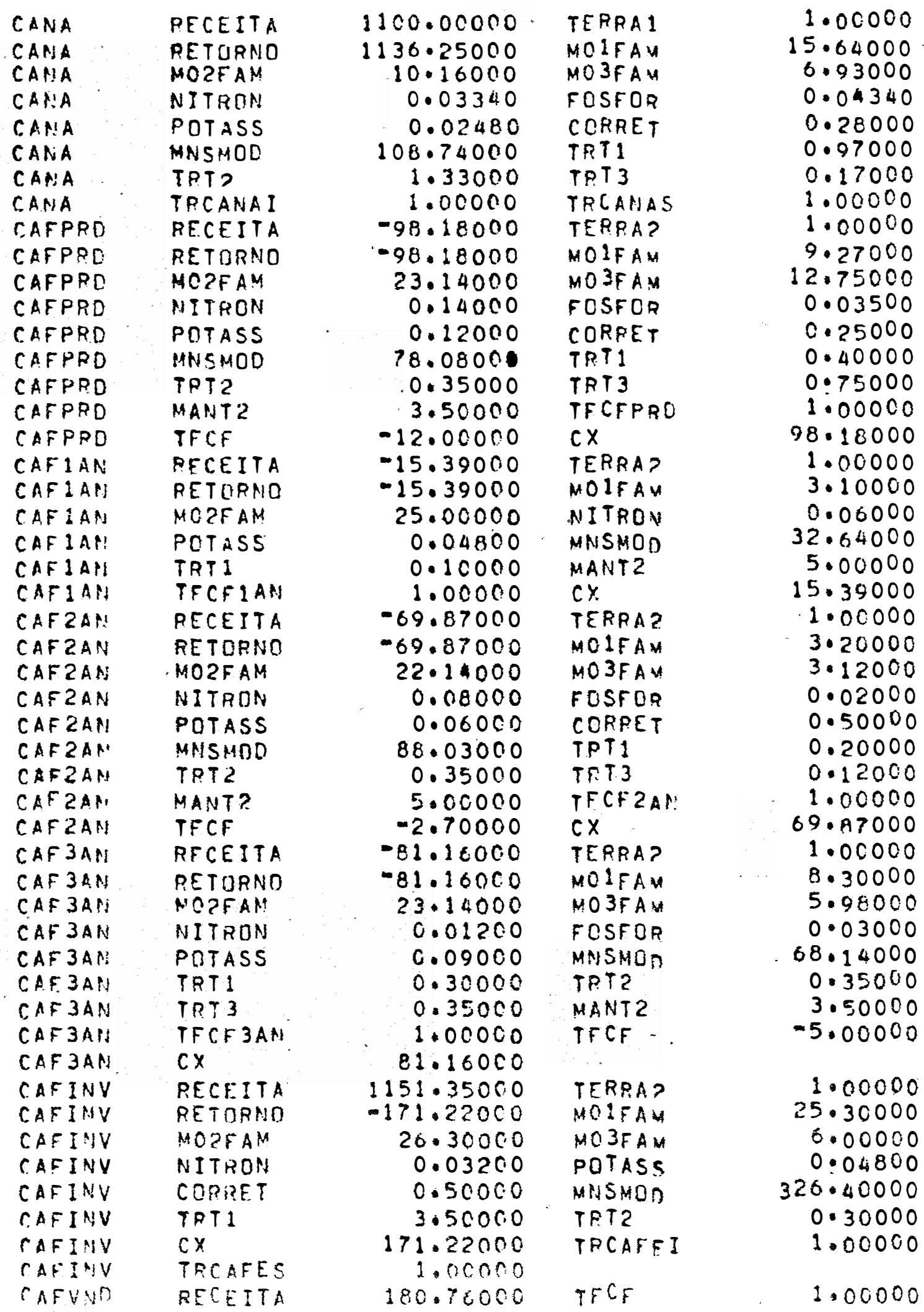




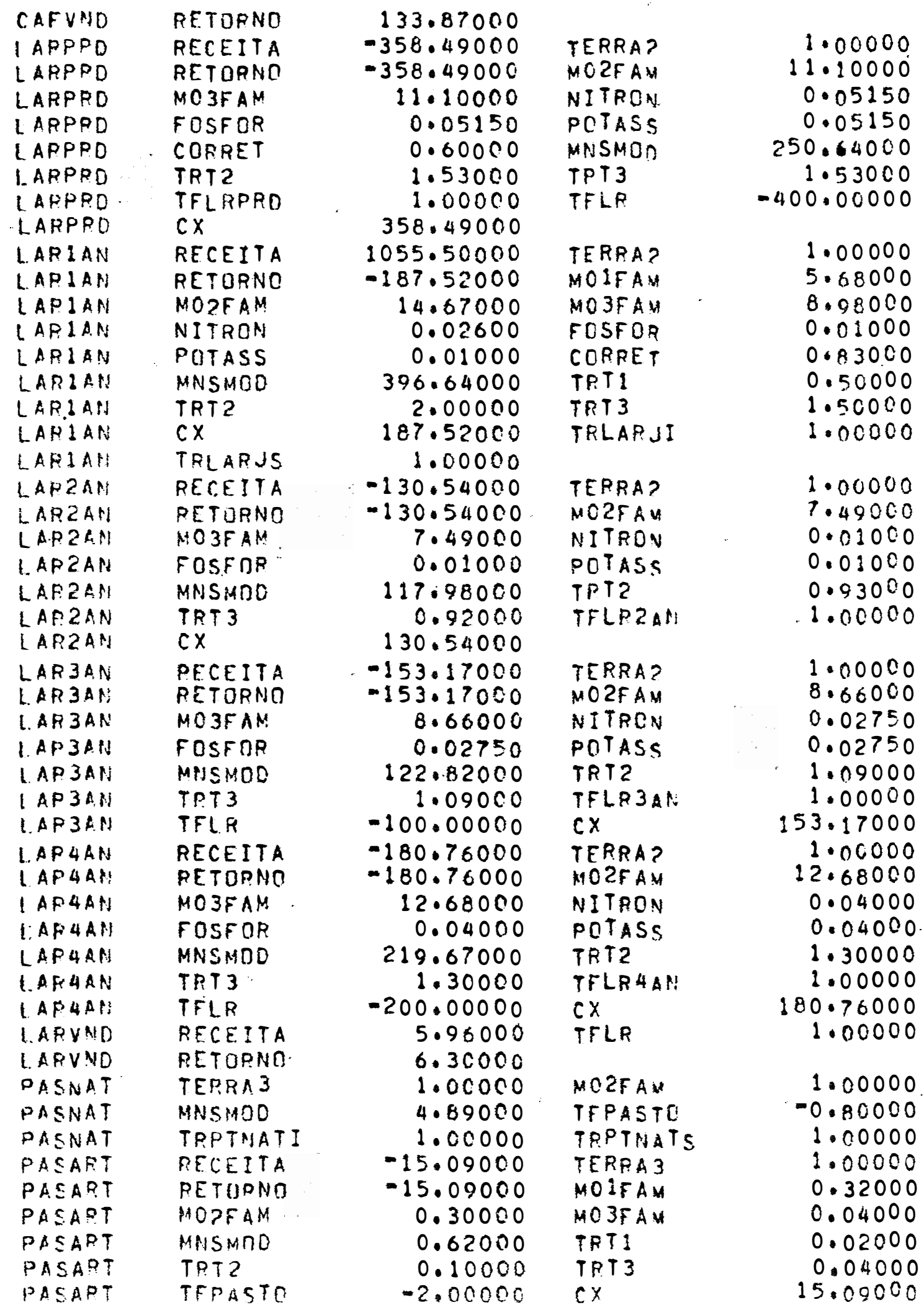




\begin{tabular}{|c|c|c|c|c|}
\hline $\begin{array}{l}\text { PASART } \\
\text { PECCT } \\
\text { PECCT } \\
\text { PECCT } \\
\text { PECCT }\end{array}$ & $\begin{array}{l}\text { TRPTARTI } \\
\text { RECEITA } \\
\text { FETORNO } \\
\text { MO BFAM } \\
\text { TFPASTO }\end{array}$ & $\begin{array}{r}1.00000 \\
180.92000 \\
180.92000 \\
5.25000 \\
2.84000\end{array}$ & $\begin{array}{l}\text { TRPTARTS } \\
\text { MOIFAV } \\
\text { MO2FAK } \\
\text { MNSMOD } \\
\text { LMIFCT }\end{array}$ & $\begin{array}{r}1.00000 \\
5.25000 \\
5.25000 \\
27.56000 \\
2.84000\end{array}$ \\
\hline $\begin{array}{l}P E C C T \\
D E C L A \\
D E C L 9\end{array}$ & $\begin{array}{l}\text { LMSPCT } \\
\text { RECEITA } \\
\text { RETRPNE }\end{array}$ & $\begin{array}{r}2.84000 \\
-85.10000 \\
-85.10000\end{array}$ & $\begin{array}{l}\text { MO1FAH } \\
M 02 F A H\end{array}$ & $\begin{array}{l}30.00000 \\
30.00000\end{array}$ \\
\hline $\begin{array}{l}P E C L B \\
P E C L R \\
P E C L A\end{array}$ & $\begin{array}{l}\text { MOZFAM } \\
\text { TFMLH } \\
\text { TFPASTO }\end{array}$ & $\begin{array}{r}30.00000 \\
6.30000 \\
1.63000\end{array}$ & $\begin{array}{l}\text { MNSMOO } \\
\text { TFLEITE } \\
\text { CX }\end{array}$ & $\begin{array}{r}595.74000 \\
-2250.00000 \\
85.10000\end{array}$ \\
\hline $\begin{array}{l}\text { PECLB } \\
\text { PECLC } \\
\text { PECLC } \\
\text { PECLC } \\
\text { PECLC }\end{array}$ & $\begin{array}{l}\text { LMIFLTR } \\
\text { PECEITA } \\
\text { RETORNO } \\
\text { MOBFAM } \\
\text { TFLEITC }\end{array}$ & $\begin{array}{r}0.61000 \\
-14.34000 \\
-14.34000 \\
10.00000 \\
-980.00000\end{array}$ & $\begin{array}{l}\text { LMSPLTE } \\
\text { MOIFAM } \\
\text { MOLFAM } \\
\text { MNSMON } \\
\text { TFPASTC }\end{array}$ & $\begin{array}{r}0.61000 \\
10.00000 \\
10.00000 \\
147.84000 \\
1.70000\end{array}$ \\
\hline $\begin{array}{l}P E C L C \\
P E C L C\end{array}$ & $\begin{array}{l}C X \\
\text { MSPLTC }\end{array}$ & $\begin{array}{r}14.34000 \\
0.59000\end{array}$ & LMIFLTC & 0.59000 \\
\hline 1. EVNO & PECEITA & 0.57000 & TFLEITE & 1.0000 \\
\hline I RVN? & RETOPNO & 0.57000 & $c x$ & 000 \\
\hline $\begin{array}{l}\text { I GVND } \\
\text { GUND }\end{array}$ & $\begin{array}{l}\text { PECEITA } \\
\text { OETOPNO }\end{array}$ & $\begin{array}{l}0.39000 \\
0.39000\end{array}$ & TFLEITC & $\begin{array}{r}1.00000 \\
-0.19000\end{array}$ \\
\hline ICNS & TFLEITC & 1.00000 & MORES 3 & 0.01400 \\
\hline SUI I & PECEITA & 919.10000 & MOLFA & 5.00000 \\
\hline BUIN? & RETORMO & 919.18000 & MOZFA & 5.00000 \\
\hline BUINB & MO $3 F A M$ & 5.00000 & MNSMOn & 18.17000 \\
\hline SUIN & $\begin{array}{l}\text { TFHLH } \\
\text { SSPSINP }\end{array}$ & 7.50000 & LMIFSINE & 7 \\
\hline $\begin{array}{l}\text { TEANTI } \\
\text { TFANTI }\end{array}$ & $\begin{array}{l}\text { MANTL } \\
\text { TFHLH }\end{array}$ & $\begin{array}{r}-1.00000 \\
0.03000\end{array}$ & LMSPANTI & 1.0000 \\
\hline $\begin{array}{l}\text { TFANTE } \\
\text { TFANT? }\end{array}$ & $\begin{array}{l}\text { MANT? } \\
\text { TFMLH }\end{array}$ & $\begin{array}{r}-1.00000 \\
0.03000\end{array}$ & LMSPAUT2 & 1.000 \\
\hline TFANT 3 & MANT 3 & -1.00000 & LMSPANT3 & 1.00000 \\
\hline TFANTB & TFKILH & 0.03000 & & \\
\hline MOPESF & RECEITA & -17.77000 & MOLFAM & -1.0000 \\
\hline MOPE SP & RETQPNO & $=17.77000$ & MOZFAM & $-1 \cdot 0000$ \\
\hline HORESP & MOZFAM & -1.00000 & MORSF & 1.0000 \\
\hline AOPESP & $c x$ & 17.77000 & & \\
\hline $\begin{array}{l}\text { HO1CONP } \\
101 C O N P \\
\text { HOICONP }\end{array}$ & $\begin{array}{l}\text { RECEITA } \\
\text { RETORNE } \\
\text { CX }\end{array}$ & $\begin{array}{l}5.88000 \\
=5.88000 \\
5.88000\end{array}$ & $\begin{array}{l}\text { MOLFAM } \\
\text { MOICON }\end{array}$ & $\begin{array}{r}1.0000 \\
1.0000\end{array}$ \\
\hline $1.02 C O N P$ & RECEITA & .6 .58000 & $M O 2 F A H$ & .0000 \\
\hline $\begin{array}{l}\text { HO2 CONP } \\
\text { HO2CONP }\end{array}$ & $\begin{array}{l}\text { RETURNO } \\
\text { CX }\end{array}$ & $\begin{array}{l}=6.58000 \\
6.58000\end{array}$ & MO2CON & $1 \rightarrow 000$ \\
\hline HO3 CONP & PECEITA & .7 .04000 & MOSFAM & -1.0000 \\
\hline $10360 \mathrm{cos}$ & RETIHANO & -7.04000 & $M 03 C D N$ & 1.000 \\
\hline $4 C 3 C O H P$ & $C x$ & 7.04000 & & \\
\hline$M O \perp F A M P$ & RECFITA & 5.65000 & MOLFAM & 1.0000 \\
\hline$M \cap 1 F A M P$ & RETURPID & 5.65000 & $c x$ & 2.8200 \\
\hline$M 02 F A+P$ & RECEITA & 5.08000 & $M 02 F A M$ & 1.0000 \\
\hline
\end{tabular}




\begin{tabular}{|c|c|c|c|c|}
\hline $\begin{array}{l}\text { MOZF AMP } \\
\text { MOZ AMP } \\
M O 3 F A M P\end{array}$ & $\begin{array}{l}\text { RETORNO } \\
\text { RECEITA } \\
\text { RETOPNO }\end{array}$ & $\begin{array}{l}5.68000 \\
6.44000 \\
6.44000\end{array}$ & $\begin{array}{l}C X \\
\text { HOB FAM } \\
C X\end{array}$ & $\begin{array}{r}-2.84000 \\
1.00000 \\
=3.22000\end{array}$ \\
\hline $\begin{array}{l}\text { HTTRONP } \\
\text { MITRONP } \\
\text { HITRONCR } \\
\text { HITRONCR } \\
\text { FOSFORP } \\
\text { OOSFORP }\end{array}$ & $\begin{array}{l}\text { RECEITA } \\
\text { RETOPNO } \\
\text { RECEITA } \\
\text { RETOBNO } \\
\text { RECEITA } \\
\text { RETUPNO }\end{array}$ & $\begin{array}{l}-268.92000 \\
-268.92000 \\
=268.92000 \\
=268.92000 \\
=278.81000 \\
=278.81000\end{array}$ & $\begin{array}{l}\text { NITRON } \\
\text { CX } \\
\text { NITRON } \\
\text { LMCRCUS } \\
\text { FOSFOR } \\
\text { CX }\end{array}$ & $\begin{array}{r}.1 .00000 \\
268.92000 \\
=1.00000 \\
268.92000 \\
=1.00000 \\
278.81000\end{array}$ \\
\hline $\begin{array}{l}\text { FOSFOPCR } \\
\text { FOSFORCF } \\
\text { POTASSP }\end{array}$ & $\begin{array}{l}\text { RECEITA } \\
\text { RETORNO } \\
\text { RECEITA }\end{array}$ & $\begin{array}{l}-278.81000 \\
-278.81000 \\
-280.21000\end{array}$ & $\begin{array}{l}\text { FOSFOR } \\
\text { LMCRCUS } \\
\text { POTASS }\end{array}$ & $\begin{array}{r}-1.00000 \\
278.81000 \\
-1.00000\end{array}$ \\
\hline $\begin{array}{l}\text { POTASSP } \\
\text { POTASSCR }\end{array}$ & $\begin{array}{l}\text { PETURNO } \\
\text { PECEITA }\end{array}$ & $\begin{array}{l}-280.21000 \\
-280.81000\end{array}$ & $\begin{array}{l}\text { CX } \\
\text { POTASS }\end{array}$ & $\begin{array}{r}280.21000 \\
-1.00000\end{array}$ \\
\hline $\begin{array}{l}\text { POTASSCR } \\
\text { CORRETP }\end{array}$ & $\begin{array}{l}\text { RETOFAO } \\
\text { RECEITA }\end{array}$ & $\begin{array}{r}-280.81000 \\
-39.78000\end{array}$ & $\begin{array}{l}\text { LMCRCUS } \\
\text { CORRET }\end{array}$ & $\begin{array}{r}280.21000 \\
-1.00000\end{array}$ \\
\hline CORRFTP & RETORNO & -39.78000 & $c x$ & 39.78000 \\
\hline MINSMOP & RECEITA & -1.00000 & MNSMOD & $=1.00000$ \\
\hline $\begin{array}{l}\text { RIINSMOP } \\
\text { NIINSMOCR }\end{array}$ & RETORNO & $\begin{array}{l}=1.00000 \\
=1.14000\end{array}$ & $c x$ & $\begin{array}{l}1.00000 \\
1.00000\end{array}$ \\
\hline $\begin{array}{l}\text { NINSMOCR } \\
\text { AINSMOCR }\end{array}$ & RETOFNO & -1.14000 & $\begin{array}{l}\text { MNSMUD } \\
\text { LMCRCUS }\end{array}$ & $\begin{array}{l}1.00000 \\
1.00000\end{array}$ \\
\hline CPFDCT & RECEITA & -1.14000 & $c x$ & -1.0000 \\
\hline $\begin{array}{l}\text { CPEDCT } \\
\text { CUSEPK }\end{array}$ & $\begin{array}{l}\text { RETDRNO } \\
\text { RECEITA }\end{array}$ & $\begin{array}{r}-1.14000 \\
0.26000\end{array}$ & $\begin{array}{l}\text { LHCRCUS } \\
C X\end{array}$ & $\begin{array}{l}1.00000 \\
1.00000\end{array}$ \\
\hline $\begin{array}{l}\text { CUSUPK } \\
\text { TFTRITR2 } \\
\text { TFTRTTR3 }\end{array}$ & $\begin{array}{l}\text { RETORNO } \\
\text { TERRAI } \\
\text { TERRA2 }\end{array}$ & $\begin{array}{l}0.26000 \\
1.00000 \\
1.00000\end{array}$ & $\begin{array}{l}\text { COPK } \\
\text { TERRA? } \\
\text { TERRA3 }\end{array}$ & $\begin{array}{r}1.00000 \\
-1.00000 \\
-1.00000\end{array}$ \\
\hline $\begin{array}{l}\text { NINVTRT } \\
\text { NINVTRT }\end{array}$ & $\begin{array}{l}\text { TRT2 } \\
\text { LMSPTRT }\end{array}$ & $\begin{array}{r}-50.00000 \\
1.00000\end{array}$ & $\begin{array}{l}\text { TRT3 } \\
\text { TFCRINV }\end{array}$ & $\begin{array}{r}-50.00000 \\
30511.01000\end{array}$ \\
\hline $\begin{array}{l}\text { MINVTPT } \\
\text { AINVTRT }\end{array}$ & $\begin{array}{l}\text { LMCRINV } \\
\text { TRTI }\end{array}$ & $\begin{array}{r}30511.00000 \\
=50.00000\end{array}$ & RECEITA & $=2746.00000$ \\
\hline $\begin{array}{l}\text { CPEDINV } \\
\text { CPEOINY }\end{array}$ & $\begin{array}{l}\text { RECEITA } \\
\text { RETDRNO }\end{array}$ & $\begin{array}{l}=0.14000 \\
=0.14000\end{array}$ & TFCRINV & -1 \\
\hline
\end{tabular}


Os símbolos definidos na matriz dos coeficientes são:

Para as linhas:

RECEITA: Renda Agrícola Esperada

RETORNO: Renda Agrícola Observada

TRALGI: Limite Inferior de Terra para Algodão

TRALGS: Limite Superior de Terra para Algodão

TRBATAGI: Limite Inferior de Terra para Batata das Aguas TRBATAGS: Limite Superior de Terra para Batata das Aguas TRBATSCI: Limite Inferior de Terra para Batata das Secas TRBATSCS: Limite Superior de Terra para Batata das Secas TRFJAGI: Limite Inferior de Terra para Feijäo das Aguas TRFJAGS: Limite Superior de Terra para Feijão das Águas TRFJSCI: Limite Inferior de Terra para Feijão das Secas TRFJSCS: Limite Superior de Terra para Feijão das Secas TRARROZI: Limite Inferior de Terra para Arroz TRARROZS: Limite Superior de Terra para Arroz TRMANDI: Limite Inferior de Terra para Mandioca TRMANDS: Limite Superior de Terra para Mandioca TRMLHI: Limite Inferior de Terra para Milino TRMLHS: Limite Superior de Terra para Milho TRTOMATI: Limite Inferior de Terra para Tomate TRTOMATS: Limite Superior de Terra para Tomate TRCANAI: Limite Inferior de Terra para Cana TRCANAS: Lim1te Superior de Terra para Cona 
TRCAFEI: Limite Inferior de Terra para Café TRCAFES: Limite Superior de Terra para Café TRLARJI: Limite Inferior de Terra para Laranja TRLARJS: Limite Superior de Terra para Laranja TRPTNATI: Limite Inferior de Terra para Pasto Natural TRPTNATS: Limite Superior de Terra para Pasto Natural TRPTARTI: Limite Inferior de Terra para Pasto Artificial TRPTARTS: Limite Superior de Terra para Pasto Artificial LMIFSINB: Limite Inferior de SuInos Tipo Banha LMSPSINB: Limite Superior de SuInos Tipo Banha LMIFSINC: Limite Inferior de SuInos Tipo Carne LMSPSINC: Limite Superior de SuInos Tipo Carne LMIFLTB: Limite Inferior de Bovino de Leite B LMSPLTB: Limite Superior de Bovino de Leite B LMIFLTC: Limite Inferior de Bovino de Leite C LMSPLTC: Limite Superior de Bovino de Leite C LMIFCT: Limite Inferior de Bovino de Corte LMSPCT : Limite Superior de Bovino de Corte LMSPTRT: Limite Superior de Trator TERRA 1: Limite de Terra 1 TERRA 2; Limite de Terra 2 TERRA 3: Limite de Terra 3 MDIFAM: Limite Superior de Mão-de-Obra Familiar Perfodo 1 MO2FAM: Lim te Superior de Mão-de-Obra Familiar Perf́odo 2 MO3FAM: Limite Supepior de Mão-de-Obra Familiar Perfodo 3 
MORSFM: Limite de Mão-de-Obra Residente Não-Familiar MOICON: Limite de Mão-de-Obra Contratada no Período 1 MD2CON: Limite de Mão-de-Obra Contratada no Período 2 MO3CON. Limite de Mão-de-Obra Contratada no Período 3 NITRON: Limite Superior de Nitrogénio FOSFOR: Limite Superior de Fösforo POTASS: Limite Superior de Potássio CORRET: Limite Superior de Corretivo MNSMOD: Limite Superior de Insumos Modernos TRT l: Limite Superior de Trator no Periodo 1 TRT2: Limite Superior de Trator no Período 2 TRT3: Limite Superior de Trator no Perfodo 3 MANT 1: Animal de Trabalho no Período 1 MANT2: Animal de Trabalho no Período 2 MANT3: Animal de Trabalho no Período 3 LMSPANTI: Limite Superior de Animal de Trabalho no Período 1 LMSPANT2: Limite Superior de Animal de Trabalho no Período 2 LMSPANT3: Limite Superior de Animal de Trabalho no Período 3 TFFJ: Transferéncia de Produtividade e Consumo de Feijão TFARROZ: Transferéncia de Produtividade e Consumo de Arroz TFMLH: Transferéncia de Frodutividade e Consumo de Milho TFCFPRD: Transferéncia da Area com Café de Mais de 3 Anos TFCF2AN: Transferēncia da Ârea com Café de 2 Anos TFCFIAN: Transferéncia da Area com Café de l Ano TFCF3AN: Transferência da Area com Café de 3 Anos 
TFCF: Transferência de Produtividade com Café TFLRPRD: Trânsferência de Area com Laranja de Mais̀ de 4 Anos TFLR2AN: Transferência de Área com Laranja de 2 Anos TFLR3AN: Transferência de Área com Laranja de 3 Anos TFLRAAN: Transferência de Área com Laranja de 4 Anos TFLR: Transferência de Produtividade com Laranja TFLEITB: Transferência de Produtividade de Leite B TFLEITC: Transferência de Profutividade e Consumo de Leite C TFPASTO: Transferência de Area com Pasto TFCRINV: Transferência de Crédito para. Investimento MORESI: Mão-de-Obra Residente Familiar no Período 1 MORES2: Mäo-de-Obra Residente Famfliar no Perfodo 2 MORES3: Mão-de-Obra Residente Familiar no Período 3 CX: Transferência do Caixa LMCRINV: Limite do Crédito para Investimento COPK: Limite Superior do Custo de Oportunidade de Capital LMCRCUS: Limite do Crédito Para Custeio 
Para as colunas:

SUINC: Atividade de Produção em Suíno Tipo Carne TOMATE: Atividade de Produção em Tomate MALGl: Atividadie de Produção em Algodão com Tecnologia 1 MALG2: Atividade de Produção em Algodão com Tecnologia 2 BATAGl: Atividade de Produção em Batata das Agues com Tecnologia I BATAG2: Atividade de Produção em Batata das Aguas com Tecnologia 2 BATSC: Atividade de Produção em Batata das Secas MAND: Atividade de Produção em Mandioca FJAGI: Atividade de Produção em Feijão das Águas com Tecnologia I FJAG2: Atividade de Produção em Feijăo das Águas com Tecnologia 2 FJSCl: Atividede de Produção em Feìjão das Secas com Tecnoìogia I FJSC2: Atividade de Produção em Fełjão das Secas com Tecnologia 2 FJVND: Atividade de Venda de Feijão FJCPR: Atividade de Compra de Feijão FJCNS: Atıvidade de Consumo de Feijão MLHI: Atividade de Produção de MIIho com Tecnologia 1 MLH2: Atividade de Produção de Milho com Tecnologia 2 MLHVND: Atividade de Venda de Milho MLHCPR: Atividade de Compra de Milho MARROZ: Atividade de Produção de Arroz MARRVND: Atividade de Venda de Arroz MARRCPR: Atividade de Compra de Arroz MARRCNS: Atividade de Consumo de Arroz 
CANA: Atividade de Produção em Cana

CAFPRO: Atividade de Produção com Café de Mais de 3 Anos

CAFIAN: Atividade de Produção com Café de I Ano

CAF2AN: Atividade de Produção com Café de 2 Anos

CAF 3AN: Atividade de Produção com Café de 3 Anos

CAFINV: Atividade de Investimento em Café

CAFVND: Atividade de Venda de Café

LARPRD: Atividade de Produção com Laranja de Mais de 4 Anos

LARIAN: Atividade de Produção com Laranja de I Ano

LAR2AN: Atividade de Produção com Laranja de 2 Anos

LAR3AN: Atividade de Produção com Laranja de 3 Anos

LAR4AN: Atividade de Produção com Laranja de 4 Anos

LARVND: Atividade de Venda de Laranja

PASNAT: Atı́idade de Produção em Pasto Natural

PASART: Atividade de Produção em Pasto Artificial

PECCT: Atividade de Produção em Pecuária de Corte

PECLB: Atividade de Produção em Pecuária de Leite $B$

PECLC: Atividade de Produção em Pecuária de Leite C

LBVND: Atividade de Venda de Leite B

LCVNO: Atividade de Venda de Leite C

LCCNS: Atividade de Consumo de Le1te C

SUINB: Atividade de Produção em Suíno Tipo Banha

TFANT1: Atıvidade de Transferência de Animal de Trabalho Per ́rodo I TFANT2: Atívidade de Transferência de Animal de Trabalho Perf́odo 2 TFANT3: Atividade de Transferencie de Animal de Trabalho Período 3 
MORESP: Atividade de Compra de Mão-de-Obra Residente Não Familiar MOICONP: Atividade de Compra de Mão-de-Obra Volante Período 1 MO2CONP: Atividade de Compra de Mão-de-Obra Volante Feríodo 2 MO3CONP: Atividade de Compra de Mão-de-Obra Volante Período 3 MOIFAMP: Atividade de Compra de Mão-de-Obra Residente Familiar no Período 1

MO2FAMP: Atividade de Compra de Mão-de-Obra Residente Familiar no Período 2

M03FAMP: Atividade de Compra de Mão-de-Obra Residente Familiar no Perínodo 3

NITRONP: Atividade de Compra de Nitrogênio

NITRONCR: Atividade de Compra de Nitrogênio com Crédito

FOSFORP: Atividada de Compra de Fósforo

FOSFORCR: Atividade de Compra de Fósforo com Crédito

POTASSP: Atividade de Compra de Potássio

POTASSCR: Atividade de Compra de Potássio com Crédito

CORRETP: Atividade de Compra de Corretivo

MINSMDP: Atividade de Compra de Insumos Modernos

MINSMOCR: Atividade de Compra de Insumos Modernos corn Crédito

CREDCT: Atividades de Compra de Corretivo e Mão-de-Obra

CUSOPK: Atividacie de Custo de Oportunidade do Capital

TFTRITR2: Atividade de Transferência de Terra 1 para Terra 2

TFTR2TR3: Atividade de Transferêncla de Terra 2 para Terra 3

MINVTRT: Atividades de Investimento

CREDINV: Atividades de Investimento com Crédito 